\title{
Stimuli-Responsive Polymers Providing New Opportunities for Various Applications
}

\section{Çeşitli Uygulamalar için Yeni Fırsatlar Sağlayan Uyaranlara Duyarlı Polimerler Gökhan Koçak $^{1 \oplus}$, Cansel Tuncer ${ }^{2 \oplus}$ and Vural Bütün ${ }^{2 *}$ \\ ${ }^{1}$ Department of Chemistry and Chemical Process Technologies, Vocational School of Higher Education, Adiyaman University, Adiyaman, Turkey. ${ }^{2}$ Department of Chemistry, Faculty of Science and Letters, Eskisehir Osmangazi University, Eskisehir, Turkey.}

\section{ABSTRACT}

Ctimuli-responsive polymers significantly change their physical or chemical properties when there is a small change in the conditions of their environments. Depending on the changes on conditions, they can self-assemble to form various nanosized structures having important usages in different fields. In this review, we report an analysis of some of the recent literatures on the basic subjects such as the architectures of different environmentally sensitive polymers, their classifications according to susceptibility and applications in various areas. During the last two decades, there have been great reports in the strategies for the preparation of novel stimuli-responsive polymers and/or polymeric materials which are suitable for various applications including materials science, nanotechnology, biotechnology, colloid and surface science, etc. In order to make this very broad polymer type more understandable to readers, basic concepts/topics are generally schematized. Furthermore, the strategies that can be followed in the production of these materials are tried to be given at a sufficient level.

\section{Key Words}

Stimuli-responsive polymers, self-assembly, nanostructures, smart polymers.

\section{öz}

yaranlara duyarlı polimerler, çevrelerindeki koşullarda küçük bir değişiklik olduğunda fiziksel veya kimyasal özelliklerini önemli ölçüde değiştirir. Koşullardaki değişikliklere bağlı olarak, bu tür kopolimerler kendiliğinden bir araya gelebilir ve çeşitli nanoboyutlu yapılar oluşturabilir. Bu tür polimerlerin farklı alanlarda önemli kullanımları vardır. Bu derlemede, çevreye duyarlı farklı polimerlerin mimarileri, duyarlııklarına göre sınıflandırmaları ve çeşitli alanlardaki uygulamaları gibi temel konulardaki bazı güncel literatür raporlarının bir analizini sunuyoruz. Son yirmi yılda, biyoteknoloji, nanoteknoloji, kolloid ve yüzey bilimi, malzeme bilimi vb. dahil olmak üzere çeşitli uygulamalar için uygun uyarıcıya duyarlı yeni polimerlerin ve polimerik malzemelerin hazırlanmasına yönelik sentetik yöntemlerde ve stratejilerde büyük gelişmeler olmuştur. Çok geniş kapsamı olan bu polimer türünün okuyucular tarafından daha anlaşılır olabilmesi için genellikle temel kavramlar/konular şematize edilmiştir. Ayrıca, bu malzemelerin üretiminde izlenebilecek stratejiler yeter düzeyde verilmeye çalışılmıştır.

\section{Anahtar Kelimeler}

Uyarıya-duyarlı polimerler, kendi-kendine-düzenlenme, nanoyapılar, akıllı polimerler. 


\section{INTRODUCTION}

\section{Stimuli-Responsive Polymers Providing New Opportunities for Various Applications}

Stimuli-responsive polymers have response to the changes on their environmental conditions which result with significant changes in their physical or chemical properties. Stimuli-responsive polymers and polymeric materials are called as "sensitive", "talented" or "smart". Environmental conditions that cause changes in the structures or behaviors of polymers; it can be examined under the chemical, physical and biochemical titles (Figure 1). Such polymeric materials produced can be of a type that can respond to one or more of the external stimuli. If a polymer has a response to two or more stimuli, it is called as multi-responsive polymer Such polymers have been very popular in recent years [1-6]. Polymers of this type are prepared using two or more polymers (or monomers) which are sensitive to environmental conditions [3-7]. The interest available with these combinable properties has increased further Polymers obtained from some special monomers such as $\mathrm{N}$-isopropylacrylamide (NIPAM), (2-dimethylamino) ethyl methacrylate (DMA), (2-diethylamino)ethyl methacrylate (DEA), (2-diisopropylamino)ethyl methacrylate (DPA) and (2-N-morpholino)ethyl methacrylate (MEMA) can be sensitive to temperature, ionic strength and/or $\mathrm{pH}$ [7-9].
Smart polymers are an important field of study that attracts the attention of the commercial and academic environment due to their wide range of applications. Considering the years, the number of publications whose titles are "responsive polymer/gel, intelligent polymer/gel, sensitive polymer/gel, and smart polymer/gel" is increasing every year and this number has exceeded 800 annually in recent years (Figure 2). These polymers are used in a wide variety of fields, such as sensors, gene delivery vehicle, controlled active compound release systems, gene transport, artificial muscle, surface coatings, membranes, tissue engineering, regenerative medicine, optical or micro-electromechanical, selfhealing and self-cleaning material production [3, 10].

Production of polymeric materials in different architectures has become easier with the emergence of controlled/living polymerization methods such as group transfer polymerization (GTP), atom transfer radical polymerization (ATRP), nitrogen oxide-mediated polymerization (NMP), and reversible addition fragmentation chain transfer (RAFT) polymerization. Architectures of stimuli-responsive polymers can be of many different types such as linear, branched, star, brush, comb, dendrimer, nanogel, microgel, and hydrogel (macrogel). Polymer architectures can be in the form of homopolymers or copolymers (random, block, branched, graft etc.). The dimensions and structural shapes of these polymeric structures enable the application area to be determined [1, 5, 7]. Information on polymeric architectures and dimensions is given in Figure 3.

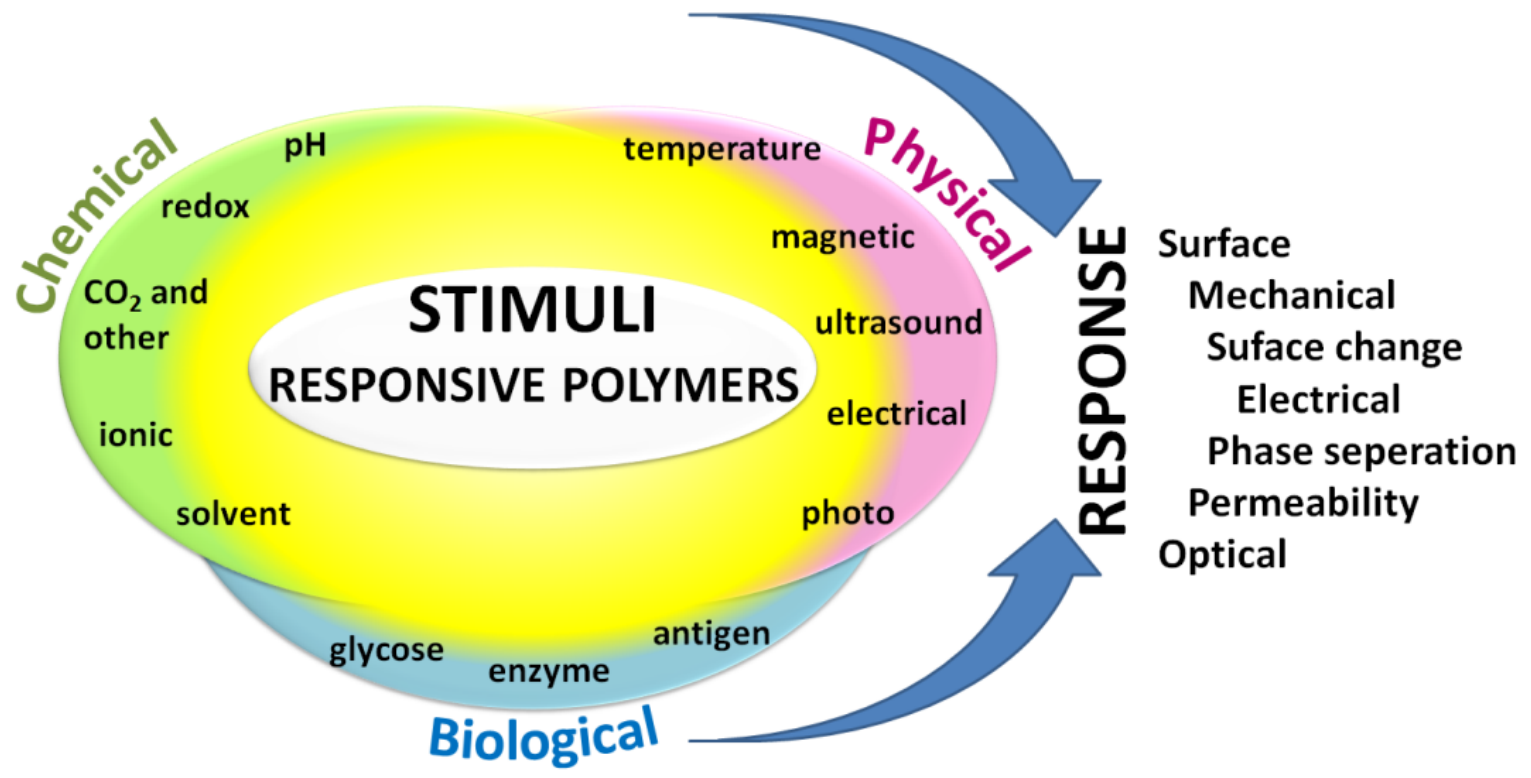

Figure 1. Classification of some stimuli-responsive polymers according to stimulus type and their responses to stimuli. 


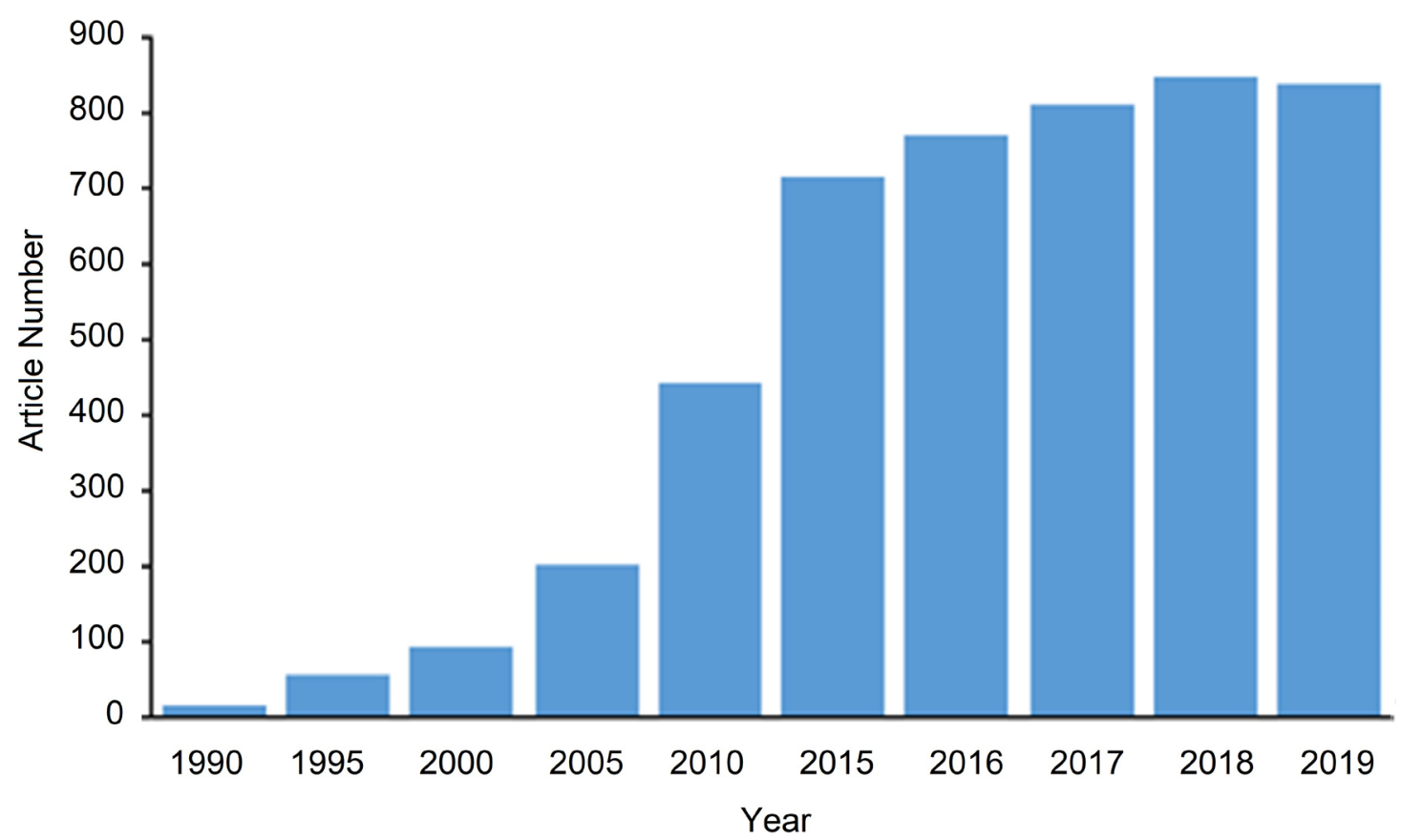

Figure 2. Number of articles published between 1990 and 2019 (Source: ISI Web of Knowledge, August 2020).

The responses of these polymers to various stimuli can be in the form of conformational change, fragmentation of the bonds, changes in hydrophilic/hydrophobic balance or collapse/dissolution. These changes can occur with very different ways, such as solubility, selfassembly of macromolecules or transformation of different morphologies, sol-gel or inverse transitions. More detailed explanations are given in schematic form in the following sections.

\section{Classification of Stimuli-Responsive Polymers}

Stimuli-responsive polymers can be grouped under three main headings. These are;

Chemical stimuli: These alter molecular interaction. These factors are $\mathrm{pH}, \mathrm{CO}_{2}, \mathrm{CO}[11], \mathrm{NO}$ [11], $\mathrm{H}_{2} \mathrm{~S}$ [12], redox chemicals, salt and solvent.

Physical stimuli: These change the dynamics of polymer chains. These factors are temperature, light, magnetic field, electrical field, ultrasound and mechanical power.

Biochemical stimuli: Real functions of biological components are used. These factors are enzyme, glucose, antigen, amino acid, nucleic acid and polysaccharide.

\section{pH-responsive polymers}

In pH-responsive polymers, structural changes such as surface activity, chain conformation, solubility, and configuration may occur with the change of the $\mathrm{pH}$ of the solution. If a polymer structure contains weak acidic or weak basic groups that can be ionized, it is called as a pH-responsive polymer. $\mathrm{pH}$-responsive polymers are frequently used in applications such as drug release (transport), gene transfer, sensor, surfaces, membrane and chromatography thanks to these properties $[7,13]$.

a) Acidic pH-responsive polymers: Polymers having weak acidic groups are used as $\mathrm{pH}$-responsive polymers. These weakly acidic groups release protons at high $\mathrm{pH}$ values in aqueous media. Therefore, depending on the $\mathrm{pK}_{\mathrm{a}}$ value, they acquire polyelectrolyte nature at different solution $\mathrm{pH}$ values. Examples of such polymers are given in Table 1. Some selected polymers belonging to the class of acidic $\mathrm{pH}$-responsive polymers are examined below [7].

Carboxylic acids: Carboxylic acid groups, which are weak acids, lose their acidic protons at basic $\mathrm{pH}$ conditions. If the $\mathrm{pH}$ is low, they take the protons again and become uncharged. Poly(acrylic acid) (PAA) and poly(methacrylic acid) (PMAA) are the most frequently studied polymers in the class of polyacid because they can polymerize cheaply and easily. 


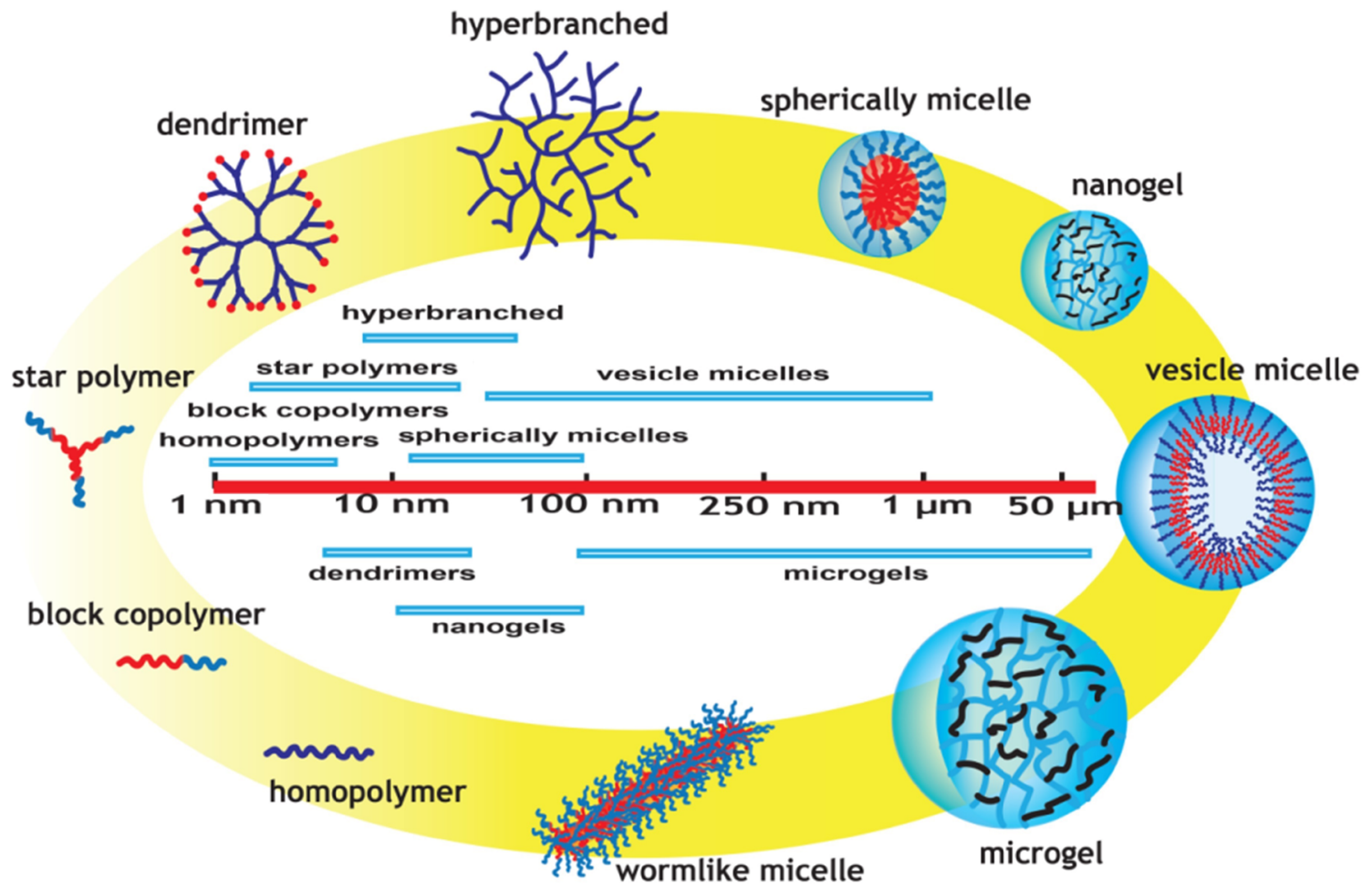

Figure 3. Stimuli-responsive polymer types in different sizes (diameter) [7].

Sulfonic acids: Both poly(4-stylenesulfonic acid) (PSSA) and poly(2-acrylamido-2-methylpropane sulfonic acid) (PAMPS) are the most used polymer types in this class. They are generally used in obtaining hydrogels .

Phosphonic acids: Phosphorus based (meth)acrylate polymers are special polymer classes used in many fields. These phosphorus-containing polymers are generally obtained by treatment of natural and synthetic polymers with different phosphorus-containing compounds.

Boronic acids: Boronic acid-containing polymers are commonly used in the production of glucose sensor and selfhealing gel applications. In particular, polymers containing phenylboronic acid groups $\left(\mathrm{Ph}-\mathrm{B}(\mathrm{OH})_{2}\right)$ are often used.

b) Basic pH-responsive polymers: Polymers with weak basic groups can also be used as $\mathrm{pH}$-responsive polymers. These weak basic groups are protonated at low $\mathrm{pH}$ values in aqueous media. Therefore, they acquire polyelectrolyte nature at different $\mathrm{pH}$ values, depending on the $\mathrm{pK}_{\mathrm{a}}$ value. Some polymers belonging to the class of basic $\mathrm{pH}$ responsive polymers are examined below [7]. Examples of basic $\mathrm{pH}$-responsive polymers are also given in Table 1.
(Meth)acrylate, (meth)acrylamide and vinyl polymers containing tertiary amines are among the polymer types that are frequently used in various studies. Tertiary amine methacrylate-containing polymers such as poly[(2-diisopropylamino)ethyl methacrylate] (PDPA), poly[(2-diethylamino)ethyl methacrylate] (PDEA) and poly[(2-dimethylamino)ethyl methacrylate] (PDMA) are the most preferred polymers [8]. Apparent $\mathrm{pK}_{\mathrm{a}}$ values of their conjugate acids are reported to be 7.0, 7.3 and 6.0, respectively. In particular, PDMA having a $\mathrm{pK}_{\mathrm{a}}$ around 7.0 can be said to be the most remarkable polymer because it has both temperature- and $\mathrm{pH}$-responsive nature [7, 9, 14]. Poly(4-vinylpyridine) (P4VP) and poly(2vinylpyridine) (P2VP) polymers are other important basic $\mathrm{pH}$-responsive polymers. These polymers lose protons when the solution $\mathrm{pH}$ rises above $\mathrm{pH} 5$ [7]. In the literature, there are other $\mathrm{pH}$-responsive basic polymers containing imidazole, piperazine, pyrrolidine and morpholine groups. Poly[(2-N-morpholino)ethyl methacrylate] (PMEMA) polymer containing morpholine groups is a salt-, temperature- and $\mathrm{pH}$-responsive polymer with a $\mathrm{pK}_{\mathrm{a}}$ of 4.9. Therefore it is interesting and an important polymer as well $[7,9,14]$. 
Table 1. Some acidic and basic $\mathrm{pH}$-responsive polymers [7].

\begin{tabular}{|c|c|}
\hline ACIDIC POLYMERS & BASIC POLYMERS \\
\hline Poly(carboxylic acids) & Poly(tertiary amines) \\
\hline Poly(acrylic acid) & Poly[(2-dimethylamino)ethyl methacrylate] \\
\hline Poly(methacrylic acid) & Poly[(2-diethylamino)ethyl methacrylate] \\
\hline Poly(ethylacrylic acid) & Poly[(2-diisopropylamino)ethyl methacrylate] \\
\hline Poly(prophylacrylic acid) & Poly[N-3-(dimethylamino)propyl methacrylamide] \\
\hline Poly(4-vinylbenzoic acid) & Poly[(2-dimethylamino)ethyl acrylate] \\
\hline Poly(itaconic acid) & Poly[2-(t-butylamino)ethyl methacrylate] \\
\hline Poly(phosphonic acids) & Poly(N,N-dialkylvinyl benzyl amine) \\
\hline Poly(ethylene glycol acrylate phosphate) & Poly[(2-diethylamino)ethyl acrylamide] \\
\hline Poly(vinylphosphonic acid) & Morpholine, pyrrolidine, and piperazine \\
\hline Poly(ethylene glycol methacrylate phosphate) & Poly[(2-N-morpholino)ethyl methacrylate)] \\
\hline Poly(4-vinyl-benzyl phosphonic acid) & Poly(acryloylmorpholine) \\
\hline Poly(sulfonic acids) & Poly[(2-N-morpholino)ethyl methacrylamide)] \\
\hline Poly(vinylsulfonic acid) & Poly(N-ethylpyrrolidine methacrylate) \\
\hline Poly(4-styrenesulfonic acid) & Poly(N-acryloyl-N'-alkenyl piperazine) \\
\hline Poly(2-acrylamido-2-methylpropane sulfonic acid) & Pyridine and imidazole \\
\hline Poly(3-sulfopropyl methacrylate potassium salt) & Poly(4-vinylpyridine) \\
\hline Poly(amino acids) & Poly(2-vinylpyridine) \\
\hline Poly(aspartic acid) & Poly(N-vinylimidazole) \\
\hline Poly(L-glutamic acid) & Poly[6-(1H-imidazol-1-yl)hexyl methacrylate] \\
\hline Poly(histidine) & Dendrimers \\
\hline Poly(boronic acids) & Poly(propyleneimine) dendrimer \\
\hline Poly(vinylphenyl boronic acid) & Poly(ethyleneimine) dendrimer \\
\hline Poly(3-acrylamidophenyl boronic acid) & Poly(amidoamine) dendrimer \\
\hline
\end{tabular}

Dextran is another important class of polymers in $\mathrm{pH}$ responsive natural polymers such as chitosan, hyaluronic acid, alginic acid, and gelatin. These types of polymers are biocompatible and biodegradable as well as being $\mathrm{pH}$-responsive. It is also remarkable that it allows to various modifications. Graft polymers can be produced after a series of reactions using natural polymers. Cross-linked hydrogels of different sizes (nano-, microand macrogel) are also produced, through the functional groups of these natural polymers. They are successfully used in various biomedical applications such as in drug release studies and self-healing gel systems [7].
There have been quite a few studies among environmentally responsive polymers involving $\mathrm{pH}$-responsive polymers. Since there are monomers suitable for the production of various $\mathrm{pH}$-responsive polymers and they can also be produced with any type of polymerization, examples of all polymeric architectures (nanogel, microgel, block copolymer, dendrimer, star, brushes, comb etc.) are well presented [7, 13]. The changes that occur with the ionization of weak basic and acidic groups that can be ionized by $\mathrm{pH}$ change are given in Figure 4 for both basic $\mathrm{pH}$-responsive polymers and acidic $\mathrm{pH}$ responsive polymers. The increase of hydrophilicity in the polymer chain provides important behaviors $[8,15]$. When these polymer chains are used in the producti- 


\section{a) Basic $\mathbf{p H}$-responsive polymers}

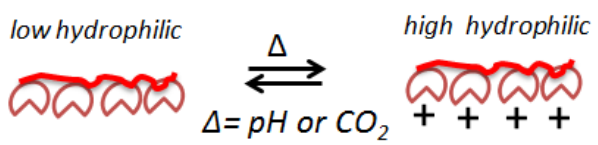

b) Acidic $\mathrm{pH}$-responsive polymers

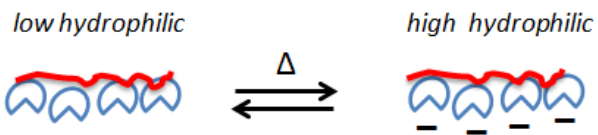

c) Formation of aggregates (micelle, vesicle etc.)
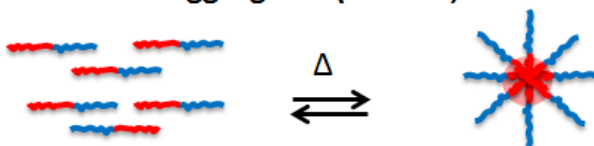

d) Size change: Gel, micelle and other aggregates

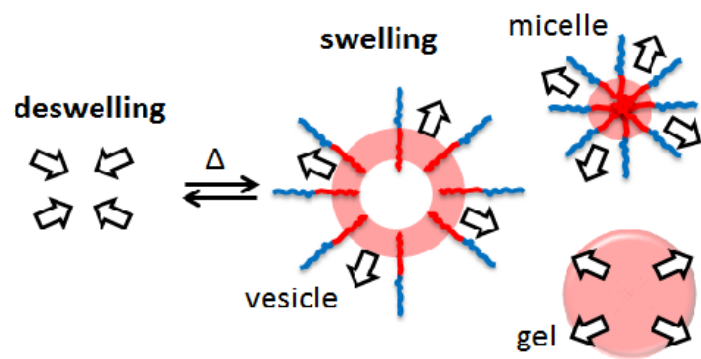

e) Charge and thickness change

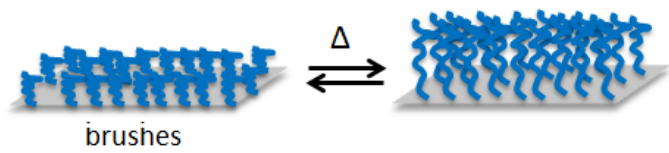

f) Pore size and charge change

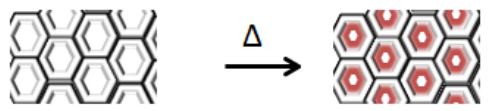

films and membrans

g) Aggregate morphology change

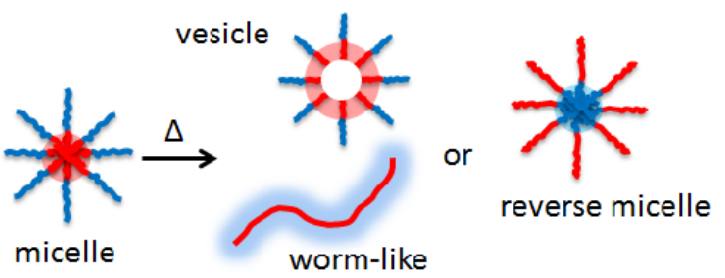

h) Bond cleaved $\quad \Delta \quad$ hydrophilic

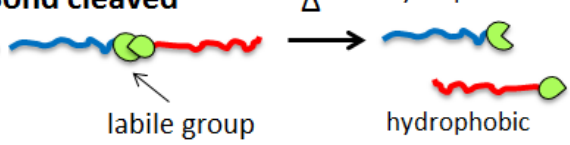

i) Bond cleaved

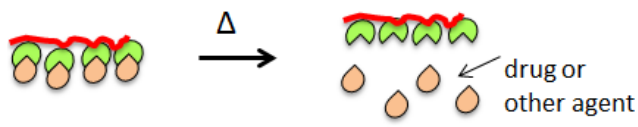

j) $\mathrm{pH}$ - or $\mathrm{CO}_{2}$ labile cross-linked bond (gels and micelles)

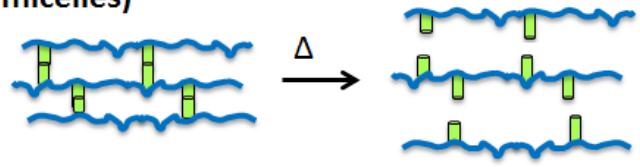

Figure 4. Behaviors of $\mathrm{pH}$-responsive and/or $\mathrm{CO}_{2}$-responsive polymers.

on of various block copolymers as seen in Figure 4c, it is possible to obtain various amphiphilic block copolymers and thus various self-assembly behaviors (spherical micelle [16, 17], flower [18, 19], vesicle [16, 20, 21], wormlike $[22,23])$ which is a very remarkable behavior [24-26]. The related aggregate structures can reversibly dissolve, swell or shrink depending on the $\mathrm{pH}$ of the medium (Figure 4d) [27-31]. When these polymers are used in various surface applications such as films, layerby-layer (LbL) technology, membranes, brushes, many behaviors such as ion selective permeability, surface charge change, wettability, change in pore size and thic kening/thinning of the polymer layer are encountered [32-39]. When these polymers are involved in surface applications such as membranes, numerous behaviors such as ion selective permeation and change in pore size are encountered (Figure 4f) [39-42]. These changes can be in various types such as micelle-reverse micelle
$[9,21,43,44]$, vesicle-reverse vesicle $[20,45,46]$, micelle-wormlike micelle $[47,48]$, vesicle-wormlike micelle [22], vesicle-spherical micelle [22, 49-51], spherical micelle-rod micelle [52] and other [53, 54] (Figure 4g).

It is possible to prepare $\mathrm{pH}$-responsive hydrogels from the monomers having weak acidic or weak basic functional groups. Such groups either accept or release protons in response to $\mathrm{pH}$ changes. As given in Figure 5, hydrogels of acidic monomers release protons at high pHs and become negatively charged. On the contrary, basic monomer based hydrogels become positively charged due to protonation of functional groups at low $\mathrm{pH}$. Both positive and negative formations cause swelling due to an increase on hydrophilicity of related groups. Such ionizations also change osmolarity and ionic interactions within the gel [15]. It is reported that deswelling of $\mathrm{pH}$-responsive hydrogel is faster than that 
Acidic Hydrogel

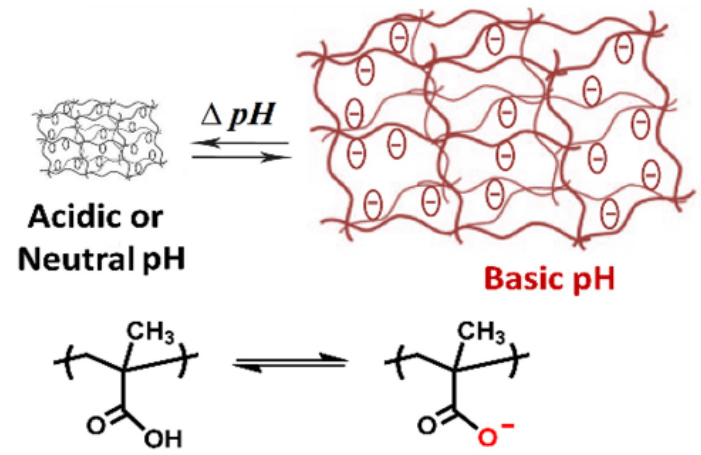

Figure 5. Swelling-shrinking of acidic and basic hydrogels with $\mathrm{pH}$.

of its swelling. Hydrogels are also classified according to their size: Macrogel $(\geq 100 \mu \mathrm{m})$, microgel (0.1-100 $\mu \mathrm{m})$ and nanogel (1-100 $\mathrm{nm})$ [55]. Depending on the $\mathrm{pH}$ change, we encounter sol-to-gel or gel-to-sol behaviors of polymer chains of different architectures $[18,19,56]$.

In another type of $\mathrm{pH}$-responsive polymer, the covalent bonds forming the polymer are broken down with the change in the solution $\mathrm{pH}$. Thus, the macromolecule structure is divided into smaller pieces. For this, these polymers must contain certain groups that are sensitive to $\mathrm{pH}$ and are degradable. Such groups and their cleavage products are given in Figure 6. These polymer types are frequently used in drug release studies $[7,13]$. These groups can be found in the polymer main/side chain, in end group and/or in the junction of blocks as can be seen in Figure $4 \mathrm{~h}$. These bonds can be irreversibly broken down at suitable $\mathrm{pH}$ values [57-60]. As can be seen in Figure $4 \mathrm{i}$, it occurs by attaching various agents as side groups to the polymer chain and breaking the bonds at the appropriate $\mathrm{pH}$ value [57-60]. In addition, as shown in Figure $4 \mathrm{j}$, the destruction of the polymeric network structure or the destruction of the cross-linked micelle structure can be achieved by breaking down the groups designed as cross-linkers in a $\mathrm{pH}$-responsive manner [61-65].

The release of drug molecules and other compounds by $\mathrm{pH}$ change can occur in two different strategies. In the first strategy, $\mathrm{pH}$-responsive systems release such small molecules via degradation of micellar type structures or swelling/deswelling behaviors with $\mathrm{pH}$ changes. In the second strategy, the release of drug molecules occurs

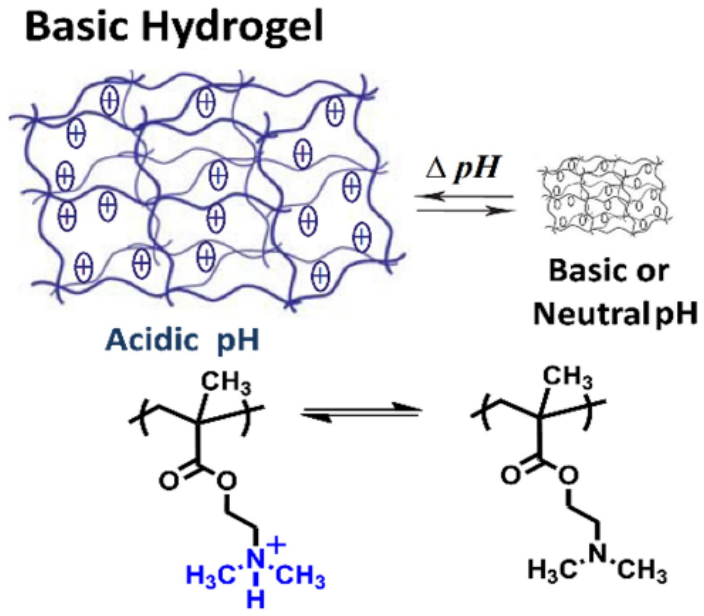

with the cleavage of covalent bonds between polymer and drug molecule by $\mathrm{pH}$ changes. The followings are commonly used in polymer structures as $\mathrm{pH}$-labile bonds for later strategy (Figure 6); hydrazone [66-71], acetal/ketal [72-75], cis-acotinyl [76-80], imine [81-83] substituted trityl [84-86], orthoester [57, 87], boranate ester [88-90], $\beta$-thiopropionate [62, 91], and others [92, 93]. $\mathrm{Xu}$ and co-workers have well presented the recent developments in the area of $\mathrm{pH}$-responsive polymerdrug conjugates with various structures and architectures [94]. They also tried to clarify the mechanism of such synthesis.

\section{$\mathrm{CO}_{2}$-responsive polymers.}

$\mathrm{CO}_{2}$-responsive polymeric systems have attracted great attention in recent years [95], since $\mathrm{CO}_{2}$ is abundant in nature, low cost, environmentally friendly, non-toxic and recyclable. In addition to these, it is preferred because of its high biocompatibility [96]. In $\mathrm{CO}_{2}$-responsive polymers, the reaction occurs simply by adding or removing $\mathrm{CO}_{2}$ gas, which is a very cheap source for changing the $\mathrm{pH}$ of the solution. Environmentally responsive polymer types based on $\mathrm{pH}$, ion, enzyme and redox, chemicals require a chemical substance to provide reversibility, and while in $\mathrm{CO}_{2}$-responsive polymers it is sufficient to pass inert gas from the media. Since the $\mathrm{CO}_{2}$ stimulus can be found in an aqueous environment, it penetrates the inner parts of the polymer and allows the $\mathrm{CO}_{2}$-sensitivity of the polymer. In this way, the problems encountered with light-, magnetic- and mechanically-sensitive polymers are not experienced and greater sensitivity is achieved in $\mathrm{CO}_{2}$-sensitive polymers. Finally, $\mathrm{CO}_{2}$-sensitive polymers have good 


Orthoester $\stackrel{\text { mo }}{\longrightarrow} \stackrel{\mathrm{H}_{\mathrm{O}}^{+}}{\longrightarrow}$

Acetal/ketal $\mathrm{pH}<\sim 4-5$

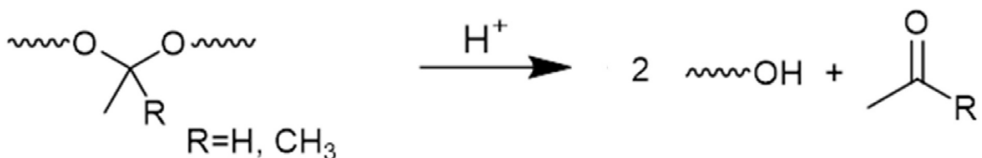

Hydrazone

$\mathrm{pH}<\sim 5$<smiles>CC=NNC</smiles><smiles>C[CH+]C</smiles><smiles>CNN</smiles>

Imine

$\mathrm{pH}<\sim 5-7$

$n^{2}>\omega^{2}$

$\stackrel{\mathrm{H}^{+}}{\longrightarrow}$ cis-aconityl $\mathrm{pH}<\sim 5.5-6.8$<smiles>CNC(=O)C=C(CC(=O)NC)C(=O)O</smiles><smiles>C[CH+]CPN(C)N</smiles><smiles></smiles><smiles>CC=NOCCO</smiles><smiles>C[CH+]C</smiles><smiles>CON</smiles>

Oxime

$\mathrm{pH}<\sim 5$<smiles>CC=NNC(C)=O</smiles><smiles>C[CH+]CCC(=O)NN</smiles><smiles>CC=O</smiles>

$\mathrm{pH}<\sim 5$<smiles>COC(=O)CCSC</smiles><smiles>C[CH+]CCSCCC(=O)[OH+]O[OH2+]</smiles>

Figure 6. $\mathrm{pH}$-responsive/degradable bonds. 
biocompatibility and membrane permeability with human cells, making them important for bio-applications [96]. $\mathrm{CO}_{2}$-sensitive polymers have been extensively studied in relation to $\mathrm{CO}_{2}$-induced self-assembly, $\mathrm{CO}_{2}$ triggered drug carriers, catalysts,"smart latex" systems, $\mathrm{CO}_{2}$-exchangeable surfaces and fibers. $\mathrm{CO}_{2}$-sensitive systems are pollution-free and have good reversibility. The use of carbon dioxide as a trigger in aqueous solutions started in 2006 with the production of a surfactant containing amide group [96].

The most commonly reported $\mathrm{CO}_{2}$-sensitive functional groups are amidine [97-99], imidazole [100, 101], primary amine [102-105], secondary amine [106], tertiary amine $[107,108]$, guanidine $[101,109]$, carboxylic acids $[104,105,110]$ and Lewis acid-base pairs [111, 112] which can easily react with carbonic acid produced by combination of $\mathrm{CO}_{2}$ with water or polar organic solvents (Figure 7). Recently, an innovative dual $\mathrm{CO}_{2}$-responsive polymer system has been reported. This system is improved based on the Lewis acid-base theory and has valuable functions in organic solvent systems. [111, 112]. This type is a new type belonging to the second generation $\mathrm{CO}_{2}$-responsive polymers class. In particular, $\mathrm{CO}_{2}$ can create bridge between polymer segments and induces assembly by incorporating Lewis acid-base pairs into the polymer structure (Figure 4). These systems have excellent reversible responses. Additionally, recyclable nano-catalysts with good activity and recyclability [112] and a novel polymer network with self-healing capability [111] could be developed by utilizing $\mathrm{CO}_{2}$ bridging chemistry. The discovery of $\mathrm{CO}_{2}$ sensitive materials that can be used effectively in organic solvent systems provides an important opportunity for the development of $\mathrm{CO}_{2}$ sensitive processes that will be applicable in many areas in the near future.

A wide variety of architectures have been designed in $\mathrm{CO}_{2}$-responsive polymers. Sample studies are given to explain the behaviors seen in Figure 4. Basic $\mathrm{pH}-$ responsive polymers take on more hydrophilic character in the presence of $\mathrm{CO}_{2}$ and their solubility in aqueous media may change (Figure 4a) [97, 108, 110]. As shown in Figure $4 \mathrm{~b}$, acidic $\mathrm{pH}$-responsive polymers can have a hydrophobic character by further reducing their ionization [105, 110]. By using the behaviors observed in Figures $4 a$ and $4 b$, the self-assembly of the designed block copolymers can provide the formation of different aggregates (micelle, vesicle, wormlike) (Figure 4c) $[101,113]$. Tertiary amine methacrylate monomers such as DMA and DEA are frequently used in the production of $\mathrm{CO}_{2}$-responsive block copolymer [114, 115]. a) Acidic polymers

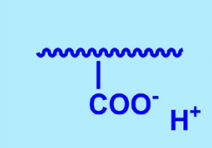

hydrophilic

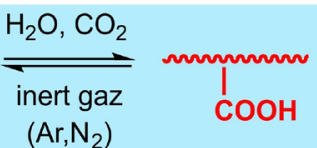

hydrophobic

\section{b) Basic polymers}

$\vdots$
$\vdots$
$\vdots$
$\vdots$
$\vdots$
$\vdots$

\section{c) Lewis acid-base pairs}

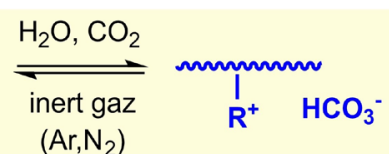

hydrophilic

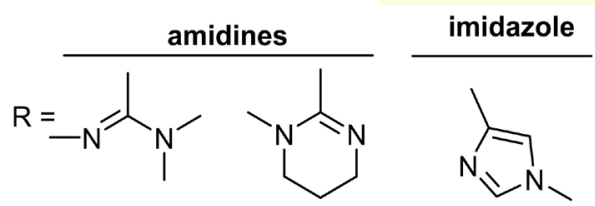

amines

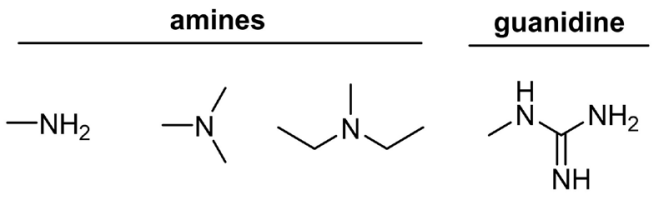

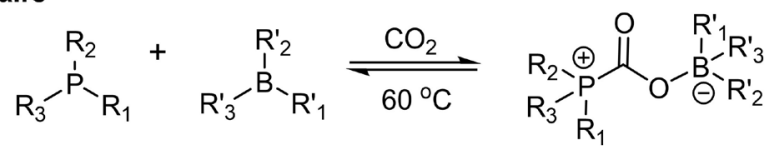

Figure 7. $\mathrm{CO}_{2}$-responsive polymers with different functional groups. 


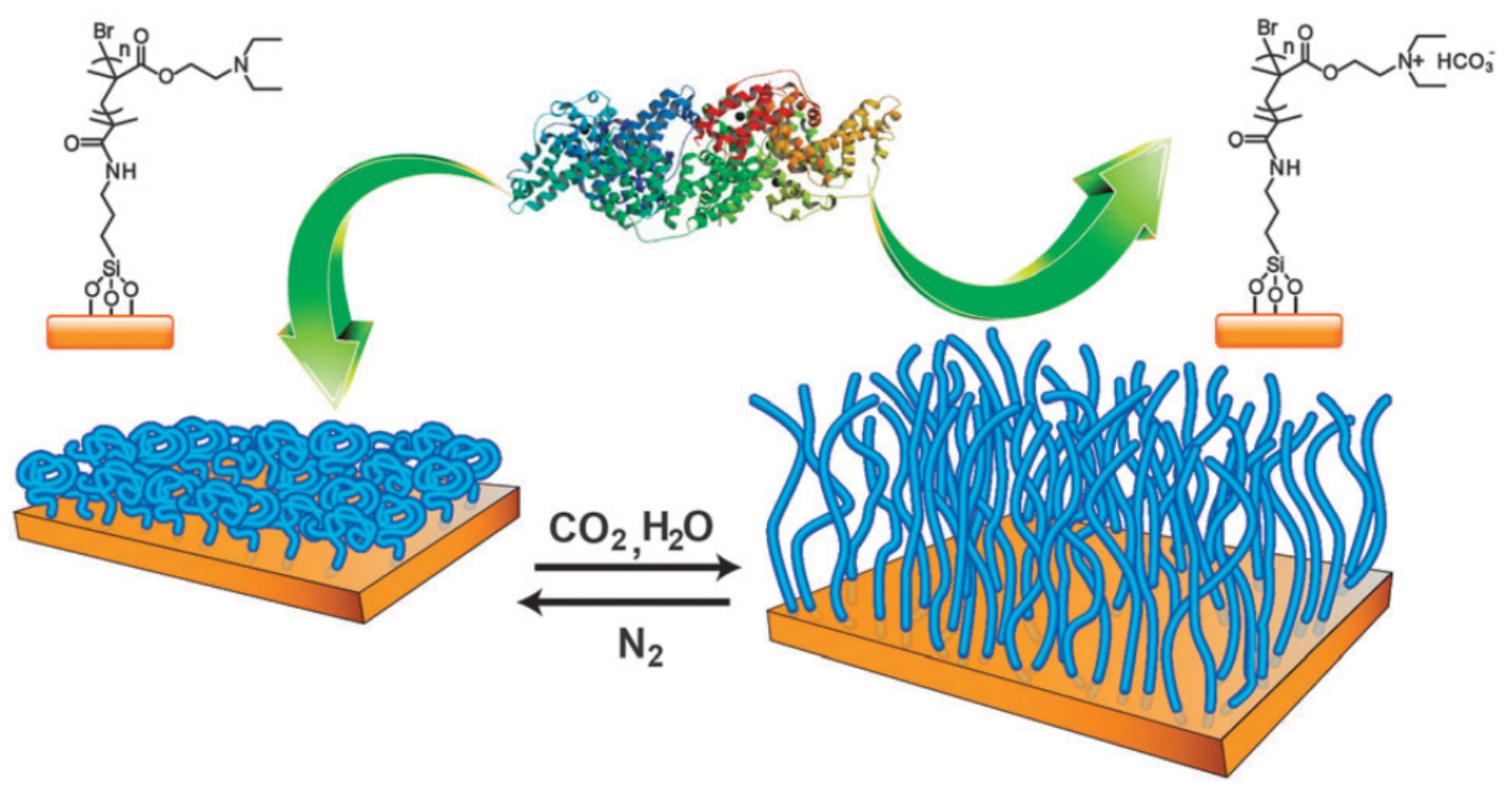

Figure 8. Schematic representation of protein capture and release via $\mathrm{CO}_{2}$ sensitive polymer brushes. The collapsed polymer brushes (before exposure to $\mathrm{CO}_{2}$ or upon removing $\mathrm{CO}_{2}$ with $\mathrm{N} 2$ bubbles) form a suitable surface for protein binding. On the other hand, polymer brushes in the chain-extended conformation (after exposure to $\mathrm{CO}_{2}$ ) create an unfavourable surface for protein adsorption, leading to release of proteins from surfaces [Copyright 2011, RSC, reprinted from ref. 119].

In addition, swelling of different aggregates (micelle, vesicle etc.) and gels (macrogel, microgel and nanogel) is among the important behaviors observed (Figure 4d) [26, 98, 109, 116-118]. Wetting, thickening of the polymer layer, change in pore size and change in charge are encountered in brush polymers, films and membranes (see Figures 4e and 4f) [119-125]. Another behavior is the transformations that can occur in micelle morphologies (Figure 4g) [102, 107, 115, 126]. Reversible crosslinked systems can also be obtained by using in crosslinking systems (Figure 4j) [103, 111, 112, 116, 127].

Kumar S. et al reported a successful study based on $\mathrm{CO}_{2}$-switchable polymer brushes for reversible captu$\mathrm{re} /$ release of proteins. They succeeded to absorb $\mathrm{CO}_{2}$ on the surface decorated with PDEA brushes by using $\mathrm{CO}_{2}$-saturated ultrapure water. In order to remove $\mathrm{CO}_{2}$ and bring PDEA brushes back to insoluble state, passing $\mathrm{N}_{2}$ through the solution has been determined to be enough. The process was completely reversible. The related mechanism for the conformational transition of the PDEA brushes is schematized and given in Figure 8. However, unlike the conventional $\mathrm{pH}$ change induced by acid-base addition, $\mathrm{CO}_{2}$-switchable water solubility can be repeated many times for reversible adsorption and desorption of a protein without contamination of the solution by accumulated salt. This is the great advantage of using inert gases as the trigger [119].

\section{Redox-responsive polymers}

Redox-responsive polymers have electroactive residues or groups in their structures (see Figure 9) that can be oxidized (electron loss) and/or reduced (electron gain). Changing the oxidation step of the related residues changes the properties of the redox-responsive polymers or polymeric materials. Thus, it offers different application opportunities and interesting targets in the design and use of electrochemical devices including electrochromic devices, optoelectronic devices, batteries, biosensors and/or biofuel cells. Thus, it offers different application opportunities and interesting objectives in the design and use of electrochemical devices, including batteries, electrochromic devices, optoelectronic devices, biosensors or biofuel cells. In addition, these polymers offer important advantages in active compound delivery/release systems such as pharmaceuticals, drugs. Due to the presence of redox chemicals in the human physiological fluid, they have an advantage for biological applications. [128]. This section will focus on the behavior of redox-responsive polymers in an aqueous media, and many of these are related to drug release. 
Special oxidant-responsive and reductant-responsive groups are present in the main chain or side group of polymers. These are non-reversible reduction groups such as diselenide [129, 130], trimethyl-locked benzoquinone [131], platinum (IV)-coordinate [132-135], alkyl selenide [136], alkyl telluride [137], non-reversible oxidation groups such as thioketal [138-141], alkyl sulfide [142-144], aryl oxalate ester [145, 146], phenyl boronic acid [147, 148], proline [149, 150] or reversible functional groups such as disulfide [151-154] and ferrocene [155-162]. Redox-responsive functional structures and their chemical transformations in some redox-responsive polymers are given in Figure 9.

The number of publications containing disulfide, ferrocene and platinum (IV) among the functional groups is quite high. Therefore, it will be useful for readers to give brief information about these functional groups. Various reducing agents can be used to convert disulfide bonds (S-S) to thiols (-SH). They also undergo disulfide exchange in the presence of other thiols. Thus, polymers containing disulfide bonds can be considered as redox- and thiol-sensitive [163]. Among many physiological redox pairs, glutathione ( $\gamma$-glutamyl-cysteinyl-

\section{Type or redox action Redox active group structures}

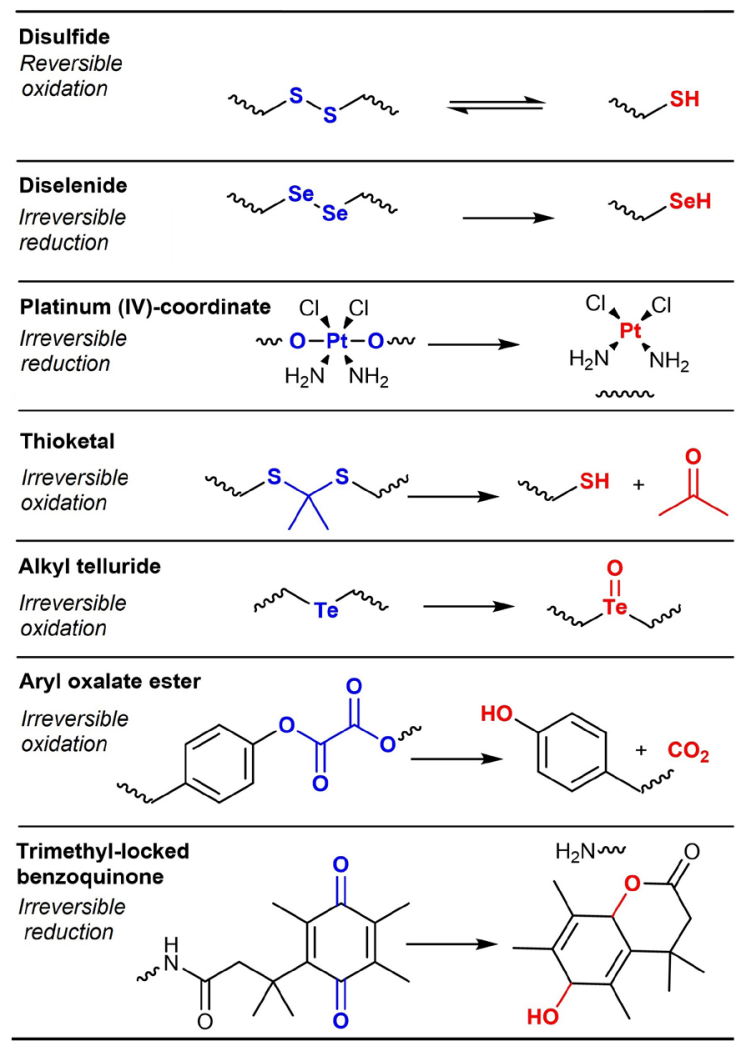

glycine; GSH) is widely used to trigger drug delivery. $\mathrm{GSH} /$ glutathione disulphide pair is the main redox pair in this system. GSH compound provides a suitable environment for drug distribution within the cell, since its concentration is very variable both inside the healthy cell and on the outer surface of the cell, and this value is quite high in cancer cells $[128,164]$. The compound dithiothreitol (DTT) is also frequently used to break down the disulfide bonds. Disulfide bonds can be found in the polymer main chain or side groups. The biodegradability of these polymers occurs faster when they are in the main skeleton [128]. Particularly, the usage of disulfide bond containing ATRP initiators or (meth)acrylate and di(meth)acrylate monomer types is very common in release studies of active compounds and self-regulation studies $[163,165]$.

Ferrocene-containing polymers are fascinating polymers with their high chemical stability and characteristic electrochemical response. Ferrocene-containing polymers are sensitive to both oxidizing and reducing agents. While it has a positive charge in its oxidized form (ferrocenium), its reduced form is neutral and gives the

Type or redox action Redox active group structures

Ferrocene
$\begin{aligned} & \text { Reversible } \\ & \text { oxidation }\end{aligned}$
$\begin{aligned} & \text { Diselenide } \\ & \text { oxidation }\end{aligned}$
$\begin{aligned} & \text { Alkyl selenide } \\ & \text { oxidation }\end{aligned}$

Phenyl boronic acid

Irreversible oxidation
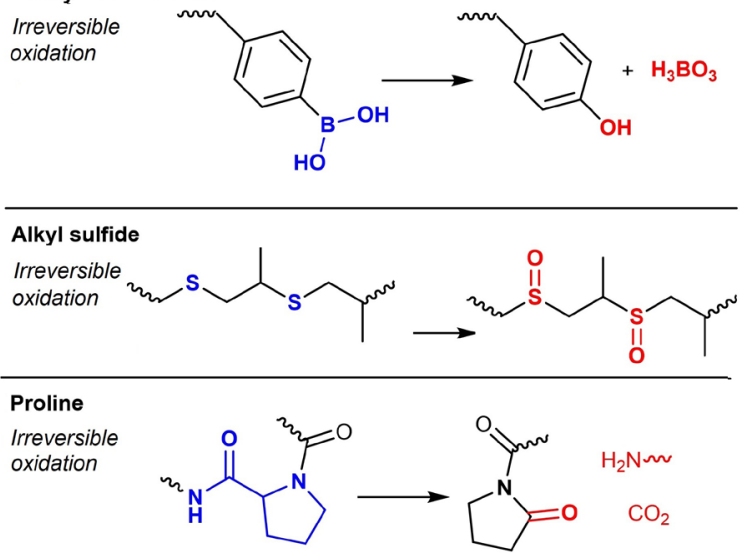

Figure 9. Redox-responsive groups in polymers and their reduction/oxidation products. 
a) Bond cleaved

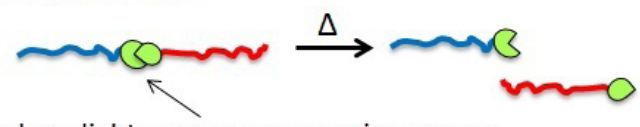

redox-, light-, enzyme-responsive groups

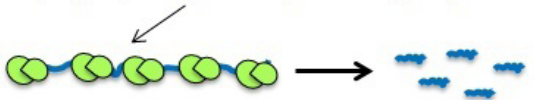

b) Polarity change by bond cleaved

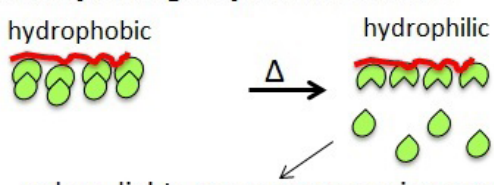

redox-, light-, enzyme-responsive groups

c) Change of hydrophilic properties by change of charge, isomerism or chemical conversion

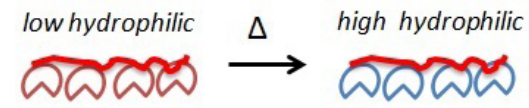

d) Bond cleaved between active compound

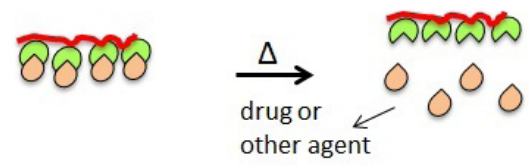

e) Photo-, enzyme- and redox- responsive crosslinked gels and micelles

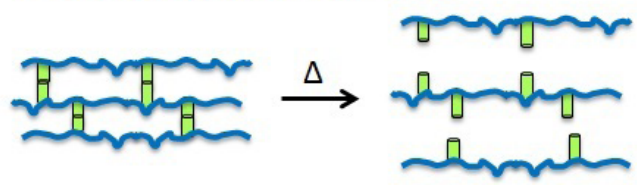

\section{f) Aggregate morphology change}

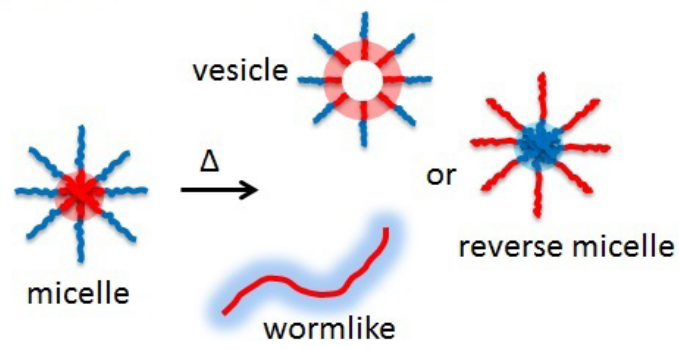

g) Size change

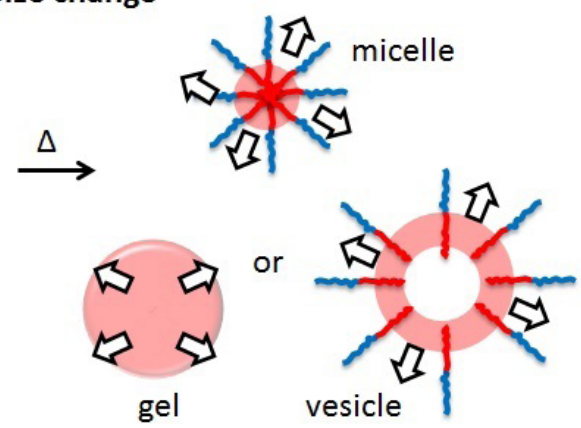

h) Pore size, polarity and charge change

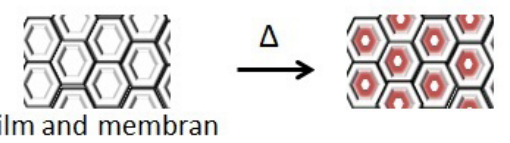

i) Polarity and thickness change

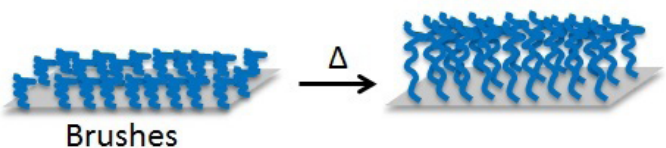

Figure 10. Behaviour of redox-, enzyme and light-responsive polymers.

polymer more hydrophilicity due to the formation of the positive charge. Platinum(IV)-coordinate polymers have been reported to be very useful in drug delivery purposes since they can behave a reducing system in the cell, which results with the release of platinum(II) and the encapsulation of drug molecules. Among redox-responsive polymers, platinum(IV)-coordinate containing polymers are one of the most interesting linkers. In order to reduce the severe side effects on normal cells, cisplatin being a broad-spectrum anticancer drug must be conjugated with polymers. Generally, cisplatin is oxidized to obtain a diol which is consumed in polycondensation reactions. Cisplatin-polymer conjugate systems can be reduced in the intracellular environment by releasing cisplatin only in tumor cells [128].
Polymers of a wide variety of architectures can be designed according to the types of changes occurring in reducing- and oxidizing-responsive polymers. Behaviors of various types of redox-responsive polymers are schematized in Figure 10. As seen in Figure 10a, the breakdown of the polymeric structure can be achieved by breaking down the redox-responsive groups in the polymer main chain. These redox-responsive groups can be located in the end group of the polymer main chain, along the main chain, and at the junction of two different blocks of the block copolymers [129, 130, 132, 138, 140, 153]. In Figure 10b, it is shown that the hydrophilicity of the polymer chain increases with the separation of the redox-responsive residues of the polymer chain [166]. In Figure 10c, the hydrophilicity of the polymer 
chain increases due to the redox-responsive ionic state of the side groups in a polymer chain or the increase in hydrophilicity due to the oxygen entering the structure as a result of chemical transformation $[137,155]$. By attaching a compound (drug, dye molecule, etc.) to the polymeric chain as a side group and cleaving the redoxresponsive bond, separation of the compound from the polymer chain can occur (see Figure 10d) [133, 141]. Another very important approach given in Figure $10 \mathrm{e}$ is redox-responsive cross-linking. By using this approach, cross-linked micelles and gels can be obtained and release studies are carried out by breaking these bonds, especially in drug applications. Bifunctional monomers or agents capable of cross-linking polymer chains on functional groups are used for this [167-169]. The main reasons of all other schematized behaviors are also based on these explained behaviors. As seen in Figure 10f, the formation of a more hydrophilic polymer chain or the breaking of cross-links can result in degradation or swelling behavior of aggregated structures [137, 151, $152,155,158,160,169,170]$. As shown in Figure 10g, aggregates (micelle, wormlike, vesicle, lamella) can be formed from block copolymers and their aggregate morphology may change as redox-responsive [154, 162, 171-174]. As Figures $10 \mathrm{~h}$ and $10 \mathrm{i}$ underline, depending on the increase in hydrophilic structure and charge change in film, membrane and brush structures, surface wetting properties, pore size, selective ion permeability and polymer thickness may change [157, 159, 175].

\section{anionic \\ polymer}

\author{
cationic \\ polymer
}
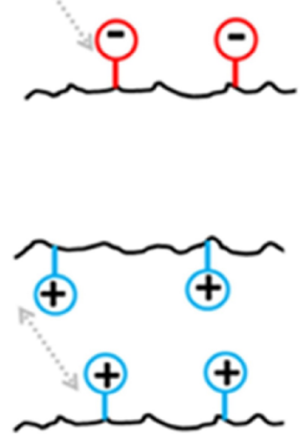

\section{Salt addition}

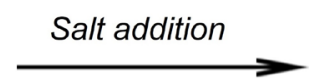

\section{zwitterionic \\ polymer}

Salt addition
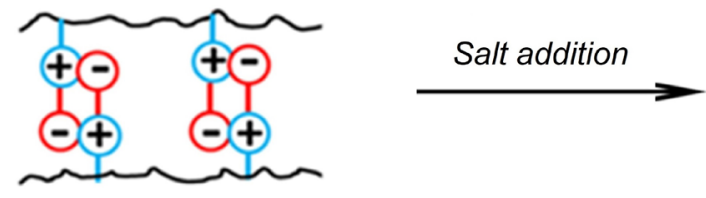

Salt addition

\section{amphoteric polymer}

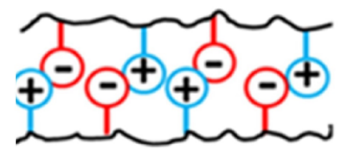

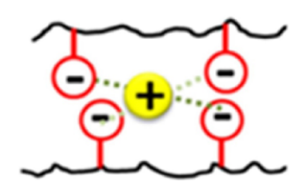
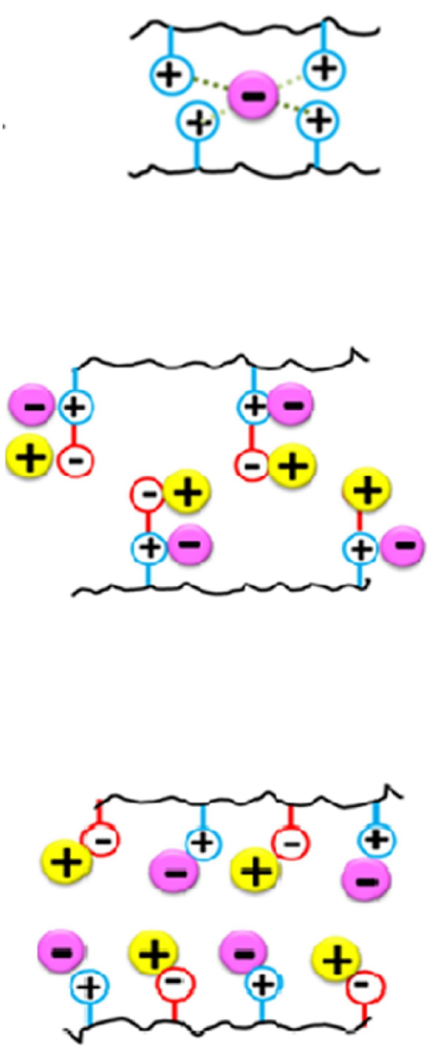

Figure 11. Intra-chain and inter-chain interactions and salt effect in polymer. 


\section{lonic strength-responsive polymers}

Response to ionic strength is typical property of some neutral and ionisable polymers. Changes in ionic strength can cause changes in the size of polymeric structures or nanoaggregates, swelling-shrinkage of gels, solubility of polymers, and fluorescent quenching kinetics of chromophores of polyelectrolytes [176-181]. Salt added to solutions of anionic and cationic polymers increases electrostatic interactions among groups in polymer chains [181]. Polyampholytes designed with two different monomers, both anionic and cationic, and zwitterionic polymers with both negative and positive groups do not dissolve at low temperatures due to the interactions between opposite charges [32, 35, 180, $182,183]$. The added salt solution reduces electrostatic interactions between polymer chains. The behavior of polyampholytes in aqueous media is also related to the type and ratio of ionic species included in the polymer $[182,184]$. Also, $\mathrm{pH}$ change significantly affects such polymers [185]. Intra-chain and inter-chain interactions and the effect of salt are schematized for different polymer types in Figure 11.

The presence of salt (such as $\mathrm{NaCl}$ and $\mathrm{CaCl}_{2}$ ) in hydrogels containing anionic groups such as PAA and carboxymethyl cellulose triggers shrinkage [178, 186-191]. Similarly, it triggers shrinkage in hydrogels containing cationic groups such as PDMA and PMEMA in the presence of salt (such as $\mathrm{Na}_{2} \mathrm{SO}_{4}$ ) [27, 192-195]. While the presence of salts in polysulfobetaine-containing hydrogels triggers swelling, salts trigger swelling in polyamphoteric hydrogels and zwitterionic hydrogels consisting of anionic and cationic monomers $[184,196]$. It also has a property that triggers physical gel formation [197]. The salt effect is a very important parameter for temperature-sensitive polymers as well, and it will be discussed in the following section.

Highly charged polyelectrolytes can be shielded by varying ionic strength, thus modifying the charge density and adsorption behavior. As an example, The $\mathrm{Cu}$ (II) cation can be immobilized on a poly(NIPAM-covinylimidazole) copolymer for protein separation using the affinity binding of specific proteins to $\mathrm{Cu}(\mathrm{II})$ cation. The increase in ionic strength precipitates polymer chains that bind proteins. The high ionic strength reduces the repulsive electrostatic strength of the copolymer, which causes an increase in hydrophobic interactions and thus leads to precipitation of the polymer. The high salt concentration reduces the repulsive electrostatic strength of the copolymer, which results with an increase in the hydrophobic interactions among polymer chains and thus leads to precipitation [198].

The most common method to obtain a response from a smart polymeric system is based on kinetically constrained diffusion of the stimulus. For example, salt- or $\mathrm{pH}$-sensitive polymer gels react by transport of external ions around the polymer backbone. Similarly, the response of temperature sensitive polymers can be adjusted by heat transfer control. Consequently, the polymer's response to many conventional stimulants is a slow process. Electric-, magnetic-, ultrasound- or electromagnetic field-responsive mechanisms can overcome this problem. In recent years, to clarify these processes, various studies have been carried out in different fields such as biomedical, sensor, organ engineering, membrane permeability, microelectronic system, surface control $[163,199]$.

\section{Temperature-responsive polymers}

It can be said that smart materials obtained with temperature-responsive polymers are the most important members of the environmentally-responsive polymer class. Temperature-responsive polymers can be produced in different polymeric architectures such as hydrogel, film, star, brush, comb, block copolymer (micelle), spherical particles of different sizes. Especially, temperature-responsive polymers between $20-40{ }^{\circ} \mathrm{C}$ are frequently studied by considering the body temperature $\left(37^{\circ} \mathrm{C}\right)$. Therefore, poly $(\mathrm{N}$-alkyl(meth)acrylamide)s are perhaps the most intensively studied temperature- or thermo-responsive polymers. Since the earliest report by Scarpa et al on the thermo-responsive PNIPAM polymer in 1967, temperature remains the most widely used stimulus in the field of sensitive polymers [200].

Temperature-responsive polymers show a sudden change in their dissolution state and total volume at certain temperatures. This temperature is known as cloud point (CP). There are two types of volume phase transition temperature for thermo-responsive water soluble polymers; the lowest critical solution temperature (LCST) and the upper critical solution temperature (UCST). The polymer is insoluble above LCST and/or below UCST (Figure 12). Both CP behaviors can be determined by using various methods, including UV-visible (UV-vis), infrared (IR), NMR and dielectric spectroscopies, differential scanning calorimetry, static and dynamic light scattering, and turbidity measurements. Figure 12c highlights 

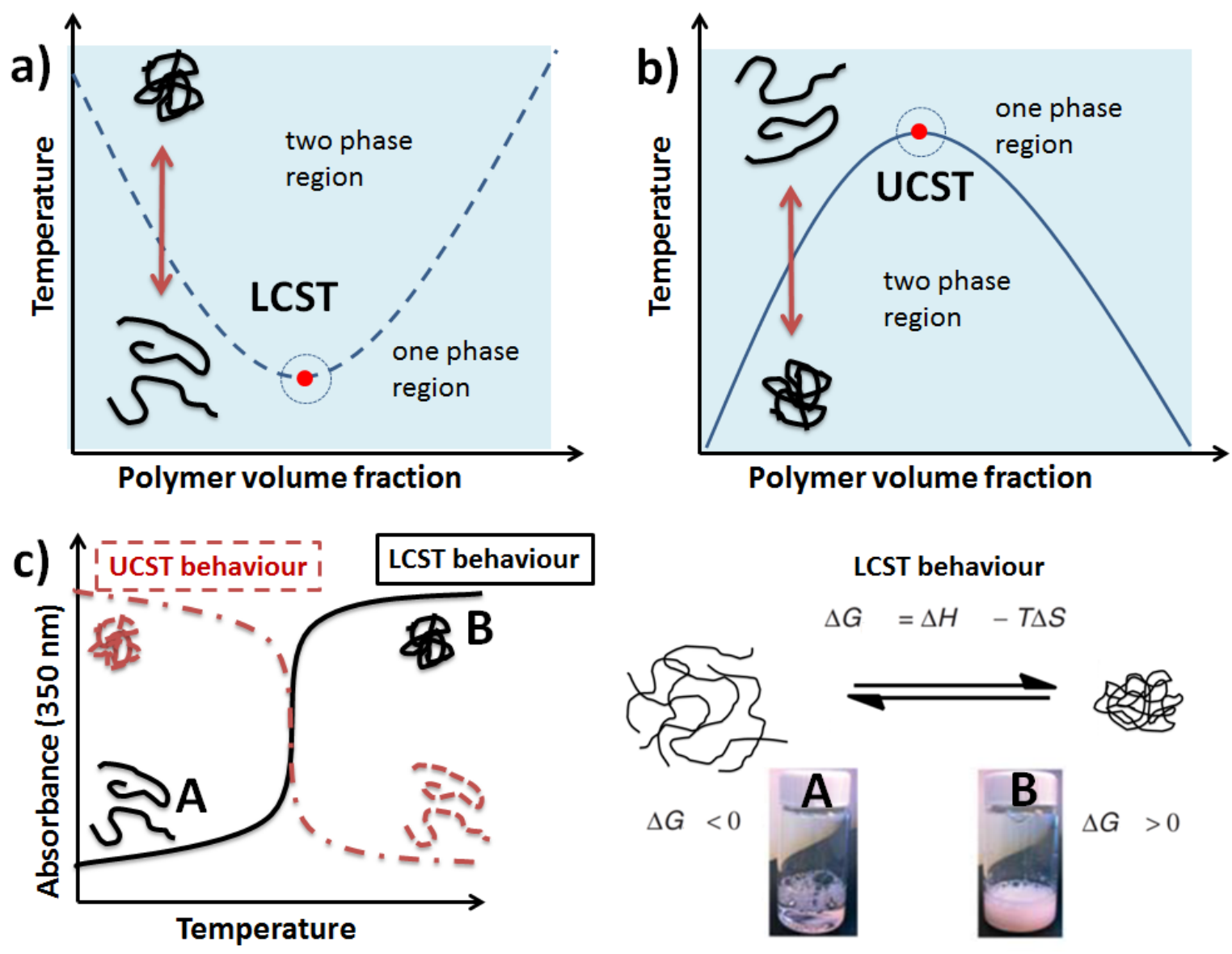

Figure 12. Overview of UCST and LCST behavior of polymers in solution.

a typical turbidity behavior of temperature-responsive polymers. Simply, a polymer solution with a concentration of 0.5 wt\% is located into a UV-spectrophotometer and the phase transition temperature (cloud point) is determined when the absorbance of the polymer solution decreases (UCST) or increases (LCST) to $50 \%$ of its maximum absorbance at the wavelength of $350 \mathrm{~nm}$ [8, 201].

For thermo-responsive polymers, the hydrophilichydrophobic balance of the polymer chain changes with temperature (an increase for LCST behavior) and the polymer becomes more hydrophobic (for LCST). If a polymer chain becomes more hydrophobic, water molecules reorient and reorganize around the newly formed hydrophobic areas of the polymer. Water molecules and polymer chains cannot do hydrogen bonds any more. The polymer-water solution undergoes phase separation and precipitation of the polymer (or colloidal) is observed [8]. The turbidity of LCST-type polymer is also shown as a function of temperature in Figure 12c. As can be seen, there is an increase in the turbidity of the polymer solution, or in other words, an increase in the absorbance with the increase in temperature.

LCST and UCST describe the minimum and maximum temperatures of both single phase and two phase areas in the phase diagram of the polymer/solvent mixture (Figure 12a and b). If the solution temperature of the polymer with LCST is below the LCST value, the poly- 
mer is soluble (single phase), when it is above the LCST value, the polymer is insoluble (two phase). If the solution temperature of the polymer with UCST is below the UCST value, the polymer is insoluble (two phases), and when it is above the UCST value, the polymer dissolves (single phase). That is, UCST and LCST are opposite behaviors.

Many theories have been proposed to explain LCST and UCST values of polymers. The most commonly cited and well-supported theory is that posed by Schild [2]. As swell known from thermodynamics, Gibbs free energy change of mixing is given as $\Delta \mathrm{G}_{\text {mix }}=\Delta \mathrm{H}_{\text {mix }}-\mathrm{T} \Delta \mathrm{S}_{\text {mix }}$ where $\mathrm{G}$ is the Gibbs free energy, $\mathrm{H}$ is the enthalpy, $\mathrm{T}$ is the temperature $(\mathrm{K})$, and $\mathrm{S}$ is the entropy. For mixing (solvation) to occur, $\Delta G_{\text {mix }}$ must be negative. While a negative $\Delta G_{\text {mix }}$ favors solvation, a positive $\Delta G_{\text {mix }}$ favors desolvation or flocculation of the polymer from solution. Neutral polymers dissolve in a solvent via hydrogen bonding and dipole-dipole interactions between water and polymer chains/side groups. In a solvation or dissolution of polymer sample, $\Delta S_{\text {mix }}$ will always be positive which favours solvation.

On the other hand, below LCST or above UCST, there is a positively modest change in entropy $\left(\Delta \mathrm{S}_{\text {mix }}\right)$, by solvation, a negative change in enthalpy of mixing $\left(\Delta \mathrm{H}_{\text {mix }}\right)$ with hydrogen bond formation. $\Delta \mathrm{G}_{\text {mix }}$ is negative and dissolution occurs, as dissolution is promoted both enthalpically and entropically. As the temperature changes, the hydrophilic-hydrophobic balance of the polymer chain changes, resulting in more hydrophobic properties. Due to an increase on the hydrophobicity of the polymer chain, the water molecules reorient around the newly emerging hydrophobic regions of the polymer and become highly organized. As the water molecules are arranged, they no longer form hydrogen bonds with the polymer, resulting in a positive enthalpy change. Also, the entropy of the system is reduced because wa- ter becomes more organized as it is organized around the hydrophobic polymer interface (hydrophobic effect). These two factors combine to make the total free energy change (Gmix) positive, making desolvation and phase separation an energetically favourable process. This (de)solvation behaviors are shown in Figure 12c for a LCST type polymer.

UCST and LCST behaviors are completely reversible. Both LCST and UCST are severely affected by the type of polymer (monomer type) [202, 203], molecular weight of the polymer [8, 202], concentration of polymer [202], monomer ratios in copolymer [204-206], solvent (alcohol etc.) and salt type and concentration [202, 203, 206, 207].

Temperature-responsive polymers are generally composed of amphiphilic monomers containing hydrophilic groups such as amide, carbonyl, secondary amine, tertiary amine and quaternary amine and hydrophobic groups such as methyl, ethyl and propyl. These polymers exhibit interesting phase behaviors depending on the temperature due to their amphiphilic structure. LCST and UCST values of some selected polymers are given in Table 2 and 3. Only linear homopolymers are given in Table 2. These CP values should be examined by considering that they will be affected by molecular weights, architecture, concentration, ionic strength and type of solvent. The CP value of copolymers can be tuned to the desired UCST or LCST values by changing the monomer ratio. LCST value decreases with increasing molecular weight of polymers exhibiting LCST property [8]. On the other hand, in polymers with UCST properties, as the molecular weight increases, the UCST value increases [202]. As the concentration of the polymer with LCST in solution increases, the LCST value decreases. This is the opposite for polymers with UCST behavior, that is, UCST values increase [202, 203]
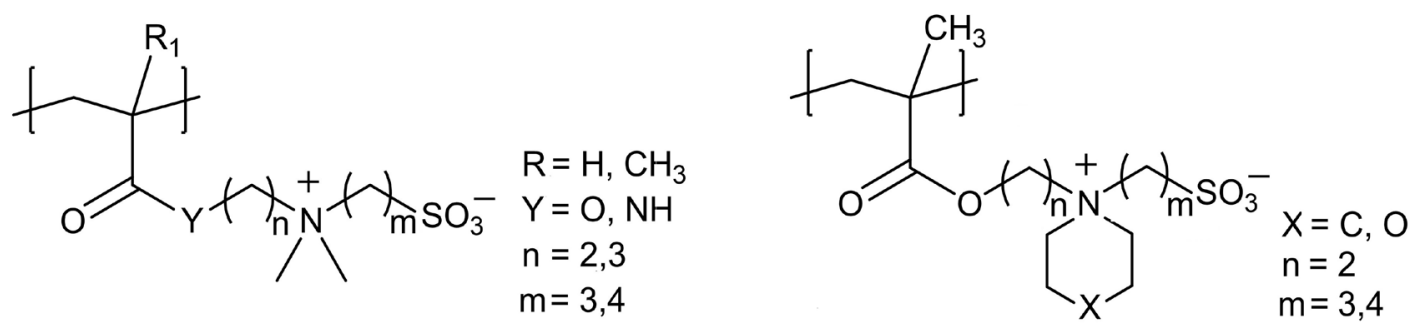

Figure 13. Structures of some sulfobetaine-containing polymers. 
Table 2. Some polymers exhibiting LCST behavior and their temperatures [211-213].

\section{Polymers}

LCST (CP)*

\section{Poly(acrylamide) and poly(methacrylamide)}

\begin{tabular}{|c|c|}
\hline Poly(N-isopropylacrylamide) & $27.0-36.0^{\circ} \mathrm{C}$ \\
\hline Poly ( $N$-isopropylacrylamide) & $61.0-41.2^{\circ} \mathrm{C}(3000-420000 \mathrm{~g} / \mathrm{mol})$ \\
\hline Poly(N-ethylacrylamide) & $72.8-85.5^{\circ} \mathrm{C}(3300-7400 \mathrm{~g} / \mathrm{mol})$ \\
\hline Poly(N,N-ethylmethylacrylamide) & $58.0-68.8^{\circ} \mathrm{C}(5400-36500 \mathrm{~g} / \mathrm{mol})$ \\
\hline Poly(N-ethylmethacrylamide) & $58.0^{\circ} \mathrm{C}$ \\
\hline Poly(N,N-diethylacrylamide) & $28.6-32.9^{\circ} \mathrm{C}(9600-593000 \mathrm{~g} / \mathrm{mol})$ \\
\hline Poly(N,N-propylacrylamide) & $25.0^{\circ} \mathrm{C}(10000 \mathrm{~g} / \mathrm{mol})$ \\
\hline Poly(N-acryloylpyrrolidine) & $51.0^{\circ} \mathrm{C}(15000 \mathrm{~g} / \mathrm{mol})$ \\
\hline \multicolumn{2}{|l|}{ Poly(acrylate) and poly(methacrylate) } \\
\hline PDMA & $32.0-50.0^{\circ} \mathrm{C}$ \\
\hline PMEMA & $34.0-53.0^{\circ} \mathrm{C}$ \\
\hline \multicolumn{2}{|l|}{ Poly(N-vinyl amide) } \\
\hline Poly(N-vinyl caprolactam) & $31.0-38.0^{\circ} \mathrm{C}(3200-470000 \mathrm{~g} / \mathrm{mol})$ \\
\hline \multicolumn{2}{|l|}{ Poly(peptide) } \\
\hline Poly(N-acryloyl-L-proline methyl ester) & $17.5^{\circ} \mathrm{C}(12200 \mathrm{~g} / \mathrm{mol})$ \\
\hline \multicolumn{2}{|l|}{ Poly(oxazoline) } \\
\hline Poly(2-n-propyl-2-oxazoline) & $23.8^{\circ} \mathrm{C}(12000 \mathrm{~g} / \mathrm{mol})$ \\
\hline Poly(2-isopropyl-2-oxazoline) & $38.7^{\circ} \mathrm{C}(9700 \mathrm{~g} / \mathrm{mol})$ \\
\hline \multicolumn{2}{|l|}{ Poly(oxides) } \\
\hline Poly(ethylene oxide) or poly(ethyleneglycol) & $96.0^{\circ} \mathrm{C}(20000 \mathrm{~g} / \mathrm{mol})$ \\
\hline Poly(propylene oxide) or PEG & $15.0 \mathrm{oC}-35.0^{\circ} \mathrm{C}(1200-3000 \mathrm{~g} / \mathrm{mol})$ \\
\hline \multicolumn{2}{|l|}{ Poly(vinyl ethers) } \\
\hline Poly(methyl vinyl ether) & $37.0^{\circ} \mathrm{C}$ \\
\hline Poly(2-ethoxyethylvinylether) & $20.0^{\circ} \mathrm{C}(22000 \mathrm{~g} / \mathrm{mol})$ \\
\hline Poly[2-(2-ethoxy)ethoxyethylvinylether] & $40.0-40.5^{\circ} \mathrm{C}(20000-34000 \mathrm{~g} / \mathrm{mol})$ \\
\hline
\end{tabular}

\footnotetext{
* The effect of the concentrations has not been studied
} 
The number of UCST type polymers is more limited than LCST type polymers. Generally, sulfobetaine derivative polymers are studied in the literature [202, 203]. Copolymers or mixtures of homopolymers consisting of two different monomers can also exhibit this behavior. Sulfobetaine polymers, which are very common, were obtained by the reaction of tertiary amine groups containing polymers such as DMA with various sultone chemicals (1,3-propanesultone, 1,4-butanesultone) [203, 208]. Polymers containing both the quaternary amine group $\left(-\mathrm{NR}_{3}{ }^{+}\right)$and the sulfonate group $\left(-\mathrm{SO}_{3}{ }^{-}\right)$in the terminal group are obtained by the reaction over the tertiary nitrogen atom where the steric hindrance is low [202]. It is possible to obtain sulfobetaines containing both a quaternary amine group $\left(-\mathrm{NR}_{3}^{+}\right)$and a sulphate $\left(-\mathrm{SO}_{4}{ }^{-}\right)$group in the end group by different methods $[209,210]$. The structures of (meth)acrylate and (meth) acrylamide type sulfobetaine polymers containing different hydrophilic and hydrophobic parts are summarized in Figure 13.
Another important feature of sulfobetaine type polymers is that they are biocompatible [214]. Gel formation may also occur with the increase in solution concentration and molecular weights of polymers exhibiting UCST behavior [215]. It has been observed that the UCST values of sulfobetaine homopolymer solutions (50.0 g $\left.\mathrm{L}^{-1}\right)$ with different molecular weights differ up to $60^{\circ} \mathrm{C}$ with the change of molecular weight. It was observed that there were changes up to $30{ }^{\circ} \mathrm{C}$ in UCST value with the change of polymer concentration in this study [202]. The hydrophilic and hydrophobic parts of the polymer structure are the main reason for these changes. Copolymers such as poly(acrylonitrile-co-acrylamide) $[\mathrm{P}(\mathrm{AN}-\mathrm{CO}-\mathrm{AM})]$ and $\mathrm{P}(\mathrm{AA}-\mathrm{CO}-\mathrm{AM})$ also appear to exhibit UCST behavior. Homopolymers of the monomers that constituting this polymer exhibit the behavior of UCST in the copolymer state, while the homopolymers do not exhibit UCST behavior. The UCST values of such copolymers are significantly affected by the change in comonomer ratio [204, 205, 216, 217].

Table 3. Some polymers exhibiting UCST behaviour and their temperatures [202, 203, 212].

\begin{tabular}{|c|c|}
\hline Polymer & UCST (CP )* \\
\hline \multicolumn{2}{|l|}{ (Meth)acrylates } \\
\hline Poly[4-((3-(methacryloyloxy)propyl)dimethyl ammonium)butane-1-sulfonate] & $41.0^{\circ} \mathrm{C}(37000 \mathrm{~g} / \mathrm{mol})$ \\
\hline Poly[3-((3-(methacryloxy)propyl)dimethyl ammonium)propane-1-sulfonate] & $5.0^{\circ} \mathrm{C}(74000 \mathrm{~g} / \mathrm{mol})$ \\
\hline Poly[4-((2-(methacryloxy)ethyl)dimethyl ammonium)butane-1-sulfonate] & $\begin{array}{l}82.0^{\circ} \mathrm{C}(22000 \mathrm{~g} / \mathrm{mol}) \\
26.5^{\circ} \mathrm{C}(11000 \mathrm{~g} / \mathrm{mol})\end{array}$ \\
\hline Poly[4-((2-(acryloyloxy)ethyl)dimethyl ammonium)butane-1-sulfonate] & $52.7^{\circ} \mathrm{C}(16000 \mathrm{~g} / \mathrm{mol})$ \\
\hline Poly[3-((2-(methacryloyloxyethyl)dimethyl ammonium)propane-1-sulfonate] & $\begin{array}{l}41.0^{\circ} \mathrm{C}(29000 \mathrm{~g} / \mathrm{mol}) \\
13.2^{\circ} \mathrm{C}(15000 \mathrm{~g} / \mathrm{mol})\end{array}$ \\
\hline Poly[3-(4-(2-(methacryloxy)ethyl)morpholino)propane-1-sulfonate] & $24.0^{\circ} \mathrm{C}(41000 \mathrm{~g} / \mathrm{mol})$ \\
\hline Poly[4-(4-(2-(methacryloxy)ethyl)morpholino)butane-1-sulfonate] & $70,0^{\circ} \mathrm{C}(30000 \mathrm{~g} / \mathrm{mol})$ \\
\hline Poly[4-(1-(2-(methacryloxy)ethyl)piperidin-1-ium-1-yl)butane-1-sulfonate] & $4,0^{\circ} \mathrm{C}(93000 \mathrm{~g} / \mathrm{mol})$ \\
\hline Poly[3-(1-(2-(methacryloxy)ethyl)piperidin-1-ium-1-yl)propane-1-sulfonate] & $0^{\circ} \mathrm{C}<(104000 \mathrm{~g} / \mathrm{mol})$ \\
\hline \multicolumn{2}{|l|}{ (Meth)acrylamides } \\
\hline Poly[3-((3-methacrylamidopropyl)dimethyl ammonium)propane-1-sulfonate] & $9.0^{\circ} \mathrm{C}$ \\
\hline Poly[3-((3-acrylamidopropyl)dimethylammonio)propane-1-sulfonate] & $8.5^{\circ} \mathrm{C}(34500 \mathrm{~g} / \mathrm{mol})$ \\
\hline Poly[3-((2-methacrylamidoethyl)dimethyl ammonium)propane-1-sulfonate] & $16.0^{\circ} \mathrm{C}$ \\
\hline Poly(methacrylamide) & $57.0^{\circ} \mathrm{C}$ \\
\hline
\end{tabular}

* The effect of the concentrations has not been studied 
The UCST value of aqueous polymer solutions is significantly affected by the type and amount of salt added $[208,215]$. As given in Figure 11, salt added to the media is directed to positive and negative charges and the interaction within the sulfobetaine units decreases. Salt addition also reduces the interactions between neighbor sulfobetaine units within the polymer chain and sulfobetaine units among other polymer chains. The solubility of polymer chains increases with decreasing interaction. Thus, the cloud point is observed at lower temperatures (UCST decreases). The effect of anionic and cationic charges formed by dissolution of salts has been studied in detail in different studies [202]. Solution viscosity decreases, respectively, when salts containing $\mathrm{Fe}^{3+}, \mathrm{Al}^{3+}, \mathrm{Ca}^{2+}, \mathrm{K}^{+}, \mathrm{Ni}^{2+}$ cations are used, while salts containing $\mathrm{Cl}^{-}, \mathrm{Br}, \mathrm{l}^{-}$anions increase in this order [206].

Random, sequential, gradient and block copolymer types are structures that can be obtained according to the order of the monomers in the polymer chain. Homopolymers and random and gradient copolymers can only exhibit precipitation or dissolution behavior in aqueous media, depending on environmental conditions (Figures 14a and 14b). While the polymers showing LCST with the temperature increase become hydrophobic [201], the polymers showing UCST on the contrary, when the temperature decreases, they become hydrophobic and go to phase separation in the aqueous solution environment [8, 203, 210, 218].

Among the polymeric structures of different architectures, block copolymers are the most widely used type due to their wide usage area [7]. Block copolymers exhibit special behaviors such as self-assemble and disassemble (Figure 14c). The block copolymers may be in different architectures and the number of blocks can be more than two. However, it may be useful to make an explanation on diblock copolymers. One block of dib-

\section{a) Change of hydrophilic properties (LCST)}

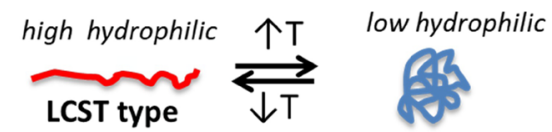

b) Change of hydrophilic properties (UCST)

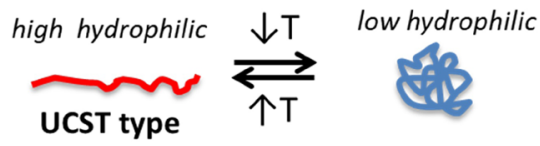

\section{c) Self-assemble and disassemble behaviour}
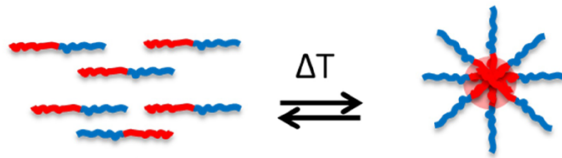

UCST and/or LCST blocks

d) Size change by polarity change

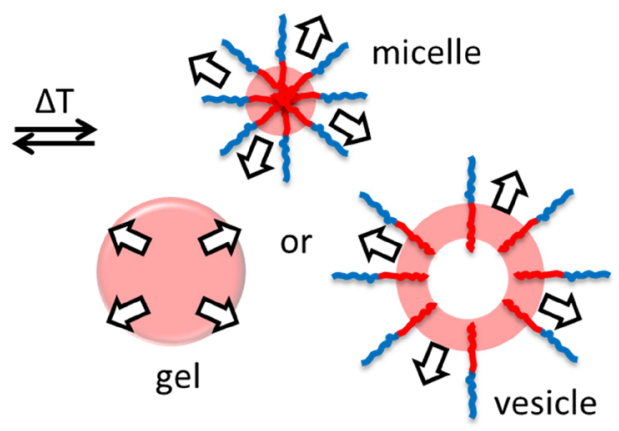

e) Aggregate morphology change by polarity change

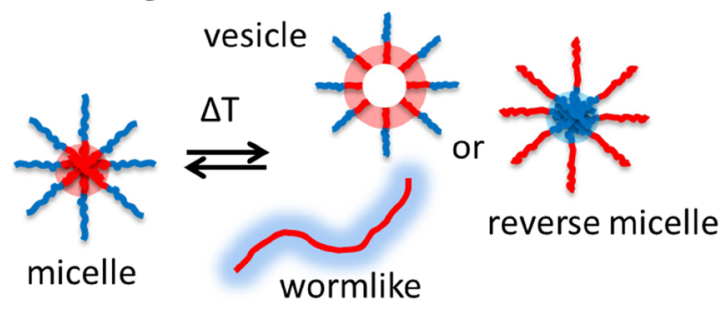

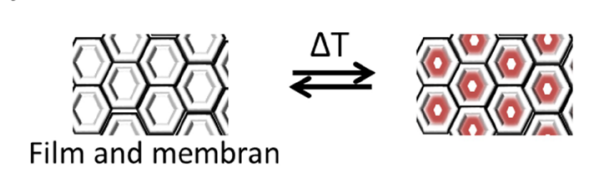

\section{g) Polarity and thickness change}

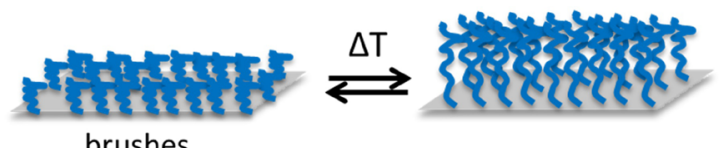

Figure 14. Behaviors of thermo-responsive polymers. 
lock copolymers can be produced from polymer capable of displaying UCST or LCST behavior. Both blocks can be designed from blocks showing LCST/UCST behavior or one block showing LCST and the other block UCST. Numerous aggregates (spherical micelle, wormlike, vesicle, lamellar and other) and changes in aggregate morphology (micelle to reverse micelle [210], micelle to vesicle [219], micelle to wormlike [220] and other) that can be produced in this way are observed (Figure 14e). If micelles are prepared with amphiphilic block copolymers having thermo-responsive block, they may exhibit swelling/shrinkage behavior with temperature (Figure 14d).

Another important behavior of temperature-sensitive polymeric systems is the swelling-shrinkage behavior we encounter in chemical gels (nano-, micro- and macro-). As the solution temperature increases (LCST behavior polymer) or decreases (UCST behavior polymer), the dehydrated chemical gel shows volumetric shrinkage (Figure 14d). Aqueous solutions of block copolymers at high concentrations are also used in the production of physical gels $[18,220]$. This is all about how the copolymer was designed and its concentration. PNIPAMcontaining hydrogels are the most widely used type of the class showing LCST behavior. PNIPAM can be found alone or as a comonomer in the structure of hydrogels [221-225]. Besides having low toxicity, when it comes to temperature values such as $30-33^{\circ} \mathrm{C}$, they show great volumetric decrease. PNIPAM containing gels can be of different sizes such as macrogel [221-224], nanogel [226] and microgel [225, 227]. Apart from that, many chemical gels of LCST-type [27, 192, 221, 228-236] and UCST-type [215, 217, 237-243] can be produced. It can also be obtained in physical gels with UCST-type [215, 244-246] and LCST-type [18, 247] polymers.

When these polymers are involved in various surface applications such as film, thin film [248], membrane [249-257], brush [258-270], numerous behaviors such as ion-selective permeability, surface charge change, wettability, change in pore size, and thickening/thin-
Below CMC

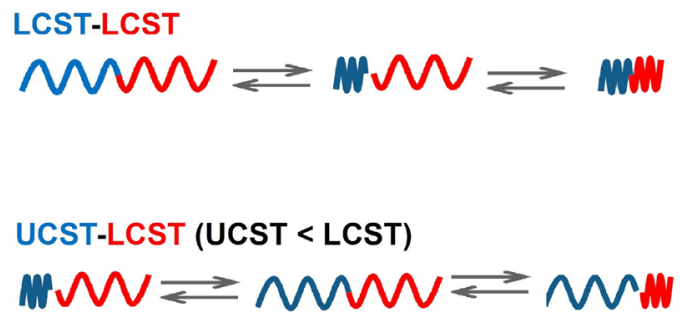

UCST-UCST

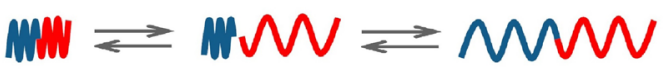

Above CMC

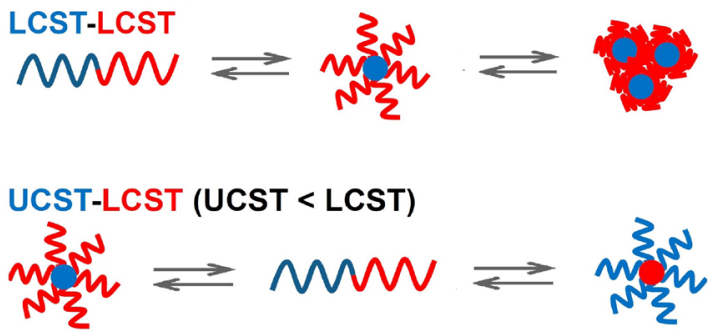

UCST-LCST (UCST > LCST)

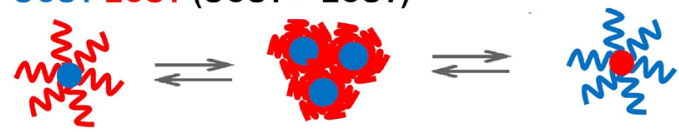

UCST-UCST

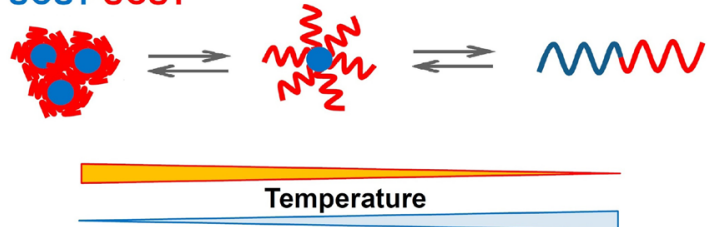

Figure 15. Conformational changes that may occur in the aqueous solution of the block copolymer (double temperature-sensitive) with UCST and LCST [212]. 
ning of the polymer layer are encountered (Figure 14g). If micelles are formed at a certain solution $\mathrm{pH}$, it is called the critical micellization $\mathrm{pH}(\mathrm{CMpH})$ and if it occurs at a certain solution temperature, it is called the critical micellization temperature (CMT). When these CMT and $\mathrm{CMpH}$ values are not reached, micelle formation is not observed in the solution medium. If the block copolymer is designed from blocks with both UCST and LCST behavior, it is possible to obtain double temperaturesensitive polymers These changes will also show significant changes with the critical micellization concentration above or below [210, 212]. These changes are schematized in Figure 15.

Generally, temperature-sensitive behaviors of polymers in solution are discussed in above section. It also has an important value in temperature-sensitive shape memory polymers. Shape memory polymers (SMPs) are smart materials that can change their shape to a predefined state under a suitable stimulus. Such polymers provide important additives in various application areas. In particular, two- and multiple-ways SMPs provide unique opportunities to realize untethered soft robots with programmable morphology and/or properties, repeatable actuation, and advanced multi-functionalities. [271-275].

\section{Magnetic field-responsive polymers}

Magnetic field-responsive polymers are hybrid species in which magnetic particles are stabilized with polymers or embedded in the polymeric network. Such polymers can be produced using a variety of strategies [276278]. Essentially, this feature is not a characteristic of the polymer itself, but a property that arises from the added magnetic particles. Magnetic field-responsive polymers have found various applications in different fields such as chemical adsorbent, separation science, catalysis, microfluidic valve and active compound distribution [10, 277, 279].

Magnetic field-responsive polymers are directed to the desired location by the effect of the magnetic field. Maghemite $\left(\gamma-\mathrm{Fe}_{2} \mathrm{O}_{3}\right)$ or magnetite $\left(\mathrm{Fe}_{3} \mathrm{O}_{4}\right)$ particles, especially small $(<100 \mathrm{~nm})$, exhibit super magnetic properties and they are the most preferred types. In addition, magnetic particles such as $\mathrm{Co}, \mathrm{CoFe}_{2} \mathrm{O}_{4}, \mathrm{Ni}$, FeN, FePt, FePd are also used in the production of magnetic field-responsive polymers $[1,277,280]$. It is very common for magnetic field-responsive polymers to be obtained by embedding magnetic particles in a crosslinked polymeric network. It can also be produced by physical adsorption to the polymeric surface or by modifying the surfaces of magnetic particles or by bonding the previously produced polymer chain $[10,163,279$, 281]. Both components (polymer and magnetic particle) of polymer-magnetic particle hybrid materials can be produced during the experiment (in-situ) or before the experiment (ex-situ) [278]. For example, magnetic particles can be produced by first adsorbing $\mathrm{Fe}^{2+} / \mathrm{Fe}^{3+}$ to the polymer or polymer-inorganic hybrid material. Polymer-magnetic particle hybrid system can also be prepared by first producing the magnetic particle and adding it to the polymerization media. Figure 16 shows the magnetic field-responsive microgels obtained by physically adsorbing $\mathrm{Fe}_{2} \mathrm{O}_{3}$ nanoparticles onto the microgel and how these microgels are oriented in the magnetic field.

Magnetic targeting is based on attracting magnetic microparticles or nanoparticles to an external source of magnetic field. It provides a suitable media for controlled drug release by creating a magnetic field in the desired tissue [199, 279, 282, 283]. Magnetic field-responsive polymers are preferred in the production of
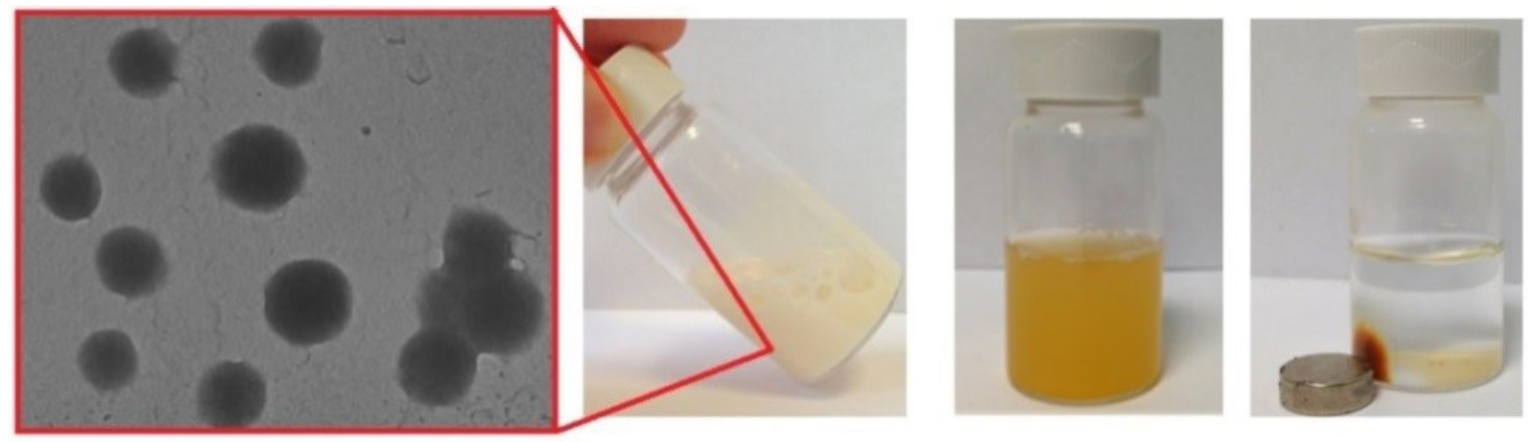

Figure 16. Microgel loaded with $\mathrm{Fe}_{2} \mathrm{O}_{3}$ particles and their orientation in the magnetic field. 
multi-responsive polymer (temperature-magnetic, $\mathrm{pH}$ magnetic, light-magnetic, etc.) [282]. General mechanisms for the production of polymer/inorganic hybrid materials are given in Figure 17 [7]. Some selected polymer-magnetic particle hybrid systems are also given in Table 4.

\section{Light/photo-responsive polymers}

Light-responsive polymers can change some of their properties when exposed to light with an appropriate wavelength (UV, NIR, or visible). These changes are due to light-dependent structural transformations of specific functional groups of the polymer [163, 279, 282]. The physical (mechanical stiffness, swelling/contraction, unwinding, shape, rate of degradation) and chemical properties (surface hydrophilicity) of light-responsive polymers can be adjusted very precisely by the light wavelength, intensity, exposure time and the type of lightresponsive groups [10]. Advantages of light-responsive polymers compared to other responsive polymers are; (i) availability of a wide spectrum of wavelengths (UV to infrared) that can be effectively applied to the polymer, (ii) 4D control over material sensitivity, (iii) adjustable therapeutic light dose, (iv) facilitates regulation of the in vivo response in the optical tissue window range [10].

Suggested possible applications of this type of polymers are reversible photomechanical transduction, bioactivity change of proteins, tissue engineering, optical storage, viscosity control, and release of active compounds [163]. Light-responsive polymers are used especially in controlled drug release and drug encapsulation studies. Functional structures that form photo-responsive polymers (Figure 18) and the classification according to the type of change that occurred is made as follows;

Photo-isomerization (reversible): It includes ring opening-closing and cis-trans transformations. Polarity change or ionic structure formation takes place. For example; azobenzene, spiropyran, dithienylethen, triphenylmethane leuko and ciprooxacin derivatives can be given.

Photo-dimerization (reversible): Photo-cross-linking occurs by the [2+2] cyclocation mechanism. For example; cinnamic ester, cinnamic acid and coumarin derivatives can be given.

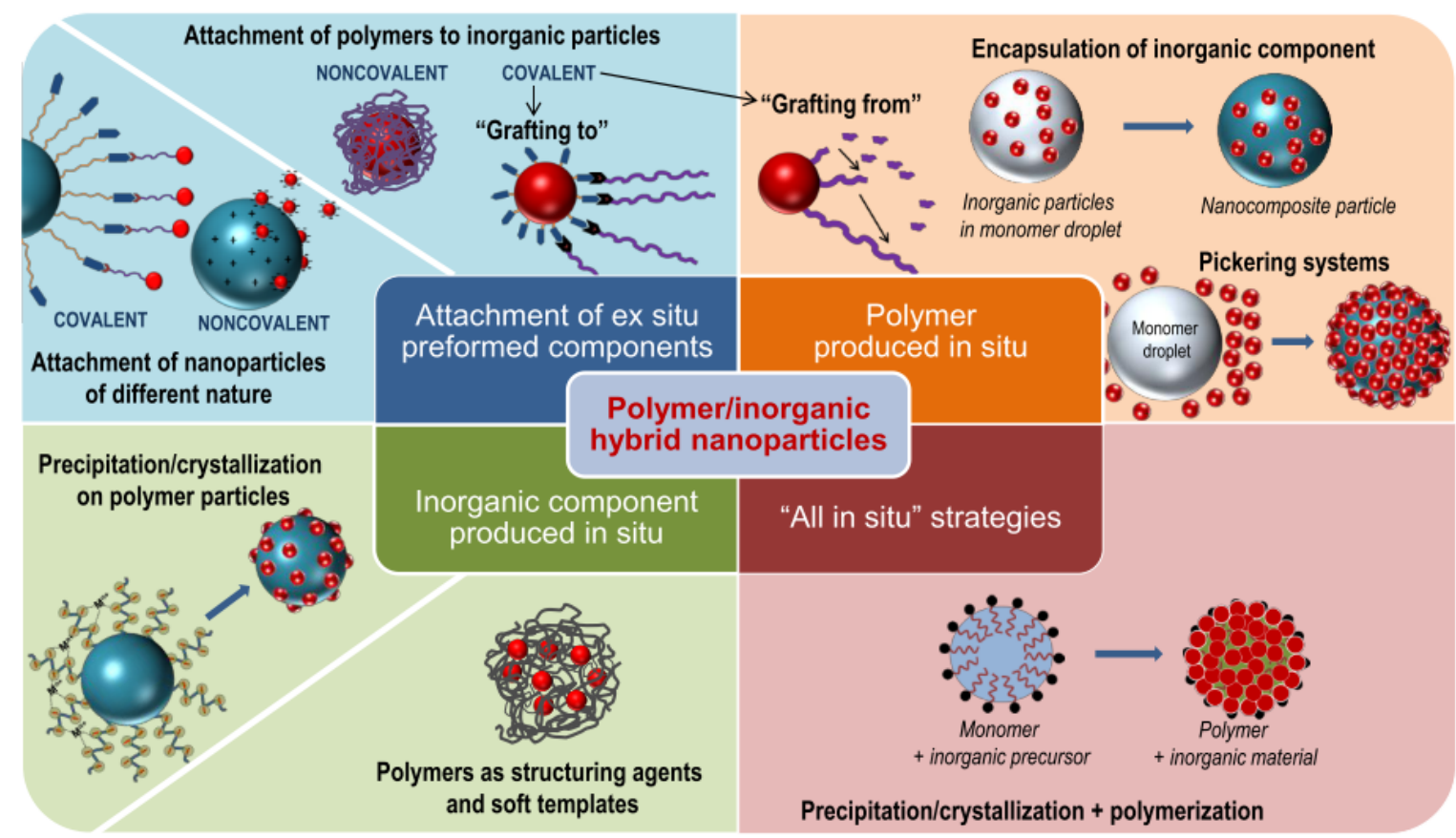

Figure 17. General mechanisms for the production of polymer/inorganic hybrid materials [278]. 
Table 4. Some selected polymer-magnetic particle hybrid systems.

\begin{tabular}{|c|c|c|c|c|c|}
\hline Polymer Types & $\begin{array}{c}\text { Magnetic } \\
\text { Particle Type }\end{array}$ & Polymer Name & Stimuli & Purpose of Usage & Ref. \\
\hline Microgel & $\mathrm{Fe}_{3} \mathrm{O}_{4} \mathrm{NPS}$, inside & PNIPAM & $\mathrm{T}$ & Controlled drug delivery & {$[284]$} \\
\hline $\begin{array}{l}\text { Comb polymer } \\
\text { functionalized } \\
\text { MPs aggregates }\end{array}$ & $\mathrm{Fe}_{3} \mathrm{O}_{4} \mathrm{NPs}, 20 \mathrm{~nm}$ & PMA-g-PVA comb polymer & $\mathrm{pH}$ & $\begin{array}{l}\text { Controllable removal of } \\
\text { heavy metal ions. }\end{array}$ & [285] \\
\hline \multirow{2}{*}{ Block copolymer } & $\begin{array}{l}\text { Gold/iron oxide } \\
\text { NPs }\end{array}$ & (PNIPAM-co-AM)-b-poly( $\varepsilon$-caprolactone) & $\mathrm{T}$ & $\begin{array}{l}\text { Drug delivery, imaging, } \\
\text { magnetic hyperthermia }\end{array}$ & [286] \\
\hline & $\mathrm{Fe}_{3} \mathrm{O}_{4^{\prime}} \sim 10 \mathrm{~nm}$ & P(NIPAM-CO-AM) & $\mathrm{T}$ & Multi-modal cancer therapy & {$[287]$} \\
\hline \multirow{2}{*}{$\begin{array}{l}\text { Core-shell } \\
\text { nanoparticles }\end{array}$} & $\mathrm{Fe}_{3} \mathrm{O}_{4} \mathrm{NPs}, 3-8 \mathrm{~nm}$ & PDEA & $\mathrm{pH}$ & Adsorption of DNA & {$[288]$} \\
\hline & $\mathrm{Fe}_{3} \mathrm{O}_{4} \mathrm{NPS}$ & $\begin{array}{l}\text { PDEA and poly(poly(ethylene glycol) methyl } \\
\text { ether methacrylate)) (PPEGMA) }\end{array}$ & & Adsorption of DNA & {$[289]$} \\
\hline Encapsulation & $\mathrm{Fe}_{3} \mathrm{O}_{4}, 13 \mathrm{~nm}$ & $\begin{array}{l}\text { Poly(D,L-lactic-co-glycolic acid)-L-lysineD- } \\
\text { galactose (PTX-MNP-PLGA-Lys-Gal) }\end{array}$ & $\mathrm{T}$ & \multirow{2}{*}{$\begin{array}{l}\text { Controlled drug delivery/ } \\
\text { release }\end{array}$} & [290] \\
\hline \multirow[t]{3}{*}{ Encapsulation } & $\begin{array}{l}\text { Magnetic NP, 10 } \\
\mathrm{nm}\end{array}$ & P(NIPAM-AM-ALAm) & $\mathrm{T}$ & & {$[291]$} \\
\hline & $\mathrm{Fe}_{3} \mathrm{O}_{4}, 10-15 \mathrm{~nm}$ & $\begin{array}{l}\text { Magnetic chitosan-cis-aconitic anhydride- } \\
\text { doxorubicin nanocomposite }\end{array}$ & & Controlled drug delivery & [292] \\
\hline & $\mathrm{Fe}_{3} \mathrm{O}_{4^{\prime}} \sim 500 \mathrm{~nm}$ & $P(P E G M A-c o-Q D E A)$-grafted MNP & $\mathrm{pH}$ & Separation & {$[293]$} \\
\hline \multirow[t]{2}{*}{ Encapsulation } & $\mathrm{Fe}_{3} \mathrm{O}_{4}$ & PEG & & & {$[294]$} \\
\hline & $\mathrm{MnFe}_{2} \mathrm{O}_{4}, 15-20 \mathrm{~nm}$ & PNIPAM-co-polyglutamic acid & $\mathrm{T}$ & \multirow{3}{*}{ Drug delivery } & {$[295]$} \\
\hline \multirow{3}{*}{$\begin{array}{l}\text { Core-shell } \\
\text { nanoparticles }\end{array}$} & $\mathrm{Fe}_{3} \mathrm{O}_{4}, 7-8 \mathrm{~nm}$ & $\begin{array}{l}\text { PEG- } b \text {-P(AA-co-nBuMA)- } b \text {-PGmMA and the } \\
\text { folate-conjugated block copolymer folate- } \\
\text { PEG- } b \text {-PGmMA }\end{array}$ & & & [296] \\
\hline & $\mathrm{Fe}_{3} \mathrm{O}_{4}$ & Salphen-In & $\mathrm{pH}$ & & {$[297]$} \\
\hline & $\mathrm{Fe}_{3} \mathrm{O}_{4}$ & $\begin{array}{l}\text { PEG with 4-hydroxybenzaldehyde terminal } \\
\qquad(\text { PEG-CHO) }\end{array}$ & $\mathrm{pH}$ & $\begin{array}{l}\text { Drug delivery and MR } \\
\text { imaging }\end{array}$ & {$[298]$} \\
\hline Bead & & Poly(HEMA-co-MMA)-g-PGMA beads & - & & [299] \\
\hline Nanofiber & & Double-layer LA/PNIPAM & $\mathrm{T}$ & & {$[300]$} \\
\hline Microspheres & $\mathrm{Fe}_{3} \mathrm{O}_{4}, 200 \mathrm{~nm}$ & PMAA and PAM & $\mathrm{pH}$ & - & [301] \\
\hline Film & $\mathrm{Fe}_{3} \mathrm{O}_{4}, 200-400 \mathrm{~nm}$ & Poly(vinylidene fluoride) fibers & & Oil-water separation & {$[302]$} \\
\hline $\begin{array}{l}\text { Hollow } \\
\text { microsphere }\end{array}$ & $\mathrm{Fe}_{3} \mathrm{O}_{4}, 11 \mathrm{~nm}$ & PMAA & $\begin{array}{l}\mathrm{pH}, \\
\text { redox }\end{array}$ & \multirow{2}{*}{ Drug release } & [303] \\
\hline $\begin{array}{l}\text { LbL hollow } \\
\text { microsphere }\end{array}$ & $\mathrm{Fe}_{3} \mathrm{O}_{4}, 10 \mathrm{~nm}$ & Chitosan-sodium alginate-PEG & & & [304] \\
\hline Microsphere & $\begin{array}{l}\mathrm{SiO}_{2} @ \mathrm{Fe}_{3} \mathrm{O}_{4^{\prime}} \\
250 \mathrm{~nm}\end{array}$ & $\begin{array}{l}\text { Poly(4-[(4-methacryloyloxy) phenylazo] } \\
\text { benzenesulfonic acid) }\end{array}$ & Photo & Sensor & [305] \\
\hline Bruch sphere & $\mathrm{Fe}_{3} \mathrm{O}_{4}, 10 \mathrm{~nm}$ & PAMAM- $b$-PDMA- $b$-PPEGMA & $\mathrm{pH}$ & Drug release & [306] \\
\hline Macrogel & $\mathrm{Fe}_{3} \mathrm{O}_{4}, 22 \mathrm{~nm}$ & $\begin{array}{l}\text { PAM-carboxymethyl cellulose-PAM- } \\
\text { methylcellulose }\end{array}$ & Electric & Drug-delivery & [307] \\
\hline $\begin{array}{l}\text { Spherical } \\
\text { brushes }\end{array}$ & $\begin{array}{l}\gamma-\mathrm{Fe}_{2} \mathrm{O}_{3} @ \text { silica, } \\
15.0 \text { and } 28.8 \mathrm{~nm}\end{array}$ & PDMA & $\mathrm{pH}, \mathrm{T}$ & Gene delivery & [308] \\
\hline \multirow{2}{*}{ Block copolymer } & $\mathrm{Fe}_{3} \mathrm{O}_{4}, 5-30 \mathrm{~nm}$ & PEO- $b$-PVIm & $\mathrm{pH}$ & MR imaging & [309] \\
\hline & $\mathrm{CoFe}_{2} \mathrm{O}_{4}, 18 \mathrm{~nm}$ & PAA-PS & & Magnetic storage system & {$[310]$} \\
\hline Core-shell & $\mathrm{Fe}_{3} \mathrm{O}_{4^{\prime}} \sim 10 \mathrm{~nm}$ & PMAA@PNIPAM & $\mathrm{pH}, \mathrm{T}$ & Drug release & {$[311]$} \\
\hline Nanocapsules & $\mathrm{Fe}_{3} \mathrm{O}_{4}, 5 \mathrm{~nm}$ & poly(vinyl alcohol) & & Drug release & {$[312]$} \\
\hline
\end{tabular}

PNIPAM: poly(N-isopropylacrylamide) PMA : poly(maleic anhydride) PVA : poly(vinyl alcohol) PAM : poli(acrylamide)

PHEMA : poly(hydroxyethyl methacrylate) PVIm: poly(1-vinylimidazole) PALAm: poly(allylamine) QDEA: Quaternary DEA 


\section{Reversible photo-response groups}

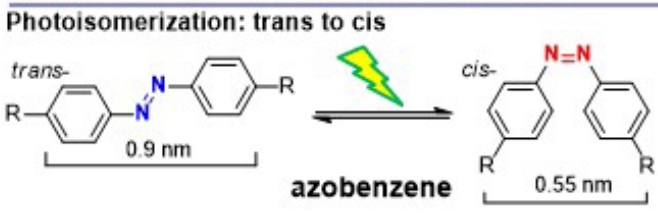

Photoisomerization: open to closed

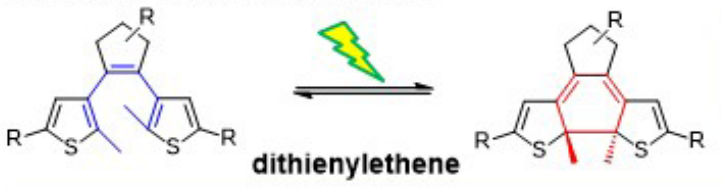

Photocycloaddition: dimerization
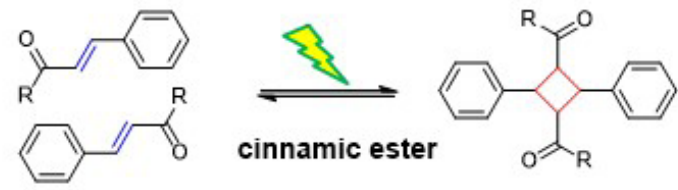

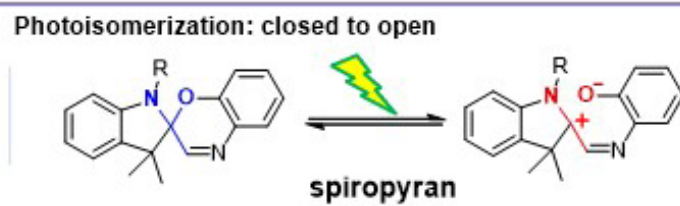

Photoisomerization: closed to open

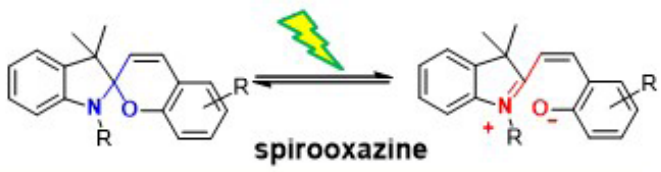

Photocycloaddition: dimerization

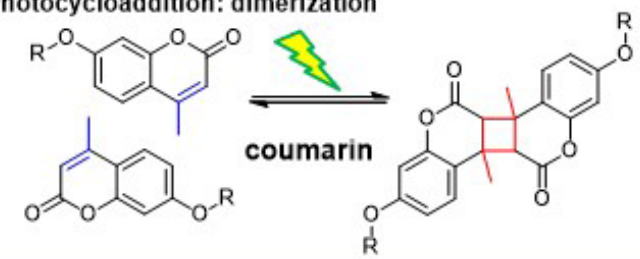

Photo-induced ionic dissociation<smiles>[R]c1ccc(C(Cl)(c2ccc(N(C)C)cc2)c2ccc(N(C)C)cc2)cc1</smiles>

\section{Irreversible photo-response groups}

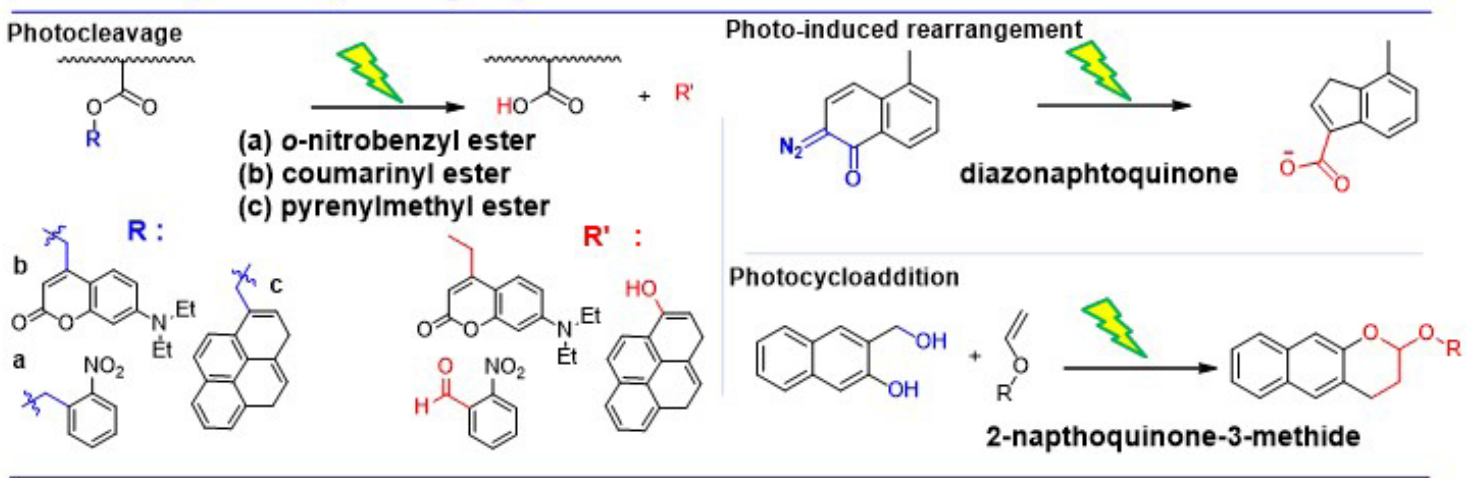

Figure 18. Some light-responsive polymers and the reversible/irreversible changes caused by light [163, 199, 313-315].

Photo-requlation (irreversible): It is the wolff rearrangement that occurs irreversibly. Examples are diazonaphthoquinone derivatives.

Photo-fragmentation (irreversible): It is separated from the structure and hydrophobic-hydrophilic transformation occurs. As examples; o-nitrobenzyl ester, coumarinyl ester and pyrenylmethyl ester derivatives can be given [163, 199, 313-315]. Considering these classifications, some photo-responsive polymers can be designed as shown in Figure 18 [199].
Examples of each group are given in Figure 18. As can be seen, azobenzene is a well-known chromophore for cistrans isomer exchange due to reversible irradiation. Its geometric shape and polarity changes with the irradiation. Trans-azobenzene has no dipole moment, whereas cis-azobenzene has dipole moment. This change leads to material with self-regulating behavior. Coumarin derivatives [2+2] are frequently used as reversible photocross-linking chemicals as a result of photo-dimerization by cyclocation mechanism [199]. The behavior of different functional groups in polymeric systems, whe- 
re the effect of light is clearly shown, is schematized in Figure 10. A wide variety of behaviors from spherical polymeric particles, block copolymer and macromolecular structures designed in many other polymeric architectures are schematized in Figure 10.

As seen in Figure 10a, the degradation of the polymeric structure can be achieved by breaking down the lightresponsive groups in the polymer main chain [316-323] These photo-responsive groups can be located in the end group of the polymer main chain, along the main chain or at the junction of two different blocks of block copolymers. In Figure 10b, it is seen that the photoresponsive side group attached to the polymer chain is separated. Generally hydrophobic polymer chain becomes hydrophilic [324, 325]. The changes that occur with the formation of different isomer structures of the light-responsive groups in the polymer main chain without separation are also given in Figure 10c [325, 326]. In Figure 10d, it is shown that a compound (dye, drug, etc.) is attached to the polymeric chain as a side group and reversibly separated from the polymer chain by photo-cross-linking [327]. It is worth to mention that this model is not very common since the group to be attached [2+2] should be suitable for participation. Another very important approach is the use of polymer chains with side groups suitable for photo-dimerization as photo-responsive reversible cross-linkers (see Figure 10e). Many micelles and gels have been obtained using this approach [328-332]. Additionally, when exposed to light, the followings may occur: (i) the formation of different micelle morphologies with the increase of hydrophilicity (Figure 10f) [333], (ii) swelling with the formation of hydrophilic structure or breaking photocross-links in structures (Figure 10g) [334-336], (iii) change on wetting properties of the surfaces and (iv) changes in film thickness (Figure 10h and 10i) [337-340].

On the upper part, polymers are designed according to the types of change caused by the effect of light. A large number of polymeric systems can be produced with various structures in many different architectures (homopolymer, block copolymer, dendrimer, micelle, gel etc.) and polymers containing various light-responsive groups in terms of their reaction to light [314, 341, 342]. Some selected light-sensitive polymer structures are given in Figure 19.

Until now, examples of polymers that can be used to release active compounds such as drugs in solution media are given. Shape-changing and shape-memory
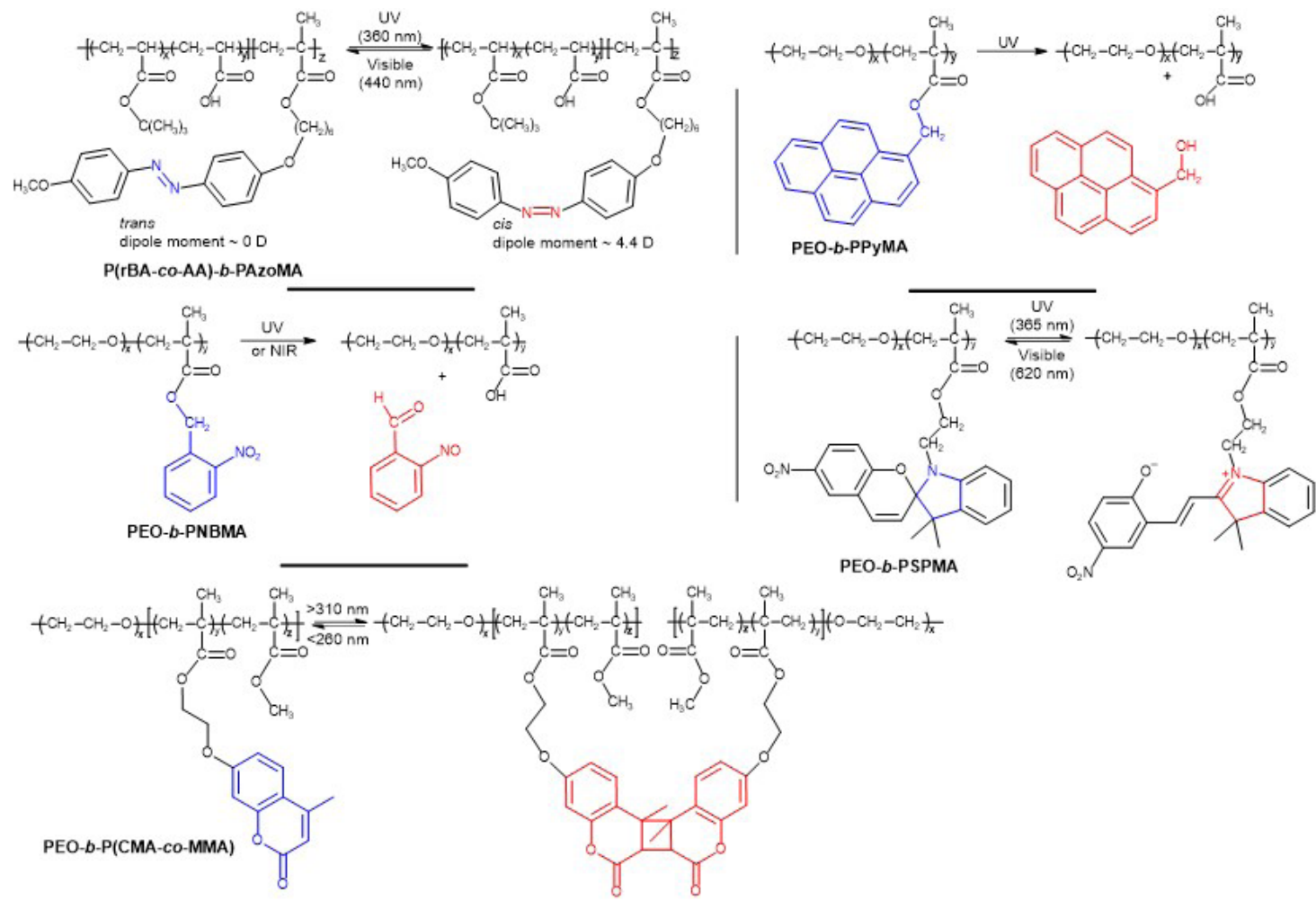

Figure 19. Chemical structures of some polymers designed to be light-responsive. 


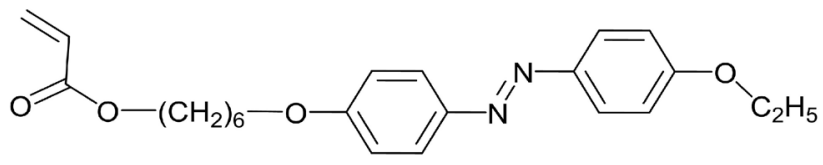

Molecule 2

Molecule 1

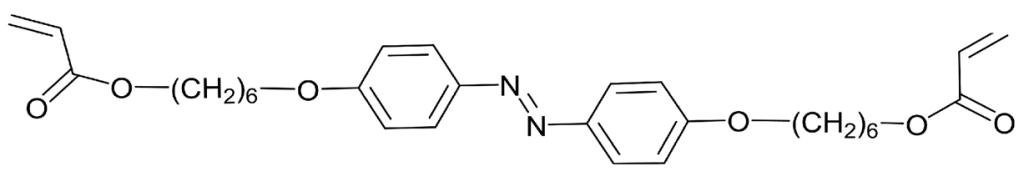

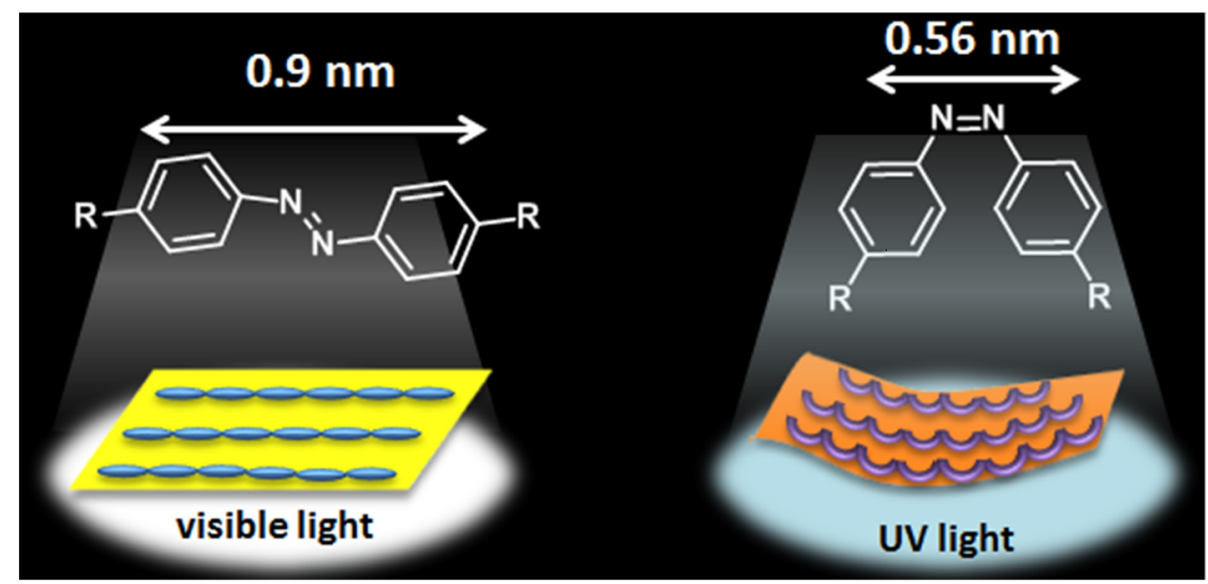

Figure 20. Transformation of trans/cis isomeric azobenzene containing polymer and light-driven liquid-crystal film.

polymeric systems can be produced using similar approaches [313, 343]. Among the different stimuli playing role in polymer actuation, light provides very useful opportunities to control some properties of such systems, including precise spatial/temporal remote control, easily tunable properties, and pausing/resuming of actuation [343]. Such responsive polymers opens a door for new application areas where reversible configurability and adaptability play important roles, e.g. soft robotics, sensors, micromachines, and biomedical devices [313, 343].

Azobenzene chromophore has cis and trans isomers. Irradiation with ultraviolet (UV) and visible lights can cause conversion to each other of these isomers. Both isomers have different lengths, thus, the length of azobenzene chromophore can be varied by UV and visible light irradiation. As seen in Figure 20, light-driven liquidcrystal film containing azobenzene chromophores can be bent reversibly by UV and visible light, respectively [344, 345]. Trans-isomeric azobenzene has a length of $0.9 \mathrm{~nm}$ and it converts to cis-isomeric azobenzene with a length of $0.56 \mathrm{~nm}$ when irradiated by UV light. Irridation with white light causes a reversible recovery of its original state.

\section{Ultrasound-responsive polymers}

Ultrasound is harmless and can penetrate deep into tissues [10]. The concept of ultrasound-responsive polymeric systems for use in the delivery and targeting of drugs is based on the dosage accumulation in the desired area by local ultrasound effect of drugs as external stimuli. Ultrasound is the local stimulant used to trigger the release of the active compound in the desired 
Drug encapsulated into polymeric micelle

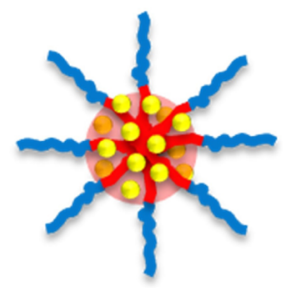

\section{Drug encapsulated into polymeric vesicle}

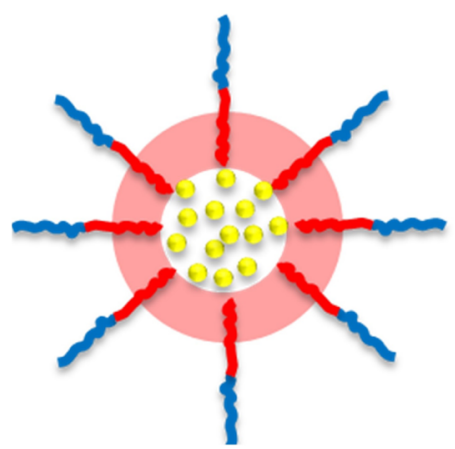

$=$ drug

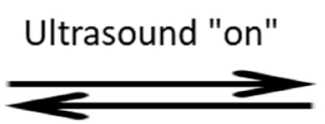

Ultrasound "off"

\section{Loose aggregate}

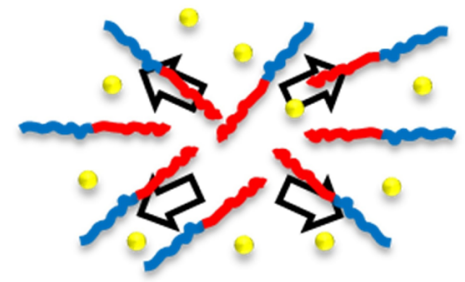

Ultrasound disruption and re-selfassembly result in smaller vesicle

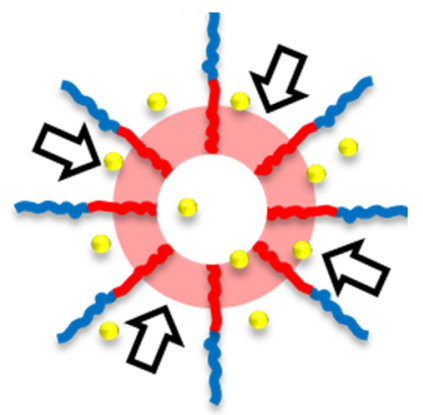

Ultrasound

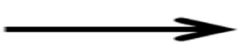

$=$ amphiphilic block copolymer

hydrophobic block

$\sim$ hydrophilic block<smiles>CCCOCCOCCCC(C)(C)C(=O)OC1CCCCO1</smiles>

Figure 21. Ultrasound-responsive drug delivery from block copolymer micelles.

tissue site of encapsulated drugs from microemulsions, polymer micelles, multilayer capsules, and liposomes (Figure 21) [346].
Three types of frequencies are generally used for biomedical applications: Low (<1 MHz), medium (1-5 MHz) and high (5-10 MHz) frequency. When ultrasound is applied to the target tissue, various physical factors can trigger the release of the drug. These include pressure variation, acoustic fluid flow, cavitation and heating of 
local tissue (hypothermia). Ultrasound also acts in the breakdown of cell membranes and increasing the permeability of blood vessels. In this way, the delivery of active compounds to cells or tissues increases. It is also reported that ultrasound causes a high rate of drug release in the local area [163].

Bonds may be broken by the effect of ultrasound in some structures. Zhao and co-workers introduced an amphiphilic block copolymer based on 2-tetrahydropyranyl methacrylate (THPMA) as ultrasound-responsive polymer. A PEO- $b$-THPMA block copolymer was synthesized which form micelles by PTHPMA block forming micelle-core and PEO block forming corona in aqueous media. After ultrasound irradiation, the cleavage of the tetrahydropyranyl groups resulted with a hydrophilic PAA block formation which causes destabilization of the micelles and quick release of the related cargo in the micellar structures (Figure 21).

\section{Electric field-responsive polymers (EFP)}

Smart materials that change their properties such as size and shape are called as "electro-active", "electric field-responsive polymers" or electro-responsive". Electro-responsive polymers occupy an important place in the smart material class because they can convert electrical energy into mechanical energy. They are promising materials for various applications such as in biomechanics, artificial muscle training, sensing, energy transmission, noise reduction, chemical separations, and controlled drug delivery $[10,163]$. The deformation (usually bending) of the gel in an electric field is affected by factors such as variable osmotic pressure based on voltage-induced motions of ions in solution, the $\mathrm{pH}$ value or salt concentration of the surrounding environ- ment, the position of the gel relative to the electrode, the thickness or shape of the gel, and the applied voltage. Applying an electric field to the polymer results with a conversion of polymer via a physical action. In general, responses appear as gel precipitation in an electric field, electrochemical reactions, electrically active complex formation, ionic polymer-metal complexations, or changes in electrophoretic mobility [163]. While polypyrrole, polyaniline, polythiophene, sulfonated styrene, acrylic acid and polyvinyl alcohol can be given as examples of some synthetic electro-responsive polymers, alginate, chitosan and hyaluronic acid are examples of natural electro-responsive polymers. It is known that hydrogels prepared from these polymers have polyelectrolyte properties and exhibit properties such as electrically responsive swelling, shrinkage and bending properties [10]. In recent years, studies on hydrogels stand out among electric field-responsive polymer architectures [163].

The deformation of polyelectrolyte gels under electric field is caused by anisotropic swelling or directing charged ions towards the anode or cathode side of the gel. For example, when ionized poly(acrylic acid) gels in aqueous media are under an electric field, mobile hydronium ions migrate towards the cathode, while negatively charged immobile acrylate groups in negative networks create a uniaxial stress in the gel by attracting towards the anode. The region surrounding the anode is subjected to the greatest stress while the region around the cathode is subjected to the smallest stress. This stress gradient contributes to anisotropic gel deformation under an electric field (Figure 22) [163].

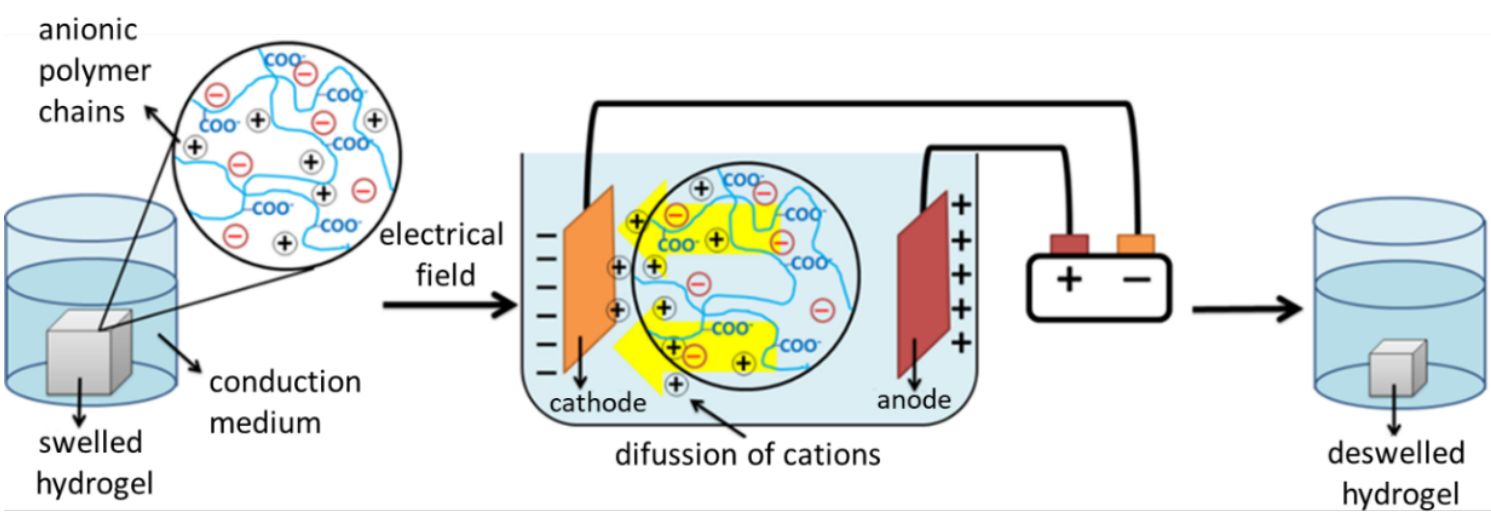

Figure 22. Volumetric transformation of electro-responsive hydrogels under applied voltage. 


\section{Biochemical stimuli-responsive polymers}

Protein-responsive polymers can be considered under two main headings as enzyme- and antigen-responsive. Another important class is glucose-responsive polymers. Apart from these, nucleic acid (RNA and DNA, amino acid, peptide and polysaccharide) responsive polymers are also available [347, 348].

a) Enzyme-responsive polymers: Enzymes are important compounds that catalyse various reactions in the human body and take part in highly specific reactions. It is an important approach that enzymes can break down specific bonds in the designed natural or synthetic polymer. Enzyme-responsive polymers have a significant advantage in drug delivery due to their self-occurrence in the biological environment. However, there are important issues which are the polymers to be designed do not react with other enzymes, are biocompatible, non-toxic, and release active compounds such as drugs in the target tissue. Considering these important points, polymers such as PEG, polysaccharides, polypeptides, poly(lactic acid) (PLA), and poly(lactic-co-glycolic acid) (PLGA) have been used [349].

There are enzymes being responsible for different types of reactions in polymeric structures (Figure 23). Enzymes used in this field can be classified as follows;
- Hydrolase: Enzymes that break the chemical bond between large molecule atoms in the presence of water. These enzymes can be in various types that cleave peptide, glycosidic and ester bonds.

- Enzymes that cleave peptide bonds: For example; lipase, $\alpha$-chymotrypsin [350352], elastase [352, 353], matrix metalloproteinase [354, 355], caspase [356], cathepsin [357, 358], plasmin [359], thrombin [360, 361], thermolysin [352, 362] and trypsin [363].

- Enzymes that break down ester bonds: For example; acetylcholinesterase [364], esterase [365], phospholipases [366] and phosphatase [367-369].

- Enzymes that break down glycosidic bonds: For example; amylase [370], galactosidase [371], glucuronidase [372] and $\alpha$-L-fucosidase [373].

- Oxidoreductase: It is the enzyme that catalyzes the transfer of an electron from one molecule to another. For example; peroxidases [374, 375] and azoructase [376].

\section{Bond formation (condensation)}

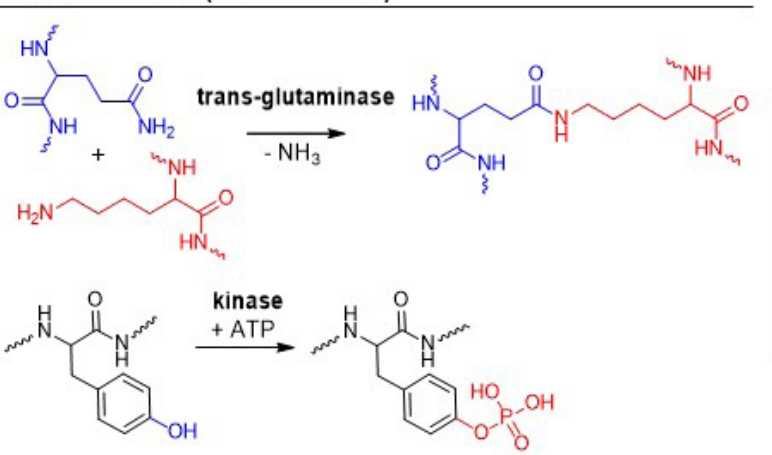

Bond cleavege (hydrolysis)

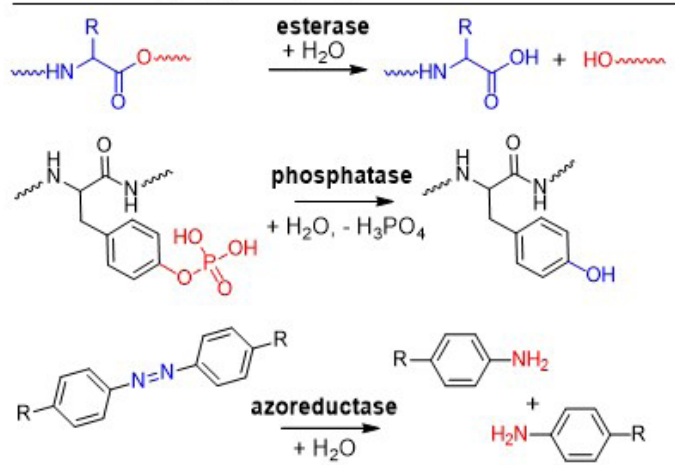

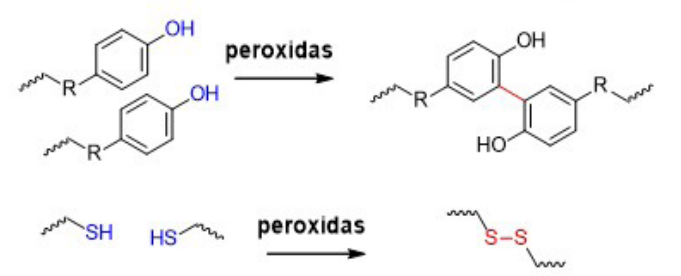

Bond formation and bond cleavege

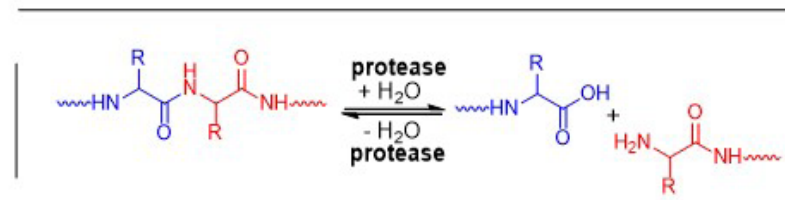

Figure 23. Transformations performed by enzymes on some specific groups. 
- Transferase: It is the type of enzyme that catalyzes the transfer of various chemical groups (except hydrogen) from one compound to another. For example; kinase [369, 377], phosphopantetheinyl transferase [378] and trans-glutaminase [379].

Various architectures of polymers are designed according to the types of changes occurring in enzyme-responsive polymers. Some of them are schematized in Figure 10. Degradation of polymeric structure can be achieved by breaking down the enzyme-responsive groups in the polymer chain (Figure 10a). These enzymeresponsive groups can be located in the end group of the polymer chain, along the main chain, and at the junction of two different blocks of block copolymers [376, 380-382]. In Figure 10b, changes occur in the hydrophilicity of the polymer chain by enzyme-responsive group separation or addition of the side groups in the polymer chain $[383,384]$. The attachment of a compound to the polymeric chain as a side group and separation of the compound from the polymer chain by enzyme sensitive bond cleavage is schematized in Figure 10d [350, 371, 372, 385, 386]. Another very important approach is enzyme-responsive cross-linking or breaking of cross-links that is given in Figure 10e. Crosslinked micelles and gels can be obtained using this approach as well [387, 388].

Hydrogels are a kind of hydrophilic polymer networks that may absorb water up to thousands of times of their dry weight. Hydrogels (macrogel, microgel and nanogel) have chemical or physical cross-linking among their chains and can swell/shrink with solvent or different stimuli, but remain insoluble in aqueous media [55]. Crosslinking of polymers can be carried out by electrostatic interactions or molecular interactions among polymer chains (physical gels) or by chemically linking of polymer chains with cross-linkers (chemical gels). They have an important place among enzyme-sensitive polymers. The enzyme-responsive hydrogels can be designed to form or degrade a hydrogel with enzyme. Hydrogel formation was accomplished either by enzymatically forming cross-links between polymer strands (transglutaminase) or by generating reactive groups that form cross-links with neighbouring strands (tyrosinase and horseradish peroxidase, see Figure 10e) [363, 389-394]. Natural polymer based hydrogels can often be degraded directly. Generally, synthetic polymers require incorporation of enzyme-sensitive moieties, typically in the form of enzyme cleavable cross-linkers such as short peptide sequences. In this manner, polymer hydrogels that can be degraded with matrix metalloproteinases, elastase and other enzymes were also reported [395-399]. In addition to create or destroy bonds in polymer hydrogels, enzymes also employed to control the morphology of hydrogel particles. Degree of swelling can be changed by changing the overall charge of the particles via enzymes such as thermolysin, elastase, trypsin, and matrix metalloproteinases [352, 400-405]. Finally, enzyme sensitive sol-gel and gel-sol behaviors can be obtained [369, 384, 406]. Similar approaches can be used in degradation of polymeric solid particles and polymer capsules as well.

The behaviors that occur in basic polymers have been explained above. In this part, polymers that show changes according to polymer architectures are schematized in Figure 10. The most important of them is the special behavior encountered in block copolymers. The behavior of self-assembly [407, 408] and disassemble [376, 383,384 ] is obtained by the change in hydrophilicity of
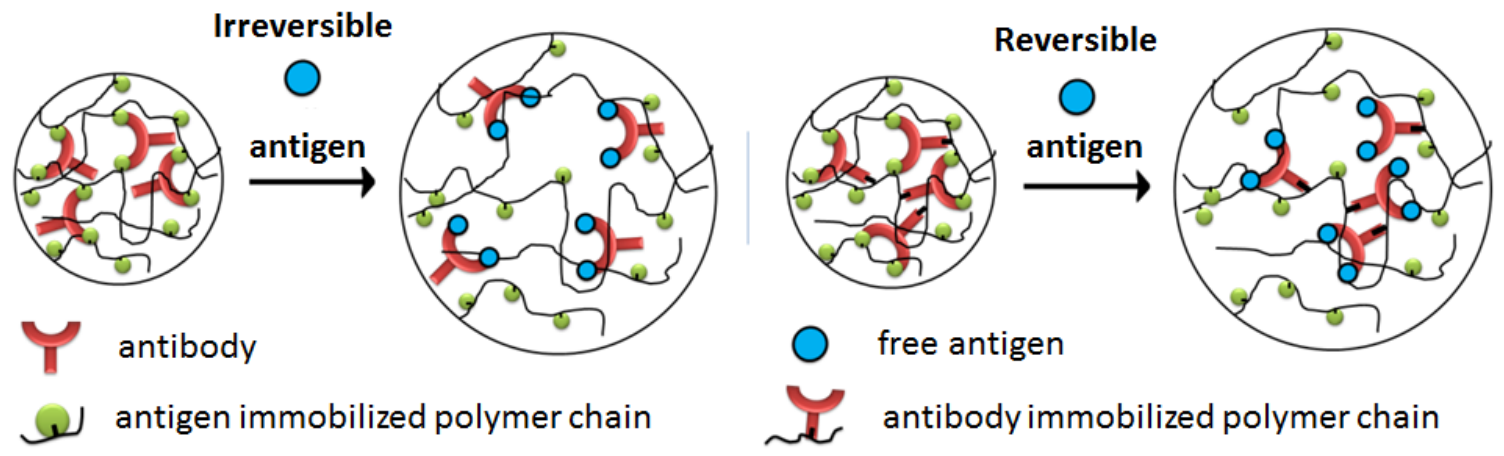

Figure 24. Antigen-responsive reversible and irreversible hydrogels (irreversibly the antibody is not covalently bound to the polymer but reversibly covalently bound). 
one block of a block copolymer (Figure 10f). In addition to this behavior observed in micelles, changes occur in micelle morphologies due to their enzyme-sensitive natures (Figure 10g) [355, 409-418]. Additionally, enzyme-responsive surfaces can be produced for different purposes [419-422] (Figure 10h and 10i). Various polymeric drug delivery systems have been designed and produced by using above polymeric structures given in Figure 23.

Drug-active or diagnostic enzyme-active compounds can be released directly from a polymeric system of different architecture by specific enzymatic bond cleavage in the side chain. Loading of the active compounds into polymeric materials can be provided by covalent bonding or physical encapsulation techniques (cross-linked polymeric matrix, self-arrangement or lattice porous structure). For example, the release of active compounds covalently bonded to the polymeric side chain by means of enzymes will be released by the enzyme degradation of the cross-linkers using active compounds physically adsorbed in hydrogel or cross-linked micelles. Physically adsorbed active compounds will also be released as a result of the breakdown of the bonds that form the main backbone of the polymer. Polymeric enzyme-responsive active compound carriers can be activated by enzymes to reveal targeting ligands for cellular distribution. In the other approach, enzymes can facilitate the formation of specific products that cause drug release from the polymeric material. These mechanisms may vary greatly depending on the polymeric system to be designed [423].

b) Antigen-responsive polymers: The antigen-responsive polymer contains antibody-antigen interaction, which is highly selective and specific interaction. An- tibodies (immunoglobulins) are globular proteins that use special binding sites to identify and capture foreign molecules called antigens [347]. Antigen and antibody groups interacting with each other are grafted onto different polymer chains. The mixture of these polymers forms cross-linked structures [424-426]. Free antigen added to the medium is displaced by breaking the existing antigen-antibody interaction. As a result, gel-sol formation, gel swelling behavior or change of pore size in membrane studies are triggered (Figure 24) [427-431]. Antigen-responsive polymers can be used in different studies such as sensor [432], controlled drug release [429].

c) Glucose-responsive polymers: Glucose-responsive polymers have respond to changes in glucose concentration and are promising in the treatment of diabetes. As diabetes has become one of the social health problems, interest in glucose-responsive polymer is increasing. Changes in glucose concentration cause changes in the properties of the polymer [433].

Diabetes is a metabolic disease in which the sugar (glucose) value in the blood is higher than normal. Insulin injection has been the main treatment for diabetes so far. Injection shortage, dietary restriction, hospital controls, and sometimes side effects of treatment reduce patients' living standards. Because of all this, a continuous and harmless insulin delivery system is needed to create a feedback-controlled, closed-loop insulin release system that can directly direct responses to blood glucose levels [433].

In practice, it can be divided into two categories as insulin release and glucose concentration diagnosis. Glucose-responsive polymeric systems divided into three

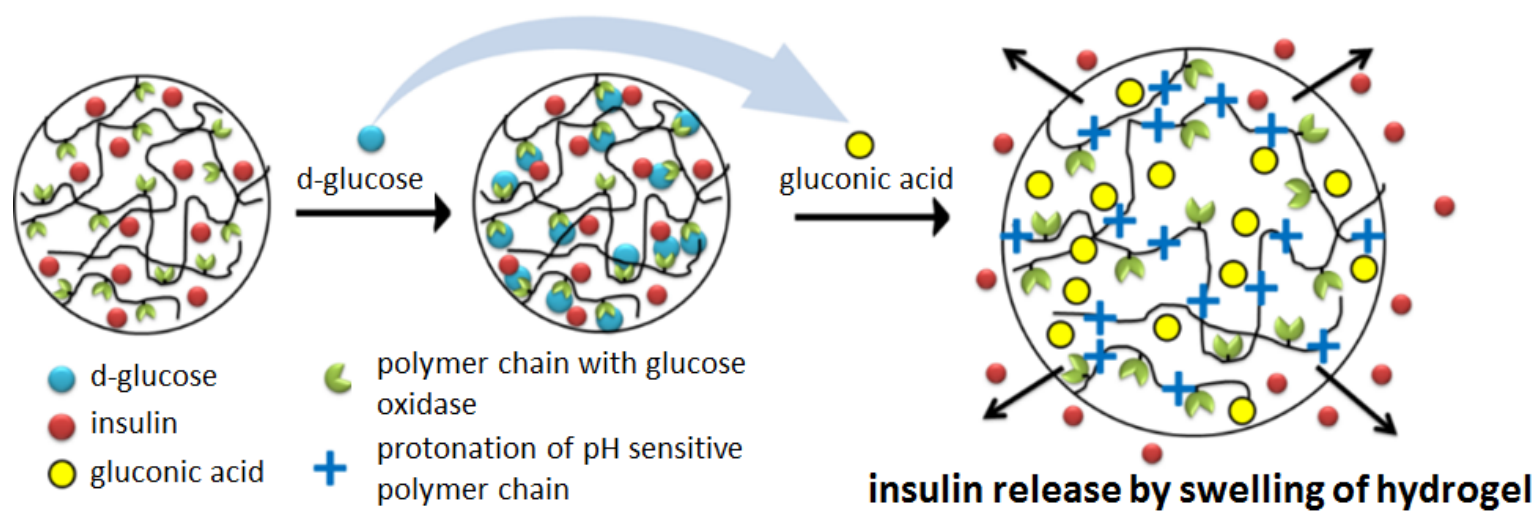

Figure 25. Polymeric systems modified with glucose oxidase and insulin release with glucose sensitivity. 

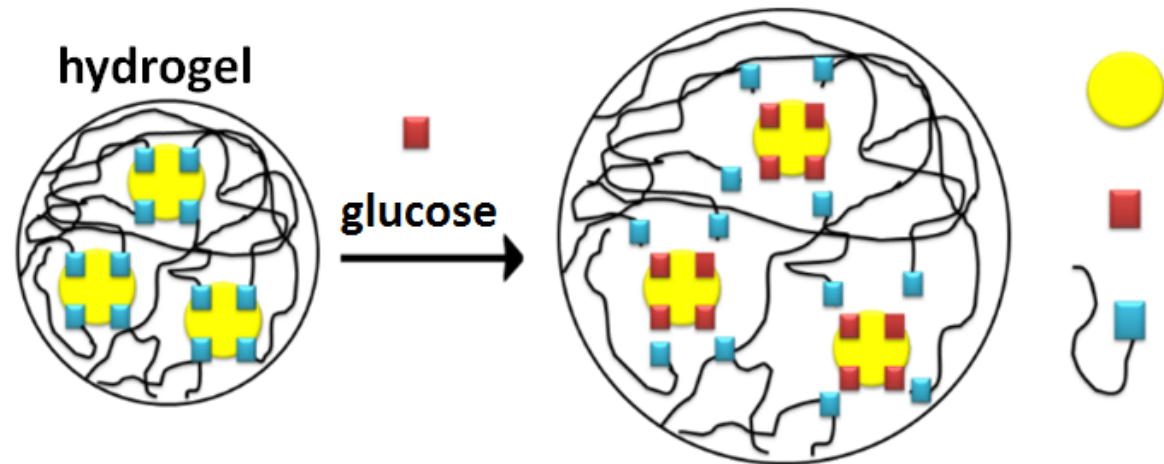

concanavalin A

glucose

polymer chain with saccharide

\section{hydrogel swelling}

Figure 26. ConA modified polymeric systems and glucose-responsive insulin release.

categories [163, 433];

- Enzymatic oxidation of glucose by glucose oxidase (GOx),

- Glucose binding with concanavalin A (ConA),

- The formation of reversible covalent bonds between glucose and boronic acids.

i) Glucose oxidase modified systems: Most studies of glucose-responsive polymers are well reported on the reaction of glucose with glucose oxidase (GOx) catalyzed oxygen. Glucose-sensitivity is not caused by the direct interaction of glucose with the responsive polymer, but by the reaction of the polymer to products resulting from the enzymatic oxidation of glucose. The enzymatic action of GOx on glucose is highly specific and occurs to gluconic acid and $\mathrm{H}_{2} \mathrm{O}_{2}$ byproducts $[434,435]$.
Therefore, the inclusion of a polymer that responds to any of such small molecules could indirectly lead to a glucose-responsive system. Typically, the sensitive polymer design includes GOx and the $\mathrm{pH}$-responsive polymer. The gluconic acid product resulting from the reaction with glucose acts on the $\mathrm{pH}$-responsive macromolecule, causing swelling (or shrinkage) of the insulin-containing hydrogel (or other type of polymeric system) matrix used to treat diabetes. (Figure 25) [435438]. Glucolic acid formation will cause hydrophilicity $[437,439]$ or swelling if a basic $\mathrm{pH}$-responsive polymeric system is present, whereas it will cause hydrophobicity and shrinkage with protonation if an acidic $\mathrm{pH}$ responsive polymeric system is present [438, 440-442]. Glucose sensitive polymers are used in chemical gels as well as glucose-responsive physical gels and membrane studies $[443,444]$.<smiles>[R]c1ccc(B(O)O)cc1</smiles>

(1)<smiles>OC1CCCCC1</smiles><smiles>CC=[TeH2]O</smiles><smiles></smiles>

(2)<smiles>CCC(O)CCCCO</smiles><smiles></smiles><smiles>[R]c1ccc(B2OCCCO2)cc1</smiles>

(4)

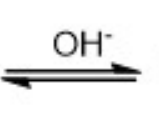

(3)<smiles>[R]c1ccc([B-]2(O)OCCCO2)cc1</smiles>

Figure 27. Ionization equilibria of boronic acids (Note that the balance shifts towards the anionic boronate form of boronic acid with an increase on diol concentration). 

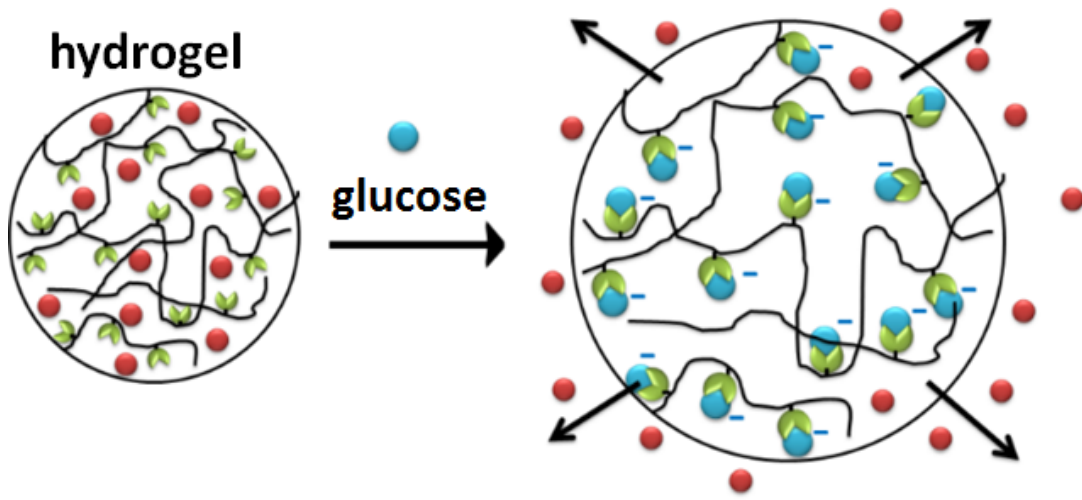

glucose

insulin

phenylboronic acid unit

\section{insulin release by swelling of hydrogel}

Figure 28. Phenylboronic acid containing polymeric systems and glucose sensitivity

ii) ConA-based glucose-responsive systems: This mechanism is based on the competitive binding of glucose with glycopolymer-lectin complexes [445]. Lectins are proteins that specifically bind carbohydrates [446-448]. Like GOx, it is also possible to use them as biosensors to develop glucose-responsive systems. ConA is the most extensively used lectin to sensitize glucose [163]. ConA is considered the most important protein with its four binding sites $[446,449]$.

In the basic mechanism for glucose-responsive drug release, ConA is attached to polysaccharide units on the chain, resulting in a three-dimensional polymer structure in which insulin is trapped $[449,450]$. In the presence of glucose in the blood, the complex between ConA and the saccharide residue is degraded by the formation of the ConA-free glucose bond (Figure 26). As a result, gelsol transition or swelling behavior will be observed in the structure [446, 449, 451-453]. It is also designed in different block copolymers [448, 454-456].

iii) Phenylboronic acid containing systems: While glucose-responsive systems based on GOx and lectins are versatile and highly specific, adherence to proteinbased components can limit applications under nonbiological conditions or longer time intervals that can promote denaturation $[163,433]$. Since phenylboronic acid (PBA) and its derivatives are known to form reversible covalent complexes with 1,2 or 1,3 diols, they serve as promising components for glucose-responsive sensors [457-459]. As shown in Figure 27, PBA compounds have two forms that are in equilibrium in water. Non-ionic species (1) is abundant in the environmental while the ionic form is hydrophobic, it forms the hydrophilic structure (2). When glucose is added to the aqueous system (3), the charged phenylborate can form a stable complex with glucose through reversible covalent bonding. Therefore, the equilibrium shifts in the direction of the increasingly charged (hydrophilic) phenylborate forms (3) [460]. The solubility of boronic acid-containing polymers is dependent from both $\mathrm{pH}$ and the concentration of compatible diols in the medium. The formation of the hydrophilic structure triggers changes in polymers of different architectures. For example, it triggers changes such as swelling in hydrogels [461], (Figure 28), reversible gel formation [462464], self-assembly and disassembly behaviors in block copolymers [465-473], surface studies [474, 475], film thickness and pore size changes [459, 476, 477]. If insulin is included in the polymeric system, insulin is released and its use in diabetes is provided $[471,478]$.

The most important problem of the mechanism given in Figure 27 is that PBA-diol complex formation requires an alkaline environment. New types of PBA derivatives are developed to adjust the $\mathrm{pK}_{\mathrm{a}}$ value of the PBA compound to around 7.4, which is the physiological $\mathrm{pH}$ value. In addition, some studies are also carried out on species that can make complexes in $\mathrm{pH} 7.4$ environment using various copolymer structures $[479,480]$.

\section{Closing Remarks}

It seems that the extraordinary behavior/properties of stimulus-sensitive polymers will continue to generate more activity in scientific and technological pathways. Such polymers are very useful for developing new materials that are very useful for human health and ease of daily life. In this review, we have specifically highlighted some stimulus-sensitive polymer or polymer-based 
examples reported over the last two decades. We have also focused on possible synthetic pathways for their syntheses, their classifications, self-assembly behaviors due to changes on their environments, their nanoand micro-aggregates, their derivative nanostructures/ materials, and applications in various fields. Given the existence of many useful alternative synthetic procedures and the diversity of many available biocompatible monomers, it can be predicted that biodegradable stimulus sensitive polymers, in particular, will lead to significant advances in biotechnological applications, due to their response to biological conditions.

\section{References}

1. Z.Q. Cao, G.J. Wang, Multi-stimuli-responsive polymer materials: particles, films, and bulk gels, Chem. Rec., 16 (2016) 1398-1435.

2. P. Liu, Multiresponsive polymeric carriers, stimuli responsive polymeric nanocarriers for drug delivery applications, Woodhead Publishing, 2019.

3. G. Pasparakis, M. Vamvakaki, Multiresponsive polymers: Nano-sized assemblies, stimuli-sensitive gels and smart surfaces, Polym. Chem., 2 (2011) 1234-1248.

4. F. Liu, M.W. Urban, Recent advances and challenges in designing stimuli-responsive polymers, Prog. Polym. Sci., 35 (2010) 3-23.

5. P. Schattling, F.D. Jochum, P. Theato, Multi-stimuli responsive polymers - the all-in-one talents, Polym. Chem., 5 (2014) 25-36

6. S. Guragain, B.P. Bastakoti, V. Malgras, K. Nakashima, Y. Yamauchi, Multi-stimuli-responsive polymeric materials, Chem. Eur. J., 21 (2015) 13164-13174.

7. G. Koçak, C. Tuncer, V. Bütün, pH-responsive polymers, Polym. Chem., 8 (2017) 144-176.

8. V. Bütün, S.P. Armes, N.C. Billingham, Synthesis and aqueous solution properties of near-monodisperse tertiary amine methacrylate homopolymers and diblock copolymers, Polymer, 42 (2001) 5993-6008.

9. V. Bütün, N.C. Billingham, S.P. Armes, Unusual aggregation behavior of a novel tertiary amine methacrylate-based diblock copolymer: Formation of micelles and reverse micelles in aqueous solution, J. Am. Chem. Soc., 120 (1998) 11818-11819.

10. D. Qureshi, S.K. Nayak, S. Maji, A. Anis, D. Kim, K. Pal, Environment sensitive hydrogels for drug delivery applications, Eur. Polym. J., (2019) 109220.

11. M.M. Xu, R.J. Liu, Q. Yan, Biological stimuli-responsive polymer systems: design, construction and controlled selfassembly, Chin. J. Polym. Sci., 36 (2018) 347-365.

12. Q. Yan, W. Sang, $\mathrm{H}_{2} \mathrm{~S}$ Gasotransmitter-responsive polymer vesicles, Chem. Sci., 7 (2016) 2100-2105.

13. S. Ganta, H. Devalapally, A. Shahiwala, M. Amiji, A review of stimuli-responsive nanocarriers for drug and gene delivery, J. Controlled Release, 126 (2008) 187-204.

14. V. Bütün, S.P. Armes, N.C. Billingham, Z. Tuzar, A. Rankin, J. Eastoe, R. Heenan, The remarkable "Flip- Flop" selfassembly of a diblock copolymer in aqueous solution, Macromolecules, 34 (2001) 1503-1511.
15. O.E. Philippova, D. Hourdet, R. Audebert, A.R. Khokhlov, pHresponsive gels of hydrophobically modified poly(acrylic acid), Macromolecules, 30 (1997) 8278-8285.

16. F. Checot, J. Rodriguez-Hernandez, Y. Gnanou, S. Lecommandoux, $\mathrm{pH}$-responsive micelles and vesicles nanocapsules based on polypeptide diblock copolymers, Biomol. Eng., 24 (2007) 81-85.

17. S.Y. Liu, N.C. Billingham, S.P. Armes, A schizophrenic watersoluble diblock copolymer, Angew. Chem., Int. Ed., 40 (2001) 2328-2331.

18. F.F. Taktak, V. Bütün, Synthesis and physical gels of $\mathrm{pH}$ - and thermo-responsive tertiary amine methacrylate based $A B A$ triblock copolymers and drug release studies, Polymer, 51 (2010) 3618-3626.

19. P. Lundberg, N.A. Lynd, Y.N. Zhang, X.H. Zeng, D.V. Krogstad, T. Paffen, M. Malkoch, A.M. Nystrom, C.J. Hawker, pHtriggered self-assembly of biocompatible histaminefunctionalized triblock copolymers, Soft Matter, 9 (2013) 82-89.

20. F.T. Liu, A. Eisenberg, Preparation and pH triggered inversion of vesicles from poly(acrylic acid)-block-polystyrene-blockpoly(4-vinyl pyridine), J. Am. Chem. Soc., 125 (2003) 1505915064.

21. J. Rao, , Y. Zhang, J. Zhang, S. Liu, Facile preparation of well-defined $A B>2$ Y-shaped miktoarm star polypeptide copolymer via the combination of ring-opening polymerization and click chemistry, Biomacromolecules, 9 (2008) 2586-2593.

22. C. Fernyhough, A.J. Ryan, G. Battaglia, pH controlled assembly of a polybutadiene-poly(methacrylic acid) copolymer in water: packing considerations and kinetic limitations, Soft Matter, 5 (2009) 1674-1682.

23. Y.Y. Xu, S. Bolisetty, M. Drechsler, B. Fang, J.Y. Yuan, M. Ballauff, A.H.E. Muller, pH and salt responsive poly(N,Ndimethylaminoethyl methacrylate) cylindrical brushes and their quaternized derivatives, Polymer, 49 (2008) 3957-3964.

24. V. Bütün, I. Bannister, N.C. Billingham, D.C. Sherrington, S.P. Armes, Synthesis and characterization of branched watersoluble homopolymers and diblock copolymers using group transfer polymerization, Macromolecules, 38 (2005) 49774982.

25. V. Bütün, C.E. Bennett, M. Vamvakaki, A.B. Lowe, N.C. Billingham, S.P. Armes, Selective betainisation of tertiary amine methacrylate block copolymers, J. Mater. Chem., 7 (1997) 1693-1695.

26. G. Koçak, , G. Solmaz, V. Bütün, A new approach for the synthesis of ph-responsive cross-linked micelles from a poly(glycidyl methacrylate)-based functional copolymer, Macromol. Chem. Phys., 217 (2016) 2744-2754.

27. C. Tuncer, Y. Samav, D. Ülker, S.B. Baker, V. Bütün, Multiresponsive microgel of a water-soluble monomer via emulsion polymerization, J. Appl. Polym. Sci., 132 (2015) 42072.

28. G. Koçak, Preparation and catalytic properties of modified PGMA-based pH-responsive hydrogel films as a novel template for in situ synthesis of $\mathrm{Au}, \mathrm{Ag}$, and $\mathrm{Au}: \mathrm{Ag}$ nanoparticles, J. Appl. Polym. Sci., 137 (2020) 48360.

29. G. Kocak, G. Solmaz, C. Tuncer, V. Bütün, Modification of glycidyl methacrylate based block copolymers and their aqueous solution behaviours, Eur. Polym. J., 110 (2019) 364377.

30. B.R. Saunders, H.M. Crowther, B. Vincent, Poly[(methyl methacrylate)-co-(methacrylic acid)] microgel particles: Swelling control using $\mathrm{pH}$, cononsolvency, and osmotic deswelling, Macromolecules, 30 (1997) 482-487. 
31. R.X. Chang, Y.L. Tian, Y. Wang, J.L. Qin, pH-responsive vesicles with tunable membrane permeability and hydrodynamic diameters from a cross-linkable amphiphilic block copolymer, Nanomater. Nanotechnol., 6 (2016)

32. C. Hippius, V. Bütün, I. Erel-Göktepe, Bacterial anti-adhesive properties of a monolayer of zwitterionic block copolymer micelles, Mater. Sci., Eng. C, 41 (2014) 354-362.

33. L. Mi, M.T. Bernards, G. Cheng, Q.M. Yu, S.Y. Jiang, pH responsive properties of non-fouling mixed-charge polymer brushes based on quaternary amine and carboxylic acid monomers, Biomaterials, 31 (2010) 2919-2925.

34. B. Onat, V. Bütün, S. Banerjee, I. Erel-Göktepe, Bacterial anti-adhesive and $\mathrm{pH}$-induced antibacterial agent releasing ultra-thin films of zwitterionic copolymer micelles, Acta Biomater., 40 (2016) 293-309.

35. S. Ulusan, V. Bütün, S. Banerjee, I. Erel-Göktepe, Biologically functional ultrathin films made of zwitterionic block copolymer micelles, Langmuir, 35 (2019) 1156-1171.

36. P. Yusan, I. Tuncel, V. Bütün, A.L. Demirel, I. Erel-Göktepe, $\mathrm{pH}$-responsive layer-by-layer films of zwitterionic block copolymer micelles, Polym. Chem., 5 (2014) 3777-3787.

37. I. Erel, H.E. Karahan, C. Tuncer, V. Bütün, A.L. Demirel, Hydrogen-bonded multilayers of micelles of a dually responsive dicationic block copolymer, Soft Matter, 8 (2012) 827-836.

38. D. Gündoğdu, V. Bütün, I. Erel-Göktepe, Preparation of layerby-layer films with remarkably different ph-stability and release properties using dual responsive block copolymer micelles, Macromol. Chem. Phys., 219 (2018) 1800128.

39. F. Zhou, W.T.S. Huck, Three-stage switching of surface wetting using phosphate-bearing polymer brushes, Chem. Commun, 48 (2005) 5999-6001.

40. G.W. de Groot, M.G. Santonicola, K. Sugihara, T. Zambelli, E. Reimhult, J. Voros, G.J. Vancso, Switching transport through nanopores with ph-responsive polymer brushes for controlled ion permeability, ACS Appl. Mater. Interfaces, 5 (2013) 1400-1407.

41. A. Brunsen, C. Diaz, L.I. Pietrasanta, B. Yameen, M. Ceolin, G.J.A.A. Soler-Illia, O. Azzaroni, Proton and calcium-gated ionic mesochannels: phosphate-bearing polymer brushes hosted in mesoporous thin films as biomimetic interfacial architectures, Langmuir, 28 (2012) 3583-3592.

42. T. Vasudevan, S. Das, S. Sodaye, A.K. Pandey, A.V.R Reddy, Pore-functionalized polymer membranes for preconcentration of heavy metal ions, Talanta, 78 (2009) 171-177.

43. C.H. Li, Z.S. Ge, J. Fang, S.Y. Liu, Synthesis and self-assembly of coil-rod double hydrophilic diblock copolymer with dually responsive asymmetric centipede-shaped polymer brush as the rod segment, Macromolecules, 42 (2009) 2916-2924.

44. V. Butun, S. Liu, J.V.M. Weaver, X. Bories-Azeau, Y. Cai, S.P. Armes, A brief review of 'schizophrenic' block copolymers, React. Funct. Polym., 66 (2006) 157-165.

45. J. Rodriguez-Hernandez, S. Lecommandoux, Reversible inside-out micellization of $\mathrm{pH}$-responsive and water-soluble vesicles based on polypeptide diblock copolymers, J. Am. Chem. Soc., 127 (2005) 2026-2027.

46. Z. Ge, J. Xu, J. Hu, Y. Zhang, S. Liu, Synthesis and supramolecular self-assembly of stimuli-responsive water-soluble Janus-type heteroarm star copolymers, Soft Matter, 5 (2009) 3932-3939.

47. J.R. Lovett, N.J. Warren, L.P.D. Ratcliffe, M.K. Kocik, S.P. Armes, pH-responsive non-ionic diblock copolymers: ionization of carboxylic acid end-groups induces an order-order morphological transition, Angew. Chem., Int. Ed., 54 (2015) 1279-1283.
48. N.J.W. Penfold, J.R. Lovett, N.J. Warren, P. Verstraete, J. Smets, S.P. Armes, pH-responsive non-ionic diblock copolymers: protonation of a morpholine end-group induces an order-order transition, Polym. Chem., 7 (2016) 79-88.

49. C. Feng, Z. Shen, L.N. Gu, S. Zhang, L.T. Li, G.L. Lu, X.Y. Huang, Synthesis and characterization of PNIPAM-b-(PEA-g-PDEA) double hydrophilic graft copolymer, J. Polym. Sci., Part A: Polym. Chem., 46 (2008) 5638-5651.

50. C. Maiti, R. Banerjee, S. Maiti, D. Dhara, pH-induced vesicleto-micelle transition in amphiphilic diblock copolymer: investigation by energy transfer between in situ formed polymer embedded gold nanoparticles and fluorescent dye, Langmuir, 31 (2015) 32-41.

51. K.E.B. Doncom, H. Willcock, R.K. O'Reilly, The $\mathrm{pH}$ induced vesicle to micelle morphology transition of a THP-protected polymer, J. Polym. Sci., Part A: Polym. Chem., 52 (2014) 30263031.

52. W.D. Zhang, W. Zhang, N.C. Zhou, J. Zhu, Z.P. Cheng, X.L. Zhu, Synthesis of miktoarm star amphiphilic block copolymers via combination of NMRP and ATRP and investigation on selfassembly behaviors, J. Polym. Sci., Part A: Polym. Chem., 47 (2009) 6304-6315

53. Z. Iatridi, C. Tsitsilianis, $\mathrm{pH}$ responsive self assemblies from an An-core-(B-b-C) $n$ heteroarm star block terpolymer bearing oppositely charged segments, Chem. Commun., 47 (2011) 5560-5562.

54. P. Zhou, Y.Y. Liu, L.Y. Niu, J. Zhu, Self-assemblies of the six-armed star triblock $A B C$ copolymer: $\mathrm{pH}$-tunable morphologies and drug release, Polym. Chem., 6 (2015) 2934-2944.

55. J. Aleman, A.V. Chadwick, J. He, M. Hess, K. Horie, R.G. Jones, P. Kratochvil, I. Meisel, I. Mita, G. Moad, S. Penczek, R.F.T. Stepto, Definitions of terms relating to the structure and processing of sols, gels, networks, and inorganic-organic hybrid materials (IUPAC Recommendations 2007), Pure Appl. Chem., 79 (2007) 1801-1827.

56. Y. Li, Y. Tang, R. Narain, A.L. Lewis, S.P. Armes, Biomimetic stimulus-responsive star diblock gelators, Langmuir, 21 (2005) 9946-9954.

57. X. Huang, S.I. Sevimli, V. Bulmuş, pH-labile sheddable block copolymers by RAFT polymerization: Synthesis and potential use as siRNA conjugates, Eur. Polym. J., 49 (2013) 2895-2905.

58. Y. Jin, L. Song, Y. Su, L.J. Zhu, Y. Pang, F. Qiu, G.S. Tong, D.Y. Yan, B.S. Zhu, X.Y. Zhu, Oxime linkage: A robust tool for the design of $\mathrm{pH}$-sensitive polymeric drug carriers, Biomacromolecules, 12 (2011) 3460-3468.

59. S. Aryal, C.M.J. Hu, L.F. Zhang, Polymer-cisplatin conjugate nanoparticles for acid-responsive drug delivery, ACS Nano, 4 (2010) 251-258.

60. K. Dan, S. Ghosh, One-pot synthesis of an acid-labile amphiphilic triblock copolymer and its $\mathrm{pH}$-responsive vesicular assembly, Angew. Chem., Int. Ed., 52 (2013) 7300 7305.

61. R. Banerjee, S. Maiti, D. Dey, D. Dhara, Polymeric nanostructures with $\mathrm{pH}$-labile core for controlled drug release, J. Colloid Interface Sci., 462 (2016) 176-182.

62. P. Samanta, K. Kapat, S. Maiti, G. Biswas, S. Dhara, D. Dhara, $\mathrm{pH}$-labile and photochemically cross-linkable polymer vesicles from coumarin based random copolymer for cancer therapy, J. Colloid Interface Sci., 555 (2019) 132-144.

63. C.P. Zhou, Z.W. Shi, F. Xu, Y. Ling, H.Y. Tang, Preparation and properties of thermo- and $\mathrm{pH}$-responsive polypeptide bearing OEG and aldehyde pendants, Colloid Polym. Sci., 298 (2020) 1293-1302 
64. S.J. Lee, K.H. Min, H.J. Lee, A.N. Koo, H.P. Rim, B.J. Jeon, S.Y Jeong, J.S. Heo, S.C. Lee, Ketal cross-linked poly(ethylene glycol)-poly(amino acid)s copolymer micelles for efficient intracellular delivery of doxorubicin, Biomacromolecules, 12 (2011) 1224-1233

65. E.S. Read, S.P. Armes, Recent advances in shell cross-linked micelles, Chem. Commun., (2007) 3021-3035.

66. Cui, J.W., Y. Yan, Y.J. Wang, and F. Caruso, Templated Assembly of $\mathrm{pH}$-labile polymer-drug particles for intracellular drug delivery, Adv. Funct. Mater., 22 (2012) 4718-4723.

67. O. Sedláček, M. Hrubý, M. Studenovský, D. Větvička, J. Svoboda, D. Kaňková, J. Kovář, K. Ulbrich, Polymer conjugates of acridine-type anticancer drugs with $\mathrm{pH}$-controlled activation, Bioorg. Med. Chem., 20 (2012) 4056-4063.

68. G.F. Walker, C. Fella, J. Pelisek, J. Fahrmeir, S. Boeckle, M Ogris, E. Wagner, Toward synthetic viruses: Endosomal $\mathrm{pH}$-triggered deshielding of targeted polyplexes greatly enhances gene transfer in vitro and in vivo, Mol. Ther., 11 (2005) 418-425.

69. H.Y. Li, M. Li, C. Chen, A.P. Fan, D.L. Kong, Z. Wang, Y.J. Zhao, On-demand combinational delivery of curcumin and doxorubicin via a $\mathrm{pH}$-labile micellar nanocarrier, Int. J. Pharm., 495 (2015) 572-578

70. K. Ulbrich, T. Etrych, P. Chytil, M. Pechar, M. Jelinkova, B Rihova, Polymeric anticancer drugs with $\mathrm{pH}$-controlled activation, Int. J. Pharm., 277 (2004) 63-72.

71. K. Ulbrich, T. Etrych, P. Chytil, M. Jelinkova, B. Rihova, HPMA copolymers with $\mathrm{pH}$-controlled release of doxorubicin - In vitro cytotoxicity and in vivo antitumor activity, J. Controlled Release, 87 (2003) 33-47.

72. Y. Gu, Y. Zhong, F. Meng, R. Cheng, C. Deng, Z. Zhong, Acetallinked paclitaxel prodrug micellar nanoparticles as a versatile and potent platform for cancer therapy, Biomacromolecules, 14 (2013) 2772-2780.

73. E.R. Gillies, A.P. Goodwin, J.M.J. Fréchet, Acetals as $\mathrm{pH}$ sensitive linkages for drug delivery, Bioconjugate Chem., 15 (2004) 1254-1263

74. Y. Chan, T. Wong, F. Byrne, M. Kavallaris, V. Bulmus, Acidlabile core cross-linked micelles for $\mathrm{pH}$-triggered release of antitumor drugs, Biomacromolecules, 9 (2008) 1826-1836.

75. S. Jiang, Y. Yao, Y.Z. Nie, J.J. Yang, J. Yang, Investigation of $\mathrm{pH}$-responsive properties of polymeric micelles with a coreforming block having pendant cyclic ketal groups, J. Colloid Interface Sci., 364 (2011) 264-271.

76. J.H. Park, Y.W. Cho, Y.J. Son, K. Kim, H. Chung, S.Y. Jeong, K Choi, C.R. Park, R.W. Park, I.S. Kim, I.C. Kwon, Preparation and characterization of self-assembled nanoparticles based on glycol chitosan bearing adriamycin, Colloid Polym. Sci. 284 (2006) 763-770

77. F.Q. Hu, L.N. Liu, Y.Z. Du, H. Yuan, Synthesis and antitumor activity of doxorubicin conjugated stearic acid-g-chitosan oligosaccharide polymeric micelles, Biomaterials, 30 (2009) 6955-6963.

78. H.S. Yoo, E.A. Lee, T.G. Park, Doxorubicin-conjugated biodegradable polymeric micelles having acid-cleavable linkages, J. Controlled Release, 82 (2002) 17-27.

79. S. Zhu, M. Hong, G. Tang, L. Qian, J. Lin, Y. Jiang, Y. Pei, Partly PEGylated polyamidoamine dendrimer for tumor-selective targeting of doxorubicin: The effects of PEGylation degree and drug conjugation style, Biomaterials, 31 (2010) 1360-1371.

80. M.C.D. Clochard, S. Rankin, S. Brocchini, Synthesis of soluble polymers for medicine that degrade by intramolecular acid catalysis, Macromol. Rapid Commun., 21 (2000) 853-859.
81. C. Ding, J. Gu, X. Qu, Z. Yang, Preparation of multifunctional drug carrier for tumor-specific uptake and enhanced intracellular delivery through the conjugation of weak acid labile linker, Bioconjugate Chem., 20 (2009) 1163-1170.

82. Y.H. Kim, J.H. Park, M. Lee, Y.H. Kim, T.G. Park, S.W. Kim, Polyethylenimine with acid-labile linkages as a biodegradable gene carrier, J. Controlled Release, 103 (2005) 209-219.

83. K. Nakabayashi, D. Noda, T. Takahashi, H. Mori, Design of stimuli-responsive nanoparticles with optoelectronic cores by post-assembly cross-linking and self-assembly of functionalized block copolymers, Polymer, 86 (2016) 56-68.

84. V.F. Patel, J.N. Hardin, J.M. Mastro, K.L. Law, J.L. Zimmermann, W.J. Ehlhardt, J.M. Woodland, J.J. Starling, Novel acid labile COL1 trityl-linked difluoronucleoside immunoconjugates: synthesis, characterization, and biological activity ${ }^{1}$, Bioconjugate Chem., 7 (1996) 497-510.

85. V.F. Patel, J.N. Hardin, G.B. Grindey, R.M. Schultz, Tritylated oncolytics as prodrugs, Bioorg. Med. Chem. Lett., 5 (1995) 513-518.

86. J. Zou, F. Zhang, S. Zhang, S.F. Pollack, M. Elsabahy, J. Fan, K.L. Wooley, Poly(ethylene oxide)-block-polyphosphoestergraft-paclitaxel conjugates with acid-labile linkages as a $\mathrm{pH}$ sensitive and functional nanoscopic platform for paclitaxel delivery, Adv. Healthcare Mater., 3 (2014) 441-448.

87. X.N. Huang, F.S. Du, J. Cheng, Y.Q. Dong, D.H. Liang, S.P. Ji, S.S. Lin, Z.C. Li, Acid-sensitive polymeric micelles based on thermoresponsive block copolymers with pendent cyclic orthoester groups, Macromolecules, 42 (2009) 783-790.

88. J. Su, F. Chen, V.L. Cryns, P.B. Messersmith, Catechol polymers for $\mathrm{pH}$-responsive, targeted drug delivery to cancer cells, J. Am. Chem. Soc., 133 (2011) 11850-11853.

89. L.X. Li, Z.W. Bai, P.A. Levkin, Boronate-dextran: An acidresponsive biodegradable polymer for drug delivery, Biomaterials, 34 (2013) 8504-8510

90. J. Lee, J. Kim, Y.M. Lee, D. Park, S. Im, E.H. Song, H. Park, W.J. Kim, Self-assembled nanocomplex between polymerized phenylboronic acid and doxorubicin for efficient tumortargeted chemotherapy, Acta Pharmacol. Sin., 38 (2017) 848-858.

91. K. Dan, R. Pan, S. Ghosh, Aggregation and $\mathrm{pH}$ responsive disassembly of a new acid-labile surfactant synthesized by thiol-acrylate michael addition reaction, Langmuir, 27 (2011) 612-617.

92. W. Chen, F.H. Meng, F. Li, S.J. Ji, Z.Y. Zhong, pH-responsive biodegradable micelles based on acid-labile polycarbonate hydrophobe: Synthesis and triggered drug release, Biomacromolecules, 10 (2009) 1727-1735.

93. X. Ke, D.J. Coady, C. Yang, A.C. Engler, J.L. Hedrick, Y.Y. Yang, $\mathrm{pH}$-sensitive polycarbonate micelles for enhanced intracellular release of anticancer drugs: a strategy to circumvent multidrug resistance, Polym. Chem., 5 (2014) 2621-2628.

94. X. Pang, Y. Jiang, Q. Xiao, A.W. Leung, H. Hua, C. Xu, pHresponsive polymer-drug conjugates: Design and progress, J. Controlled Release, 222 (2016) 116-129.

95. Z.Q. Yang, C.Q. He, H. Sui, L. He, X.G. Li, Recent advances of $\mathrm{CO}_{2}$-responsive materials in separations, J. $\mathrm{CO}_{2}$ Util., 30 (2019) 79-99.

96. H.B. Liu, S.J. Lin, Y.J. Feng, P. Theato, $\mathrm{CO}_{2}$-responsive polymer materials, Polym. Chem., 8 (2017) 12-23.

97. Q. Zhang, G.Q. Yu, W.J. Wang, H.M. Yuan, B.G. Li, S.P. Zhu, Preparation of $\mathrm{N}_{2} / \mathrm{CO}_{2}$ triggered reversibly coagulatable and redispersible latexes by emulsion polymerization of styrene with a reactive switchable surfactant, Langmuir, 28 (2012) 5940-5946. 
98. W.Z. Yuan, W.W. Huang, H. Zou, Synthesis and properties of $\mathrm{CO}_{2}$-responsive copolymer by the combination of reversible addition-fragmentation chain transfer polymerization and click chemistry, Polym. Bull., 73 (2016) 2199-2210.

99. B. Ochiai, K. Yokota, A. Fujii, D. Nagai, T. Endo, Reversible traprelease of $\mathrm{CO}_{2}$ by polymers bearing DBU and DBN moieties, Macromolecules, 41 (2008) 1229-1236.

100. S.M. Chen, X.Z. Lin, Z.H. Zhai, R.Y. Lan, J. Li, Y.S. Wang, S.M. Zhou, Z.H. Farooqi, W.T. Wu, Synthesis and characterization of $\mathrm{CO}_{2}$ sensitive temperature-responsive catalytic poly(ionic liquid) microgels, Polym. Chem., 9 (2018) 2887-2896.

101. J.Y. Quek, P.J. Roth, R.A. Evans, T.P. Davis, A.B. Lowe, Reversible addition-fragmentation chain transfer synthesis of amidinebased, $\mathrm{CO}_{2}$-responsive homo and $\mathrm{AB}$ diblock (Co)polymers comprised of histamine and their gas-triggered self-assembly in water, J. Polym. Sci., Part A: Polym. Chem., 51 (2013) 394-404

102. Y.M. Zhang, Y.J. Feng, J.Y. Wang, S. He, Z.R. Guo, Z.L. Chu, C.A. Dreiss, $\mathrm{CO}_{2}$-switchable wormlike micelles, Chem. Commun., 49 (2013) 4902-4904.

103. D. Nagai, A. Suzuki, Y. Maki, H. Takeno, Reversible chain association/dissociation via a $\mathrm{CO}_{2}$ responsive crosslinking/ decrosslinking system, Chem. Commun., 47 (2011) 8856 8858.

104. Y.M. Zhang, H.Y. Yin, Y.J. Feng, $\mathrm{CO}_{2}$-responsive anionic wormlike micelles based on natural erucic acid, Green Mater., 2 (2014) 95-103.

105. V. Fischer, K. Landfester, and R. Munoz-Espi, Molecularly controlled coagulation of carboxyl-functionalized nanoparticles prepared by surfactant-free miniemulsion polymerization, ACS Macro Lett., 1 (2012) 1371-1374.

106. M. George, R.G. Weiss, Chemically reversible organogels: Aliphatic amines as "latent" gelators with carbon dioxide, J. Am. Chem. Soc., 123 (2001) 10393-10394.

107. W. Wang, H. Liu, M. Mu, H. Yin, Y. Feng, $\mathrm{CO}_{2}$-induced reversible morphology transition from giant worms to polymersomes assembled from a block-random segmented copolymer, Polym. Chem., 6 (2015) 2900-2908.

108. C. Hils, E. Fuchs, F. Eger, J. Schobel, H. Schmalz, Converting poly(methyl methacrylate) into a triple-responsive polymer Chem. Eur. J., 26 (2020) 5611-5614.

109. B.N. Tran, Q.T. Bui, Y.S. Jeon, H.S. Park, J.H. Kim, Preparation and characterization of $\mathrm{CO}_{2}$-responsive poly(amino acid) derivatives with guanidine group, Polym. Bull., 72 (2015) 2605-2620.

110. D.H. Han, O. Boissiere, S. Kumar, X. Tong, L. Tremblay, Y. Zhao, Two-way $\mathrm{CO}_{2}$-switchable triblock copolymer hydrogels, Macromolecules, 45 (2012) 7440-7445.

111. L. Chen, R.J. Liu, X. Hao, Q. Yan, $\mathrm{CO}_{2}$-cross-linked frustrated lewis networks as gas-regulated dynamic covalent materials, Angew. Chem., Int. Ed., 58 (2019) 264-268.

112. L. Chen, R.J. Liu, Q. Yan, Polymer meets frustrated lewis pair: Second-generation $\mathrm{CO}_{2}$-responsive nanosystem for sustainable $\mathrm{CO}_{2}$ conversion, Angew. Chem., Int. Ed.,, 57 (2018) 9336-9340.

113. Q. Yan, Y. Zhao, $\mathrm{CO}_{2}$-Stimulated diversiform deformations of polymer assemblies, J. Am. Chem. Soc., 135 (2013) 16300 16303.

114. Y.T. Shieh, Y.C. Yeh, C.C. Cheng, Two-way $\mathrm{CO}_{2}$-responsive polymer particles with controllable amphiphilic properties, ACS Omega, 5 (2020) 1862-1869.

115. H.B. Liu, Z.R. Guo, S. He, H.Y. Yin, C.H. Fei, Y.J. Feng, $\mathrm{CO}_{2}$-driven vesicle to micelle regulation of amphiphilic copolymer: random versus block strategy, Polym. Chem., 5 (2014) 4756-4763.
116. D. Nagai, A. Suzuki, T. Kuribayashi, Synthesis of hydrogels from polyallylamine with carbon dioxide as gellant: development of reversible $\mathrm{CO}_{2}$ absorbent, Macromol. Rapid Commun., 32 (2011) 404-410.

117. M. Huo, H.T. Du, M. Zeng, L. Pan, T. Fang, X.M. Xie, Y. Wei, J.Y. Yuan, $\mathrm{CO}_{2}$-stimulated morphology transition of $\mathrm{ABC}$ miktoarm star terpolymer assemblies, Polym. Chem., 8 (2017) 2833-2840.

118. Q. Yan, R. Zhou, C.K. Fu, H.J. Zhang, Y.W. Yin, J.Y. Yuan, $\mathrm{CO}_{2}-$ responsive polymeric vesicles that breathe, Angew. Chem., Int. Ed., 50 (2011) 4923-4927.

119. S. Kumar, X. Tong, Y.L. Dory, M. Lepage, Y. Zhao, $\mathrm{A} \mathrm{CO}_{2}-$ switchable polymer brush for reversible capture and release of proteins, Chem. Commun., 49 (2013) 90-92.

120. H.L. Che, M. Huo, L. Peng, T. Fang, N. Liu, L. Feng, Y. Wei, J.Y. Yuan, $\mathrm{CO}_{2}$-responsive nanofibrous membranes with switchable oil/water wettability, Angew. Chem., Int. Ed., 54 (2015) 89348938.

121. H.Y. Yin, A.L. Bulteau, Y.J. Feng, L. Billon, $\mathrm{CO}_{2}$-induced tunable and reversible surface wettability of honeycomb structured porous films for cell adhesion, Adv. Mater. Interfaces, 3 (2016) 1500623.

122. N. Li, L. Thia, X. Wang, $\mathrm{A} \mathrm{CO}_{2}$-responsive surface with an amidine-terminated self-assembled monolayer for stimuliinduced selective adsorption, Chem. Commun., 50 (2014) 4003-4006.

123. H.X. Chen, Y.L. Wang, X.L. Li, B.L. Liang, S.H. Dong, T.T. You, P.G. Yin, $\mathrm{A} \mathrm{CO}_{2}$-tunable plasmonic nanosensor based on the interfacial assembly of gold nanoparticles on diblock copolymers grafted from gold surfaces, RSC Adv., 8 (2018) 22177-22181.

124. Q.F. Zhai, H. Jiang, X.W. Zhang, J. Li, E.K. Wang, Smart modification of the single conical nanochannel to fabricate dual-responsive ion gate by self-initiated photografting and photopolymerization, Talanta, 149 (2016) 280-284.

125. Q. Zhang, Z.W. Wang, L. Lei, J. Tang, J.L. Wang, S.P. Zhu, $\mathrm{CO}_{2}-$ switchable membranes prepared by immobilization of $\mathrm{CO}_{2}$ breathing microgels, ACS Appl. Mater. Interfaces, 9 (2017) $44146-44151$.

126. H.B. Liu, Y. Zhao, C.A. Dreiss, Y.J. Feng, $\mathrm{CO}_{2}$-switchable multicompartment micelles with segregated corona, Soft Matter, 10 (2014) 6387-6391.

127. A.C. Feng, C.B. Zhan, Q. Yan, B.W. Liu, J.Y. Yuan, $\mathrm{A} \mathrm{CO}_{2}$ - and temperature-switchable "schizophrenic" block copolymer: From vesicles to micelles, Chem. Commun., 50 (2014) 89588961.

128. N. Casado, G. Hernández, H. Sardon, D. Mecerreyes, Current trends in redox polymers for energy and medicine, Prog. Polym. Sci., 52 (2016) 107-135.

129. N. Ma, Y. Li, H.P. Xu, Z.Q. Wang, X. Zhang, Dual redox responsive assemblies formed from diselenide block copolymers, J. Am. Chem. Soc., 132 (2010) 442-443.

130. L. Wang, W. Cao, Y. Yi, H.P. Xu, Dual redox responsive coassemblies of diselenide-containing block copolymers and polymer lipids, Langmuir, 30 (2014) 5628-5636.

131. Q. Tang, Y.T. Nie, C.B. Gong, C.F. Chow, J.D. Peng, M.H.W. Lam, Photo-responsive molecularly imprinted hydrogels for the detection of melamine in aqueous media, J. Mater. Chem., 22 (2012) 19812-19820.

132. J. Yang, W.W. Liu, M.H. Sui, J.B. Tang, Y.Q. Shen, Platinum (IV)-coordinate polymers as intracellular reductionresponsive backbone-type conjugates for cancer drug delivery, Biomaterials, 32 (2011) 9136-9143. 
133. G.Y. Zhang, Y.M. Zhu, Y.S. Wang, D.S. Wei, Y.X. Wu, L.C. Zheng, H.M. Bai, H.H. Xiao, Z.Y. Zhang, pH/redox sensitive nanoparticles with platinum(IV) prodrugs and doxorubicin enhance chemotherapy in ovarian cancer, RSC Adv., 9 (2019) 20513-20517.

134. L. He, M. Sun, X. Cheng, Y. Xu, X.D. Lv, X. Wang, R.P. Tang, $\mathrm{pH} /$ redox dual-sensitive platinum (IV)-based micelles with greatly enhanced antitumor effect for combination chemotherapy, J. Colloid Interface Sci., 541 (2019) 30-41.

135. Y.Y. Yuan, R.T.K. Kwok, B.Z. Tang, B. Liu, Targeted theranostic platinum(IV) prodrug with a built-in aggregation-induced emission light-up apoptosis sensor for noninvasive early evaluation of its therapeutic responses in situ, J. Am. Chem. Soc., 136 (2014) 2546-2554.

136. W. Cao, Y. Li, Y. Yi, S.B. Ji, L.W. Zeng, Z.W. Sun, H.P. Xu, Coordination-responsive selenium-containing polymer micelles for controlled drug release, Chem. Sci., 3 (2012) 3403-3408.

137. R.C. Fang, H.P. Xu, W. Cao, L.L. Yang, X. Zhang, Reactive oxygen species (ROS)-responsive tellurium-containing hyperbranched polymer, Polym. Chem., 6 (2015) 2817-2821.

138. D.S. Wilson, G. Dalmasso, L.X. Wang, S.V. Sitaraman, D. Merlin, N. Murthy, Orally delivered thioketal nanoparticles loaded with TNF-alpha-siRNA target inflammation and inhibit gene expression in the intestines, Nat. Mater., 9 (2010) 923-928.

139. M.L. Wang, Y.L. Zhai, H. Ye, Q.Z. Lv, B.J. Sun, C. Luo, Q.K. Jiang, H.T. Zhang, Y.J. Xu, Y.K. Jing, L. Huang, J. Sun, Z.G. He, High Co-loading capacity and stimuli-responsive release based on cascade reaction of self-destructive polymer for improved chemo-photodynamic therapy, ACS Nano, 13 (2019) 7010-7023

140. Y.Q. Wang, C.J. Li, L. Du, Y. Liu, A reactive oxygen speciesresponsive dendrimer with low cytotoxicity for efficient and targeted gene delivery, Chin. Chem. Lett., 31 (2020) 275-280.

141. W.D. Ke, N.N. Lu, A.M.M. Japir, Q.H. Zhou, L.C. Xi, Y.H. Wang, D. Dutta, M. Zhou, Y.Y. Pan, Z.S. Ge, Length effect of stimuliresponsive block copolymer prodrug filomicelles on drug delivery efficiency, J. Controlled Release, 318 (2020) 67-77.

142. M.K. Gupta, T.A. Meyer, C.E. Nelson, C.L. Duvall, Poly(PS-bDMA) micelles for reactive oxygen species triggered drug release, J. Controlled Release, 162 (2012) 591-598.

143. D. Jeanmaire, J. Laliturai, A. Almalik, P. Carampin, R. d'Arcy, E. Lallana, R. Evans, R.E.P. Winpenny, N. Tirelli, Chemical specificity in redox-responsive materials: The diverse effects of different Reactive Oxygen Species (ROS) on polysulfide nanoparticles, Polym. Chem., 5 (2014) 1393-1404.

144. S. Bobbala, S.D. Allen, S.J. Yi, M. Vincent, M. Frey, N.B. Karabin, E.A. Scott, Employing bicontinuous-to-micellar transitions in nanostructure morphology for on-demand photo-oxidation responsive cytosolic delivery and off-on cytotoxicity, Nanoscale, 12 (2020) 5332-5340.

145. J. Kwon, J. Kim, S. Park, G. Khang, P.M. Kang, D. Lee, Inflammation-responsive antioxidant nanoparticles based on a polymeric prodrug of vanillin, Biomacromolecules, 14 (2013) 1618-1626.

146. S. Kim, K. Seong, O. Kim, S. Kim, H. Seo, M. Lee, G. Khang, D. Lee, Polyoxalate nanoparticles as a biodegradable and biocompatible drug delivery vehicle, Biomacromolecules, 11 (2010) 555-560.

147. C.C. Song, R. Ji, F.S. Du, Z.C. Li, Oxidation-responsive poly(amino ester)s containing arylboronic ester and self-immolative motif: synthesis and degradation study, Macromolecules, 46 (2013) 8416-8425.
148. C.C. Song, R. Ji, F.S. Du, D.H. Liang, Z.C. Li, Oxidationaccelerated hydrolysis of the ortho ester-containing acidlabile polymers, ACS Macro Lett., 2 (2013) 273-277.

149. S.S. Yu, R.L. Koblin, A.L. Zachman, D.S. Perrien, L.H. Hofmeister, T.D. Giorgio, H.J. Sung, Physiologically relevant oxidative degradation of oligo(proline) cross-linked polymeric scaffolds, Biomacromolecules, 12 (2011) 43574366.

150. 150. E.R. Stadtman, R.L. Levine, Free radical-mediated oxidation of free amino acids and amino acid residues in proteins, Amino Acids, 25 (2003) 207-218.

151. 151. K. Wang, G.F. Luo, Y. Liu, C. Li, S.X. Cheng, R.X.Zhuo, X.Z. Zhang, Redox-sensitive shell cross-linked PEG-polypeptide hybrid micelles for controlled drug release, Polym. Chem., 3 (2012) 1084-1090.

152. Y.C. Wang, Y. Li, T.M. Sun, M.H. Xiong, J.A. Wu, Y.Y. Yang, J. Wang, Core-shell-corona micelle stabilized by reversible cross-linkage for intracellular drug delivery, Macromol. Rapid Commun., 31 (2010) 1201-1206.

153. Y.K. Lin, Y.C. Yu, S.W. Wang, R.S. Lee, Temperature, ultrasound and redox triple-responsive poly( $\mathrm{N}$-isopropylacrylamide) block copolymer: synthesis, characterization and controlled release, RSC Adv., 7 (2017) 43212-43226.

154. H. Yuan, H. Chi, W.Z. Yuan, A star-shaped amphiphilic block copolymer with dual responses: synthesis, crystallization, self-assembly, redox and LCST-UCST thermoresponsive transition, Polym. Chem., 7 (2016) 4901-4911.

155. R.H. Staff, M. Gallei, M. Mazurowski, M. Rehahn, R. Berger, K. Landfester, D. Crespy, Patchy Nanocapsules of poly(vinylferrocene)-based block copolymers for redoxresponsive release, ACS Nano, 6 (2012) 9042-9049.

156. Y.J. Ma, W.F. Dong, M.A. Hempenius, H. Mohwald, G.J. Vancso, Redox-controlled molecular permeability of composite-wall microcapsules, Nat. Mater., 5 (2006) 724729.

157. J. Elbert, F. Krohm, C. Ruttiger, S. Kienle, H. Didzoleit, B.N. Balzer, T. Hugel, B. Stuhn, M. Gallei, A. Brunsen, Polymermodifi ed mesoporous silica thin films for redox-mediated selective membrane gating, Adv. Funct. Mater., 24 (2014) 1591-1601.

158. F. Xu, H. Li, Y.L. Luo, W. Tang, Redox-responsive selfassembly micelles from poly(N-acryloylmorpholine-block2-acryloyloxyethyl ferrocenecarboxylate) amphiphilic block copolymers as drug release carriers, ACS Appl. Mater. Interfaces, 9 (2017) 5181-5192.

159. X. Xia, H.J. Yu, L. Wang, Z. Deng, K.J. Shea, Zain-ul-Abdin, Preparation of redox- and photo-responsive ferrocene- and azobenzene-based polymer films and their properties, Eur. Polym. J., 100 (2018) 103-110.

160. M. Saleem, L. Wang, H.J. Yu, Zain-ul-Abdin, Synthesis of ferrocene boronic acid-based block copolymers via RAFT polymerization and their micellization, redox responsive and glucose sensing properties, Arabian J. Chem., 12 (2019) 800-815

161. M. Nakahata, Y. Takashima, A. Harada, Redox-responsive macroscopic gel assembly based on discrete dua interactions, Angew. Chem., Int. Ed., 53 (2014) 3617-3621.

162. Z.K. Du, X.L. Yan, N. Sun, B.Y. Ren, Dual stimuli-responsive nano-structure transition of three-arm branched amphiphilic polymers containing ferrocene $(\mathrm{Fc})$ and azobenzene (Azo) moieties in aqueous solution, Soft Matter, 15 (2019) 8855-8864. 
163. D. Roy, J.N. Cambre, B.S. Sumerlin, Future perspectives and recent advances in stimuli-responsive materials, Prog. Polym. Sci., 35 (2010) 278-301.

164. Van Hove, A., Z. Cui, and D.S.W. Benoit, Stimuli-Responsive Polymer Delivery Systems, Engineering Polymer Systems for Improved Drug Delivery, John Wiley \& Sons, Inc., 2013.

165. M. Huo, J. Yuan, L. Tao, Y. Wei, Redox-responsive polymers for drug delivery: From molecular design to applications, Polym. Chem., 5 (2014) 1519-1528.

166. H. Cho, J. Bae, V.K. Garripelli, J.M. Anderson, H.W. Jun, S. Jo, Redox-sensitive polymeric nanoparticles for drug delivery Chem. Commun., 48 (2012) 6043-6045

167. C. Dollendorf, M. Hetzer, H. Ritter, Polymeric redoxresponsive delivery systems bearing ammonium salts crosslinked via disulfides, Beilstein J. Org. Chem., 9 (2013) 1652 1662.

168. B. Gyarmati, B. Vajna, Á. Némethy, K. László, A. Szilágyi, Redoxand $\mathrm{pH}$-responsive cysteamine-modified poly(aspartic acid) showing a reversible sol-gel transition, Macromol. Biosci., 13 (2013) 633-640

169. P. Zhang, F.Y. Deng, Y. Peng, H.B. Chen, Y. Gao, H.M. Li, Redoxand $\mathrm{pH}$-responsive polymer gels with reversible sol-gel transitions and self-healing properties, RSC Adv., 4 (2014) 47361-47367.

170. A.N. Koo, K.H. Min, H.J. Lee, S.U. Lee, K. Kim, I.C. Kwon, S.H. Cho, S.Y. Jeong, S.C. Lee, Tumor accumulation and antitumor efficacy of docetaxel-loaded core-shell-corona micelles with shell-specific redox-responsive cross-links, Biomaterials, 33 (2012) 1489-1499.

171. H. Liu, R. Wang, J. Wei, C. Cheng, Y. Zheng, Y. Pan, X.L. He, M.M. Ding, H. Tan, Q. Fu, Conformation-directed micelleto-vesicle transition of cholesterol decorated polypeptide triggered by oxidation, J. Am. Chem. Soc., 140 (2018) 6604 6610.

172. T.B. Sun, Y. Jin, R. Qi, S.J. Peng, B.Z. Fan, Oxidation responsive mono-cleavable amphiphilic di-block polymer micelles labeled with a single diselenide, Polym. Chem., 4 (2013) 4017-4023.

173. X.Y. Chang, R.F. Dong, B.Y. Ren, Z.Y. Cheng, J. Peng, Z. Tong, Novel ferrocenyl-terminated linear-dendritic amphiphilic block copolymers: Synthesis, redox-controlled reversible self-assembly, and oxidation-controlled release, Langmuir, 30 (2014) 8707-8716

174. J.C. Eloi, D.A. Rider, G. Cambridge, G.R. Whittell, M.A. Winnik, I. Manners, Stimulus-responsive self-assembly: Reversible, redox-controlled micellization of polyferrocenylsilane diblock copolymers, J. Am. Chem. Soc., 133 (2011) 8903 8913.

175. S. Schottner, R. Hossain, C. Ruttiger, M. Gallei, Ferrocenemodified block copolymers for the preparation of smart porous membranes, Polymers, 9 (2017) 491.

176. E.E.L. Kathmann, L.A. White, C.L. McCormick, Water-soluble polymers, 73. Electrolyte- and $\mathrm{pH}$-responsive zwitterionic copolymers of 4-[(2-acrylamido-2-methylpropyl) dimethylammonio]butanoate with 3-[(2-acrylamido2-methylpropyl)dimethylammonio]propanesulfonate, Macromolecules, 30 (1997) 5297-5304.

177. M.E. Morrison, R.C. Dorfman, W.D. Clendening, D.J. Kiserow, P.J. Rossky, S.E. Webber, Quenching kinetics of anthracene covalently bound to a polyelectrolyte, 1 . Effects of ionicstrength, J. Phys. Chem., 98 (1994) 5534-5540.

178. J. Yang, L. Fang, F. Wang, T. Tan, Preparation and characterization of a novel $\mathrm{pH}$-,thermo-, and ionic strengthresponsive hydrogels based on xanthan gum-poly(aspartic acid), J. Appl. Polym. Sci., 105 (2007) 539-546.
179. S. Inal, L. Chiappisi, J.D. Kolsch, M. Kraft, M.S. Appavou, U. Scherf, M. Wagner, M.R. Hansen, M. Gradzielski, A. Laschewsky, D. Neher, Temperature-regulated fluorescence and association of an oligo(ethyleneglycol)methacrylate-based copolymer with a conjugated polyelectrolyte-the effect of solution ionic strength, J. Phys. Chem. B, 117 (2013) 14576-14587.

180. T. Xiang, T. Lu, W.F. Zhao, C.S. Zhao, lonic strength- and thermoresponsive polyethersulfone composite membranes with enhanced antifouling properties, New J. Chem., 42 (2018) 5323-5333.

181. M. Mohammadi, M. Salami-Kalajahi, H. Roghani-Mamaqani, M. Golshan, Effect of molecular weight and polymer concentration on the triple temperature/pH/ionic strength-sensitive behavior of poly(2-(dimethylamino)ethyl methacrylate), Intern. J. Polym. Mater. Polym. Biomater., 66 (2017) 455-461.

182. C. Zhao, L. Dolmans, X.X. Zhu, Thermoresponsive behavior of poly(acrylic acid-co-acrylonitrile) with a UCST, Macromolecules, 52 (2019) 4441-4446.

183. B. Onat, V. Bütün, S. Banerjee, I. Erel-Göktepe, Bacteria anti-adhesive and $\mathrm{pH}$-induced antibacterial agent releasing ultra-thin films of zwitterionic copolymer micelles, Acta Biomaterialia, 40 (2016) 293-309.

184. Luo, Y.L., K.P. Zhang, Q.B. Wei, Z.Q. Liu, and Y.S. Chen, Poly(MAA-co-AN) hydrogels with improved mechanical properties for theophylline controlled delivery, Acta Biomater., 5 (2009) 316-327.

185. L. Hu, M.J. Serpe, The influence of deposition solution $\mathrm{pH}$ and ionic strength on the quality of poly( $\mathrm{N}$-isopropylacrylamide) microgel-based thin films and etalons, ACS Appl. Mater. Interfaces, 5 (2013) 11977-11983.

186. Y. Wang, G.D. He, Z. Li, J.C. Hua, M.Q. Wu, J.X. Gong, J.F. Zhang, L.T. Ban, L. Huang, Novel biological hydrogel: Swelling behaviors study in salt solutions with different ionic valence number, Polymers, 10 (2018) 112

187. E. Akar, A. Altınışık, Y. Seki, Preparation of $\mathrm{pH}$ - and ionicstrength responsive biodegradable fumaric acid crosslinked carboxymethyl cellulose, Carbohydr. Polym., 90 (2012) 1634-1641.

188. R.S. Zhang, M.G. Tang, A. Bowyer, R. Eisenthal, J. Hubble, A novel $\mathrm{pH}$ - and ionic-strength-sensitive carboxy methyl dextran hydrogel, Biomaterials, 26 (2005) 4677-4683.

189. J.H. Zhou, G. Wang, J.Q. Hu, X.B. Lu, J.H. Li, Temperature, ionic strength and $\mathrm{pH}$ induced electrochemical switching of smart polymer interfaces, Chem. Commun., 46 (2006) 4820-4822.

190. X.G. Ying, L.L. Qi, X. Li, W.Y. Zhang, G.X. Cheng, Stimuliresponsive recognition of BSA-imprinted poly vinyl acetate grafted calcium alginate core-shell hydrogel microspheres, J. Appl. Polym. Sci., 127 (2013) 3898-3909.

191. Y. Zhao, H.J. Su, L. Fang, T.W. Tan, Superabsorbent hydrogels from poly(aspartic acid) with salt-, temperature- and $\mathrm{pH}$ responsiveness properties, Polymer, 46 (2005) 5368-5376.

192. V. Bütün, A. Atay, C. Tuncer, and Y. Baş, Novel multiresponsive microgels: Synthesis and characterization studies, Langmuir, 27 (2011) 12657-12665.

193. A.S. Lee, V. Bütün, M. Vamvakaki, S.P. Armes, J.A. Pople, A.P. Gast, Structure of $\mathrm{pH}$-dependent block copolymer micelles: Charge and ionic strength dependence, Macromolecules, 35 (2002) 8540-8551.

194. N.P. Bayramgil, Synthesis and characterization of new methacrylate-type hydrogels containing 2-tert-butylamino ethyl groups for sorption purposes, J. Appl. Polym. Sci., 109 (2008) 1205-1211. 
195. A. Arizaga, G. Ibarz, R. Pinol, Stimuli-responsive poly (4-vinyl pyridine) hydrogel nanoparticles: Synthesis by nanoprecipitation and swelling behavior, J. Colloid Interface Sci., 348 (2010) 668-672.

196. X.R. Yu, J.S. Liu, Y.J. Xin, M.X. Zhan, J. Xiao, L.G. Lu, S.J. Peng, Temperature and salt responsive zwitterionic polysulfamide-based nanogels with surface regeneration ability and controlled drug release, Polym. Chem., 10 (2019) 6423-6431.

197. Y. Xu, C. Wang, K.C. Tam, L. Li, Salt-assisted and saltsuppressed sol-gel transitions of methylcellulose in water Langmuir, 20 (2004) 646-652.

198. A. Kumar, I.Y. Galaev, B. Mattiasson, Affinity precipitation of alpha-amylase inhibitor from wheat meal by metal chelate affinity binding using $\mathrm{Cu}(\mathrm{II})$-loaded copolymers of 1-vinylimidazole with $\mathrm{N}$-isopropylacrylamide, Biotechnol. Bioeng., 59 (1998) 695-704.

199. T. Manouras, M. Vamvakaki, Field responsive materials: photo-, electro-, magnetic- and ultrasound-sensitive polymers, Polym. Chem., 8 (2017) 74-96.

200. J.S. Scarpa, D.D. Mueller, I.M. Klotz, Slow hydrogendeuterium exchange in a non-.alpha.-helical polyamide, J. Am. Chem. Soc., 89 (1967) 6024-6030.

201. Z. Osvath, B. Ivan, The dependence of the cloud point, clearing point, and hysteresis of poly(n-isopropylacrylamide) on experimental conditions: The need for standardization of thermoresponsive transition determinations, Macromol. Chem. Phys., 218 (2017) 1600470.

202. V. Hildebrand, A. Laschewsky, M. Pach, P. Muller-Buschbaum, C.M. Papadakis, Effect of the zwitterion structure on the thermo-responsive behaviour of poly(sulfobetaine methacrylates), Polym. Chem., 8 (2017) 310-322.

203. Y.C. Zhu, J.M. Noy, A.B. Lowe, P.J. Roth, The synthesis and aqueous solution properties of sulfobutylbetaine (co) polymers: comparison of synthetic routes and tuneable upper critical solution temperatures, Polym. Chem., 6 (2015) 5705-5718

204. A. Asadujjaman, B. Kent, A. Bertin, Phase transition and aggregation behaviour of an UCST-type copolymer poly(acrylamide-co-acrylonitrile) in water: effect of acrylonitrile content, concentration in solution, copolymer chain length and presence of electrolyte, Soft Matter, 13 (2017) 658-669.

205. J. Seuring, S. Agarwal, First example of a universal and costeffective approach: Polymers with tunable upper critical solution temperature in water and electrolyte solution, Macromolecules, 45 (2012) 3910-3918.

206. F.O. Obiweluozor, A. GhavamiNejad, S. Hashmi, M. Vatankhah-Varnoosfaderani, F.J. Stadler, A NIPAM zwitterion copolymer: Rheological interpretation of the specific ion effect on the LCST, Macromol. Chem. Phys., 215 (2014) 2125-2125.

207. P.A. Woodfield, Y.C. Zhu, Y.W. Pei, P.J. Roth, Hydrophobically modified sulfobetaine copolymers with tunable aqueous UCST through postpolymerization modification of poly(pentafluorophenyl acrylate), Macromolecules, 47 (2014) 750-762

208. D.N. Schulz, D.G. Peiffer, P.K. Agarwal, J. Larabee, J.J. Kaladas, L. Soni, B. Handwerker, R.T. Garner, Phase behaviour and solution properties of sulphobetaine polymers, Polymer, 27 (1986) 1734-1742.

209. V.A. Vasantha, J.H. Chen, T.B. Ying, A. Parthiban, Saltresponsive polysulfabetaines from acrylate and acrylamide precursors: Robust stabilization of metal nanoparticles in hyposalinity and hypersalinity, Langmuir, 31 (2015) 11124 11134.
210. J.V.M. Weaver, S.P. Armes, V. Bütün, Synthesis and aqueous solution properties of a well-defined thermo-responsive schizophrenic diblock copolymer, Chem. Commun., (2002) 2122-2123.

211. V. Aseyev, H. Tenhu, F.M. Winnik, Non-ionic thermoresponsive polymers in water, Self Organized Nanostructures of Amphiphilic Block Copolymers II, 242 (2011) 29-89.

212. Y. Kotsuchibashi, M. Ebara, T. Aoyagi, R. Narain, Recent advances in dual temperature responsive block copolymers and their potential as biomedical applications, Polymers, 8 (2016) 380

213. 213. D. Roy, W.L.A. Brooks, B.S. Sumerlin, New directions in thermoresponsive polymers, Chem. Soc. Rev., 42 (2013) 7214-7243

214. H. Chen, L. Yuan, W. Song, Z.K. Wu, D. Li, Biocompatible polymer materials: Role of protein-surface interactions, Prog. Polym. Sci., 33 (2008) 1059-1087.

215. J.Y. Ning, K. Kubota, G. Li, K. Haraguchi, Characteristics of zwitterionic sulfobetaine acrylamide polymer and the hydrogels prepared by free-radical polymerization and effects of physical and chemical crosslinks on the UCST, React. Funct. Polym., 73 (2013) 969-978.

216. D.J. Eustace, D.B. Siano, E.N. Drake, Polymer compatibility and interpolymer association in the poly(acrylic acid) polyacrylamide water ternary-system, J. Appl. Polym. Sci., 35 (1988) 707-716.

217. X. Zhou, L. Weng, Q. Chen, J. Zhang, D. Shen, Z. Li, M. Shao, J. Xu, Investigation of $\mathrm{pH}$ sensitivity of poly(acrylic acid-coacrylamide) hydrogel, Polym. Int., 52 (2003) 1153-1157.

218. V. Hildebrand, A. Laschewsky, M. Päch, P. Müller-Buschbaum, C.M.J.P.C. Papadakis, Effect of the zwitterion structure on the thermo-responsive behaviour of poly (sulfobetaine methacrylates), Polym. Chem., 8 (2017) 310-322.

219. H. Wei, S. Perrier, S. Dehn, R. Ravarian, F. Dehghani, One-pot ATRP synthesis of a triple hydrophilic block copolymer with dual LCSTs and its thermo-induced association behavior, Soft Matter, 8 (2012) 9526-9528.

220. Z. Sun, Y. Tian, W.L. Hom, O. Gang, S.R. Bhatia, R.B. Grubbs, Translating thermal response of triblock copolymer assemblies in dilute solution to macroscopic gelation and phase separation, Angew. Chem., Int. Ed., 56 (2017) 14911494

221. J. Zhang, R. Xie, S.B. Zhang, C.J. Cheng, X.J. Ju, L.Y. Chu, Rapid $\mathrm{pH} /$ temperature-responsive cationic hydrogels with dual stimuli-sensitive grafted side chains, Polymer, 50 (2009) 2516-2525

222. H. Kaşgöz, Z. Özbaş, E. Esen, C.P. Şahin, G. Gürdağ, Removal of copper(II) ions with a thermoresponsive cellulose-gpoly(n-isopropyl acrylamide) copolymer, J. Appl. Polym. Sci., 130 (2013) 4440-4448.

223. B. Taşdelen, N. Kayaman-Apohan, O. Güven, B.M. Baysal, pH-thermoreversible hydrogels, I. Synthesis and characterization of poly( $\mathrm{N}$-isopropylacrylamide/maleic acid) copolymeric hydrogels, Radiat. Phys. Chem., 69 (2004) 303-310.

224. E. Uğuzdoğan, , E.B. Denkbaş, and A. Tuncel, RNA-Sensitive $\mathrm{N}$-isopropylacrylamide/vinylphenylboronic acid random copolymer, Macromol. Biosci., 2 (2002) 214-222.

225. I. Eke, B. Elmas, M. Tuncel, A. Tuncel, A new, highly stable cationic-thermosensitive microgel: Uniform isopropylacrylamide-dimethylaminopropylmethacrylamide copolymer particles, Colloids Surf., A, 279 (2006) 247-253.

226. K. Koç, E. Alveroğlu, Tuning the gel size and LCST of $\mathrm{N}$-isopropylacrylamide nanogels by anionic fluoroprobe, Colloid Polym. Sci., 294 (2016) 285-290. 
227. N. Şahiner, P. Ilgın, Soft core-shell polymeric nanoparticles with magnetic property for potential guided drug delivery, Curr. Nanosci., 6 (2010) 483-491.

228. L. Wang, M. Liu, C. Gao, L. Ma, D. Cui, A pH-, thermo-, and glucose-, triple-responsive hydrogels: Synthesis and controlled drug delivery, React. Funct. Polym., 70 (2010) 159-167.

229. G.B. Demirel, R. von Klitzing, A new multiresponsive drug delivery system using smart nanogels, ChemPhysChem, 14 (2013) 2833-2840.

230. L.H. Gan, Y.Y. Gan, G.R. Doon, Poly(N-acryloyl-N '-propylpiperazine): A new stimuli-responsive polymer, Macromolecules, 33 (2000) 7893-7897.

231. L.H. Gan, G.R. Deen, X.J. Loh, Y.Y. Gan, New stimuliresponsive copolymers of $\mathrm{N}$-acryloyl-N '-alkyl piperazine and methyl methacrylate and their hydrogels, Polymer, 42 (2001) 65-69

232. G.R. Deen, L.H. Gan, Influence of amino group pK(a) on the properties of stimuli-responsive piperazine-based polymers and hydrogels, J. Appl. Polym. Sci., 107 (2008) 1449-1458.

233. F. Taktak, T. Alniacik, Rapid deswelling of porous poly[2-(Nmorpholino)ethyl methacrylate] hydrogel and controlled release of ibuprofen, J. Macromol. Sci. Part B Phys., 56 (2017) 114-123.

234. W. Xue, M.B. Huglin, T.G.J. Jones, Parameters affecting the lower critical solution temperature of linear and crosslinked poly(N-ethylacrylamide) in aqueous media, Macromol. Chem. Phys., 204 (2003) 1956-1965.

235. K. Van Durme, S. Verbrugghe, F.E. Du Prez, B. Van Mele, Influence of poly(ethylene oxide) grafts on kinetics of LCST behavior in aqueous poly( $\mathrm{N}$-vinylcaprolactam) solutions and networks studied by modulated temperature DSC, Macromolecules, 37 (2004) 1054-1061.

236. G.R. Deen, E.K. Lim, C.H. Mah, K.M. Heng, New cationic linear copolymers and hydrogels of $\mathrm{N}$-vinyl caprolactam and $\mathrm{N}$-acryloyl-N '-ethyl piperazine: Synthesis, reactivity, influence of external stimuli on the LCST and swelling properties, Ind. Eng. Chem. Res., 51 (2012) 13354-13365.

237. P. Bouillot, B. Vincent, A comparison of the swelling behaviour of copolymer and interpenetrating network microgel particles, ColloidPolym. Sci., 278 (2000) 74-79.

238. F.Y. Liu, S.H. Jiang, L. Ionov, S. Agarwal, Thermophilic films and fibers from photo cross-linkable UCST-type polymers, Polym. Chem., 6 (2015) 2769-2776.

239. N. Shimada, S. Kidoaki, A. Maruyama, Smart hydrogels exhibiting UCST-type volume changes under physiologically relevant conditions, RSC Adv., 4 (2014) 52346-52348.

240. L. Chen, J.P. Gong, Y. Osada, Novel thermosensitive IPN hydrogel having a phase transition without volume change, Macromol. Rapid Commun., 23 (2002) 171-174.

241. H. Katono, A. Maruyama, K. Sanui, N. Ogata, T. Okano, Y. Sakurai, Thermoresponsive swelling and drug release switching of interpenetrating polymer networks composed of poly (acrylamide-co-butyl methacrylate) and poly (acrylic-acid), J. Controlled Release, 16 (1991) 215-227.

242. F.Y. Liu, J. Seuring, S. Agarwal, A non-ionic thermophilic hydrogel with positive thermosensitivity in water and electrolyte solution, Macromol. Chem. Phys., 215 (2014) 1466-1472.

243. J. Seuring, F.M. Bayer, K. Huber, S. Agarwal, Upper critical solution temperature of poly( $\mathrm{N}$-acryloyl glycinamide) in water: A concealed property, Macromolecules, 45 (2012) 374-384.
244. F. IImain, T. Tanaka, E. Kokufuta, Volume transition in a ge driven by hydrogen-bonding, Nature, 349 (1991) 400-401.

245. Q.F. Wang, S.M. Li, Z.Y. Wang, H.Z. Liu, C.J. Li, Preparation and characterization of a positive thermoresponsive hydrogel for drug loading and release, J. Appl. Polym. Sci., 111 (2009) 1417-1425.

246. 246. J.R. Gillmor, R.W. Connelly, R.H. Colby, J.S. Tan, Effect of sodium poly(styrene sulfonate) on thermoreversible gelation of gelatin, J. Polym. Sci., Part B: Polym. Phys. 37 (1999) 2287-2295.

247. S. Sugihara, S. Kanaoka, S. Aoshima, Double thermosensitive diblock copolymers of vinyl ethers with pendant oxyethylene groups: Unique physical gelation, Macromolecules, 38 (2005) 1919-1927.

248. E.L. Lee, H.A. von Recum, Cell culture platform with mechanical conditioning and nondamaging cellular detachment, J. Biomed. Mater. Res. Part A, 93a (2010) 411418.

249. L.Y. Chu, T. Niitsuma, T. Yamaguchi, S. Nakao, Thermoresponsive transport through porous membranes with grafted PNIPAM gates, AIChE J., 49 (2003) 896-909.

250. R. Xie, Y. Li, L.Y. Chu, Preparation of thermo-responsive gating membranes with controllable response temperature, J. Membr. Sci., 289 (2007) 76-85.

251. M. Hakalahti, A. Mautner, L.S. Johansson, T. Hanninen, H. Setala, E. Kontturi, A. Bismarck, T. Tammelin, Direct Interfacial modification of nanocellulose films for thermoresponsive membrane templates, ACS Appl. Mater. Interfaces, 8 (2016) 2923-2927.

252. S.K. Li, A. D'Emanuele, On-off transport through a thermoresponsive hydrogel composite membrane, J. Controlled Release, 75 (2001) 55-67.

253. Q. Fu, G.V.R. Rao, T.L. Ward, Y.F. Lu, G.P. Lopez, Thermoresponsive transport through ordered mesoporous silica/PNIPAAm copolymer membranes and microspheres, Langmuir, 23 (2007) 170-174.

254. H. Alem, A.S. Duwez, P. Lussis, P. Lipnik, A.M. Jonas, S. Demoustier-Champagne, Microstructure and thermoresponsive behavior of poly ( $\mathrm{N}$-isopropylacrylamide) brushes grafted in nanopores of track-etched membranes, J. Membr. Sci., 308 (2008) 75-86.

255. N. Reber, A. Kuchel, R. Spohr, A. Wolf, M. Yoshida, Transport properties of thermo-responsive ion track membranes, J. Membr. Sci., 193 (2001) 49-58.

256. M.A.M.E. Vertommen, H.J.L. Cornelissen, C.H.J.T. Dietz, R. Hoogenboom, M.F. Kemmere, J.T.F. Keurentjes, Porecovered thermoresponsive membranes for repeated ondemand drug release, J. Membr. Sci., 322 (2008) 243-248.

257. J.Y. Choi, T. Yun, S.Y. Kwak, Two-step thermoresponsive membrane with tunable separation properties and improved cleaning efficiency, J. Membr. Sci.,554 (2018) 117124.

258. K. Nagase, M. Watanabe, A. Kikuchi, M. Yamato, T. Okano, Thermo-responsive polymer brushes as intelligent biointerfaces: Preparation via ATRP and characterization, Macromol. Biosci., 11 (2011) 400-409.

259. X. Laloyaux, E. Fautre, T. Blin, V. Purohit, J. Leprince, T. Jouenne, A.M. Jonas, K. Glinel, Temperature-responsive polymer brushes switching from bactericidal to cellrepellent, Adv. Mater., 22 (2010) 5024-5028. 
260. C. Tonhauser, A.A. Golriz, C. Moers, R. Klein, H.J. Butt, H Frey, Stimuli-responsive Y-Shaped polymer brushes based on junction-point-reactive block copolymers, Adv. Mater., 24 (2012) 5559-5563.

261. C.A. Naini, M. Thomas, S. Franzka, S. Frost, M. Ulbricht, N. Hartmann, Hofmeister effect of sodium halides on the switching energetics of thermoresponsive polymer brushes, Macromol. Rapid Commun., 34 (2013) 417-422.

262. J. Collett, A. Crawford, P.V. Hatton, M. Geoghegan, S. Rimmer, Thermally responsive polymeric hydrogel brushes: Synthesis, physical properties and use for the culture of chondrocytes, J. R. Soc. Interface, 4 (2007) 117-126.

263. Y.X. Zuo, G.Q. Wang, Y. Yu, C.C. Zuo, L.Y. Shi, F.L. Shi, J. Wei, Smart nanovalves with thermoresponsive amphiphilic triblock copolymer brushes, J. Macromol. Sci. Part B Phys., 56 (2017) 26-38.

264. A.M. Jonas, K. Glinel, R. Oren, B. Nysten, W.T.S. Huck, Thermo-responsive polymer brushes with tunable collapse temperatures in the physiological range, Macromolecules, 40 (2007) 4403-4405.

265. D.M. Jones, J.R. Smith, W.T.S. Huck, C. Alexander, Variable adhesion of micropatterned thermoresponsive polymer brushes: AFM investigations of poly ( $\mathrm{N}$-isopropylacrylamide) brushes prepared by surface-initiated polymerizations, Adv. Mater., 14 (2002) 1130-1134.

266. A. Mizutani, A. Kikuchi, M. Yamato, H. Kanazawa, T. Okano, Preparation of thermoresponsive polymer brush surfaces and their interaction with cells, Biomaterials, 29 (2008) 2073-2081.

267. A. Halperin, M. Kroger, Collapse of thermoresponsive brushes and the tuning of protein adsorption, Macromolecules, 44 (2011) 6986-7005

268. A.M. Jonas, Collapse transition of homogeneous and nanopatterned thermoresponsive polymer brushes, Abstracts of Papers of the American Chemical Society, 237 (2009)

269. 269. H. Takahashi, M. Nakayama, K. Itoga, M. Yamato, T. Okano, Micropatterned thermoresponsive polymer brush surfaces for fabricating cell sheets with well-controlled orientational structures, Biomacromolecules, 12 (2011) 1414-1418.

270. K. Nagase, J. Kobayashi, A. Kikuchi, Y. Akiyama, H Kanazawa, T. Okano, Interfacial property modulation of thermoresponsive polymer brush surfaces and their interaction with biomolecules, Langmuir, 23 (2007) 94099415.

271. G. Scalet, Two-way and multiple-way shape memory polymers for soft robotics: An overview, Actuators, 9 (2020)

272. R. Xiao, W.M. Huang, Heating/solvent responsive shapememory polymers for implant biomedical devices in minimally invasive surgery: Current status and challenge, Macromol. Biosci., (2020) 2000108.

273. W.M. Huang, Y. Zhao, C.C. Wang, Z. Ding, H. Purnawali, C. Tang, J.L. Zhang, Thermo/chemo-responsive shape memory effect in polymers: A sketch of working mechanisms, fundamentals and optimization, J. Polym. Res., 19 (2012)

274. W.M. Huang, B. Yang, Y. Zhao, Z. Ding, Thermo-moisture responsive polyurethane shape-memory polymer and composites: A review, J. Mater. Chem., 20 (2010) 3367-3381.

275. L.Q. Hua, M.Q. Xie, Y.K. Jian, B.Y. Wu, C.Y. Chen, C.Z. Zhao, Multiple-responsive and amphibious hydrogel actuator based on asymmetric UCST-type volume phase transition, ACS Appl. Mater. Interfaces, 11 (2019) 43641-43648.

276. E. Bourgeat-Lami, M. Lansalot, Organic/Inorganic composite latexes: the marriage of emulsion polymerization and inorganic chemistry, Adv. Polym. Sci., 233 (2010) 53-123.

277. J. Thevenot, H. Oliveira, O. Sandre, S. Lecommandoux, Magnetic responsive polymer composite materials, Chem. Soc. Rev., 42 (2013) 7099-7116.

278. M.A. Hood, M. Mari, R. Munoz-Espi, Synthetic strategies in the preparation of polymer/inorganic hybrid nanoparticles, Materials, 7 (2014) 4057-4087.

279. S.K. Ahn, R.M. Kasi, S.C. Kim, N. Sharma, Y.X. Zhou, Stimuliresponsive polymer gels, Soft Matter, 4 (2008) 1151-1157.

280. M. Nawaz, Y. Sliman, I. Ercan, M.K. Lima-Tenório, E.T. Tenório-Neto, C. Kaewsaneha, A. Elaissari, Magnetic and $\mathrm{pH}$-responsive magnetic nanocarriers, Stimuli Responsive Polymeric Nanocarriers for Drug Delivery Applications, Woodhead Publishing, 2019.

281. A. Baykal, A. Bozkurt, R. Jeremy, S.M.M. Asiri, M.K. LimaTenório, C. Kaewsaneha, A. Elaissari, Multistimuli-responsive magnetic assemblies, Stimuli Responsive Polymeric Nanocarriers for Drug Delivery Applications, Woodhead Publishing, 2019

282. P. Bawa, V. Pillay, Y.E. Choonara, L.C. du Toit, Stimuliresponsive polymers and their applications in drug delivery, Biomed. Mater., 4 (2009) 1-15.

283. Q. Dai, A. Nelson, Magnetically-responsive self assembled composites, Chem. Soc. Rev., 39 (2010) 4057-4066.

284. B. Garcia-Pinel, A. Ortega-Rodriguez, C. Porras-Alcala, L. Cabeza, R. Contreras-Caceres, R. Ortiz, A. Diaz, A. Moscoso, F. Sarabia, J. Pradosa, J.M. Lopez-Romero, C. Melguizo, Magnetically active pNIPAM nanosystems as temperaturesensitive biocompatible structures for controlled drug delivery, Artif. Cells Nanomed. Biotechnol., 48 (2020) 10221035

285. X. Liu, J.N. Guan, G.H. Lai, Q. Xu, X.B. Bai, Z.M. Wang, S.P. Cui, Stimuli-responsive adsorption behavior toward heavy metal ions based on comb polymer functionalized magnetic nanoparticles, J. Cleaner Prod., 253 (2020) 119915.

286. D.H. Kim, E.A. Rozhkova, T. Rajh, S.D. Bader, V. Novosad, Synthesis of hybrid gold/iron oxide nanoparticles in block copolymer micelles for imaging, drug delivery, and magnetic hyperthermia, IEEE Trans. Magn., 45 (2009) 4821-4824.

287. A.H. Yao, Q. Chen, F. R. Ai, D.P. Wang, W.H. Huang, Preparation and characterization of temperature-responsive magnetic composite particles for multi-modal cancer therapy, J. Mater. Sci.: Mater. Med., 22 (2011) 2239-2247.

288. P. Theamdee, B. Rutnakornpituk, U. Wichai, and M. Rutnakornpituk, Recyclable magnetic nanoparticle grafted with $\mathrm{pH}$-responsive polymer for adsorption with DNA, J. Nanopart. Res., 16 (2014) 2494

289. B. Rutnakornpituk, T. Theppaleak, M. Rutnakornpituk, T. Vilaivan, Recyclable magnetite nanoparticle coated with cationic polymers for adsorption of DNA, J. Biomater. Sci., Polym. Ed., 27 (2016) 1200-1210.

290. J.M. Shen, T. Yin, X.Z. Tian, F.-Y. Gao, S. Xu, Surface chargeswitchable polymeric magnetic nanoparticles for the controlled release of anticancer drug, ACS Appl. Mater. Interfaces, 5 (2009) 7014-7024.

291. M. Rahimi, A. Wadajkar, K. Subramanian, M. Yousef, W.N. Cui, J.T. Hsieh, K.T. Nguyen, In vitro evaluation of novel polymercoated magnetic nanoparticles for controlled drug delivery, Nanomed. Nanotechnol. Biol. Med., 6 (2010) 672-680.

292. S.S. Xu, J. Wu, W. Jiang, Synthesis and characterisation of a $\mathrm{pH}$-sensitive magnetic nanocomposite for controlled delivery of doxorubicin, J. Microencapsulation, 32 (2015) 533-537. 
293. L. Qiao, N. Gan, F.T. Hu, D. Wang, H.Z. Lan, T.H. Li, H.F. Wang, Magnetic nanospheres with a molecularly imprinted shell for the preconcentration of diethylstilbestrol, Microchim. Acta, 181 (2014) 1341-1351.

294. L. Rodriguez-Arco, I.A. Rodriguez, V. Carriel, A.B. BonhomeEspinosa, F. Campos, P. Kuzhir, J.D.G. Duran, M.T. LopezLopez, Biocompatible magnetic core-shell nanocomposites for engineered magnetic tissues, Nanoscale, 8 (2016) 81388150.

295. S. Patra, E. Roy, P. Karfa, S. Kumar, R. Madhuri, P.K. Sharma, Dual-responsive polymer coated superparamagnetic nanoparticle for targeted drug delivery and hyperthermia treatment, ACS Appl. Mater. Interfaces, 7 (2013) 9235-9246.

296. M.A. Guo, C.L. Que, C.H. Wang, X.Z. Liu, H.S. Yan, K.L. Liu, Multifunctional superparamagnetic nanocarriers with folate-mediated and $\mathrm{pH}$-responsive targeting properties for anticancer drug delivery, Biomaterials, 32 (2011) 185-194.

297. S. Xu, J. Liu, D. Li, L.M. Wang, J. Guo, C.C. Wang, C.Y. Chen, Fe-salphen complexes from intracellular $\mathrm{pH}$-triggered degradation of $\mathrm{Fe}_{3} \mathrm{O}_{4} @$ Salphen-In-III CPPs for selectively killing cancer cells, Biomaterials, 35 (2014) 1676-1685.

298. L.J. Zhu, D.L. Wang, X. Wei, X.Y. Zhu, J.Q. Li, C.L. Tu, Y. Su, J.L. Wu, B.S. Zhu, D.Y. Yan, Multifunctional pH-sensitive superparamagnetic iron-oxide nanocomposites for targeted drug delivery and MR imaging, J. Controlled Release, 169 (2013) 228-238.

299. G. Bayramoğlu, B. Altıntaş, M.Y. Arıca, Synthesis and characterization of magnetic beads containing aminated fibrous surfaces for removal of Reactive Green 19 dye: Kinetics and thermodynamic parameters, J. Chem. Technol. Biotechnol., 87 (2012) 705-713.

300. S.R. Huang, K.F. Lin, C.F. Lee, W.Y. Chiu, Synthesis and properties of thermoresponsive magnetic polymer composites and their electrospun nanofibers, J. Polym. Sci. Part A: Polym. Chem., 52 (2014) 848-856.

301. W.F. Ma, S.A. Xu, J.M. Li, J. Guo, Y. Lin, C.C. Wang, Hydrophilic dual-responsive magnetite/pmaa core/shell microspheres with high magnetic susceptibility and $\mathrm{pH}$ sensitivity via distillation-precipitation polymerization, J. Polym. Sci., Part A: Polym. Chem., 49 (2011) 2725-2733.

302. J. Wu, N. Wang, Y. Zhao, L. Jiang, Simple synthesis of smart magnetically driven fibrous films for remote controllable oil removal, Nanoscale, 7 (2015) 2625-2632.

303. A. Chatzipavlidis, P. Bilalis, L.A. Tziveleka, N. Boukos, C.A Charitidis, G. Kordas, Nanostructuring the Surface of dual responsive hollow polymer microspheres for versatile utilization in nanomedicine-related applications, Langmuir 29 (2013) 9562-9572.

304. P. Du, J. Zeng, B. Mu, P. Liu, Biocompatible magnetic and molecular dual-targeting polyelectrolyte hybrid hollow microspheres for controlled drug release, Mol. Pharm., 10 (2013) 1705-1715.

305. F.F. Chen, Y.H. Dong, Y.X. Zhao, Synthesis and characterization of photo-responsive magnetic molecularly imprinted microspheres for the detection of sulfonamides in aqueous solution, J. Sep. Sci., 39 (2016) 4866-4875.

306. X. He, X. Wu, X. Cai, S. Lin, M. Xie, X. Zhu, D. Yan, Functionalization of magnetic nanoparticles with dendriticlinear-brush-like triblock copolymers and their drug release properties, Langmuir, 28 (2012) 11929-11938.

307. N.N. Reddy, Y.M. Mohan, K. Varaprasad, S. Ravindra, P.A. Joy, K.M. Raju, Magnetic and electric responsive hydrogelmagnetic nanocomposites for drug-delivery application, J. Appl. Polym. Sci., 122 (2011) 1364-1375.
308. A.P. Majewski, U. Stahlschmidt, V. Jérôme, R. Freitag, A.H.E. Müller, H. Schmalz, PDMAEMA-grafted core-shell-corona particles for nonviral gene delivery and magnetic cell separation, Biomacromolecules, 14 (2013) 3081-3090.

309. K. Kim, T.H. Kim, J.H. Choi, J.Y. Lee, S.S. Hah, H.O. Yoo, S.S. Hwang, K.N. Ryu, H.J. Kim, J. Kim, Synthesis of a pH-sensitive PEO-based block copolymer and its application for the stabilization of iron oxide nanoparticles, Macromol. Chem. Phys., 211 (2010) 1127-1136.

310. Q. Dai, D. Berman, K. Virwani, J. Frommer, P.O. Jubert, M. Lam, T. Topuria, W. Imaino, A. Nelson, Self-assembled ferrimagnet polymer-composites for magnetic recording media, Nano Letters, 10 (2010) 3216-3221.

311. J. Zeng, P.C. Du, L. Liu, J.G. Li, K. Tian, X. Jia, X.B. Zhao, P. Liu, Superparamagnetic reduction/ph/temperature multistimuli-responsive nanoparticles for targeted and controlled antitumor drug delivery, Mol. Pharm., 12 (2015) 4188-4199.

312. S.H. Hu, B.J. Liao, C.S. Chiang, P.J. Chen, I.W. Chen, S.Y. Chen, Core-shell nanocapsules stabilized by single-component polymer and nanoparticles for magneto-chemotherapy/ hyperthermia with multiple drugs, Adv. Mater., 24 (2012) 3627-3632

313. J. Wei, Y.L. Yu, Photodeformable polymer gels and crosslinked liquid-crystalline polymers, Soft Matter, 8 (2012) 8050-8059.

314. Y. Huang, R.J. Dong, X.Y. Zhu, D.Y. Yan, Photo-responsive polymeric micelles, Soft Matter, 10 (2014) 6121-6138.

315. O. Bertrand, J.F. Gohy, Photo-responsive polymers: Synthesis and applications, Polym. Chem., 8 (2017) 52-73.

316. J.M. Schumers, A. Vlad, I. Huynen, J.F. Gohy, C.A. Fustin, Functionalized nanoporous thin films from photocleavable block copolymers, Macromol. Rapid Commun., 33 (2012) 199-205.

317. C. Choi, J. Park, K.L.V. Joseph, J. Lee, S. Ahn, J. Kwak, K.S. Lee, J.K. Kim, Simultaneous fabrication of line and dot dual nanopatterns using miktoarm block copolymer with photocleavable linker, Nat. Commun., 8 (2017) 1765.

318. J.T. Goldbach, T.P. Russell, J. Penelle, Synthesis and thin film characterization of poly(styrene-blockmethyl methacrylate) containing an anthracene dimer photocleavable junction point, Macromolecules, 35 (2002) 4271-4276

319. H. Yang, L. Jia, Z.F. Wang, A. Di-Cicco, D. Levy, P. Keller, Novel photolabile diblock copolymers bearing truxillic acid derivative junctions, Macromolecules, 44 (2011) 159-165.

320. E. Cabane, V. Malinova, W. Meier, Synthesis of photocleavable amphiphilic block copolymers: Toward the design of photosensitive nanocarriers, Macromol. Chem. Phys., 211 (2010) 1847-1856.

321. E. Cabane, V. Malinova, S. Menon, C.G. Palivan, W. Meier, Photoresponsive polymersomes as smart, triggerable nanocarriers, Soft Matter, 7 (2011) 9167-9176.

322. D.H. Han, X. Tong, and Y. Zhao, Fast photodegradable block copolymer micelles for burst release, Macromolecules, 44 (2011) 437-439.

323. D.H. Han, X. Tong, Y. Zhao, Block copolymer micelles with a dual-stimuli-responsive core for fast or slow degradation, Langmuir, 28 (2012) 2327-2331.

324. S. Shrivastava, H. Matsuoka, Photocleavable amphiphilic diblock copolymer micelles bearing a nitrobenzene block, Colloid Polym. Sci., 294 (2016) 879-887.

325. C. Park, J. Lim, M. Yun, C. Kim, Photoinduced release of guest molecules by supramolecular transformation of self-assembled aggregates derived from dendrons, Angew. Chem., Int. Ed., 47 (2008) 2959-2963. 
326. F. Khakzad, A.R. Mahdavian, H. Salehi-Mobarakeh, A.R Shirin-Abadi, M. Cunningham, Redispersible PMMA latex nanoparticles containing spiropyran with photo-, $\mathrm{pH}$ - and $\mathrm{CO}_{2}$ - responsivity, Polymer, 101 (2016) 274-283.

327. Q. Jin, F. Mitschang, S. Agarwal, Biocompatible drug delivery system for photo-triggered controlled release of 5-fluorouracil, Biomacromolecules, 12 (2011) 3684-3691.

328. E.K.P. Kumar, L.N. Fedborg, K. Almdal, T.L. Andresen, Synthesis and characterization of a micelle-based $\mathrm{pH}$ nanosensor with an unprecedented broad measurement range, Chem. Mater., 25 (2013) 1496-1501.

329. J. Babin, M. Lepage, Y. Zhao, "Decoration" of shell crosslinked reverse polymer micelles using ATRP: A new route to stimuli-responsive nanoparticles, Macromolecules, 41 (2008) 1246-1253.

330. Q.J in, X.S. Liu, G.Y. Liu, J. Ji, Fabrication of core or shell reversibly photo cross-linked micelles and nanogels from double responsive water-soluble block copolymers, Polymer, 51 (2010) 1311-1319

331. X.Y. Liu, C.L. Yi, Y. Zhu, Y.Q. Yang, J.Q. Jiang, Z.G. Cui, M. Jiang, Pickering emulsions stabilized by self-assembled colloidal particles of copolymers of P(St-alt-MAn)-co-P(VM-alt-MAn), J. Colloid Interface Sci., 351 (2010) 315-322.

332. C.L. Yi, J.H. Sun, D.H. Zhao, Q. Hu, X.Y. Liu, and M. Jiang, Influence of photo-cross-linking on emulsifying performance of the self-assemblies of poly(7-(4-vinylbenzyloxyl)-4 methylcoumarin-co-acrylic acid), Langmuir, 30 (2014) 6669 6677.

333. Jin, Q., C. Luy, J. Ji, S. Agarwal, Design and proof of reversible micelle-to-vesicle multistimuli-responsive morphological regulations, J. Polym. Sci., Part A: Polym. Chem., 50 (2012) 451-457.

334. K. Han, W. Su, M.C. Zhong, Q. Yan, Y.H. Luo, Q.J. Zhang, Y.M $\mathrm{Li}$, Reversible photocontrolled swelling-shrinking behavior of micron vesicles self-assembled from azopyridinecontaining diblock copolymer, Macromol. Rapid Commun. 29 (2008) 1866-1870.

335. D.D. Lu, M.N. Zhu, S.L. Wu, W.K. Wang, Q. Lian, B.R Saunders, Triply responsive coumarin-based microgels with remarkably large photo-switchable swelling, Polym. Chem. 10 (2019) 2516-2526

336. L.Q. Zhu, C.Z. Zhao, J.W. Zhang, D.R. Gong, Photocontrollable volume phase transition of an azobenzene functionalized microgel and its supramolecular complex, RSC Adv., 5 (2015) 84263-84268.

337. N. Feng, G.X. Han, J. Dong, H. Wu, Y.D. Zheng, G.J. Wang, Nanoparticle assembly of a photo- and pH-responsive random azobenzene copolymer, J. Colloid Interface Sci., 421 (2014) 15-21.

338. J.X. Cui, O. Azzaroni, A. del Campo, Polymer brushes with phototriggered and phototunable swelling and $\mathrm{pH}$ response, Macromol. Rapid Commun., 32 (2011) 1699-1703.

339. J.X. Cui, T.H. Nguyen, M. Ceolin, R. Berger, O. Azzaroni, A. del Campo, Phototunable response in caged polymer brushes, Macromolecules, 45 (2012) 3213-3220.

340. D. Wang, P.W. Jiao, J.M. Wang, Q.L. Zhang, L. Feng, Z.Z Yang, Fast photo-switched wettability and color of surfaces coated with polymer brushes containing spiropyran, J. Appl. Polym. Sci., 125 (2012) 870-875

341. J. Cui, A. Del Campo, Photo-responsive polymers: Properties, synthesis and applications, Smart Polymers and their Applications, Woodhead Publishing, 2014.

342. Y. Zhao, Photocontrollable block copolymer micelles: What can we control?, J. Mater. Chem., 19 (2009) 4887-4895.
343. G. Stoychev, A. Kirillova, L. Ionov, Light-responsive shapechanging polymers, Adv. Opt. Mater., 7 (2019) 1900067.

344. C.L. Huang, J.A. Lv, X.J. Tian, Y.C. Wang, Y.L. Yu, J. Liu, Miniaturized swimming soft robot with complex movement actuated and controlled by remote light signals, Sci. Rep., 5 (2015) 17414.

345. Y.L. Yu, M. Nakano, T. Ikeda, Directed bending of a polymer film by light - Miniaturizing a simple photomechanical system could expand its range of applications, Nature, 425 (2003) 145-145.

346. W.Q. Chen, J.Z. Du, Ultrasound and $\mathrm{pH}$ dually responsive polymer vesicles for anticancer drug delivery, Sci. Rep., 3 (2013) 1-9.

347. G. Sharifzadeh, H. Hosseinkhani, Biomolecule-responsive hydrogels in medicine, Adv. Healthcare Mater., 6 (2017) 1-35.

348. R.V. Ulijn, N. Bibi, V. Jayawarna, P.D. Thornton, S.J. Todd, R.J. Mart, A.M. Smith, J.E. Gough, Bioresponsive hydrogels, Mater. Today, 10 (2007) 40-48.

349. J. Wang, H. Zhang, F. Wang, X. Ai, D. Huang, G. Liu, P. $\mathrm{Mi}$, Enzyme-responsive polymers for drug delivery and molecular imaging, Stimuli Responsive Polymeric Nanocarriers for Drug Delivery Applications, Volume 1, Woodhead Publishing, 2018.

350. A.N. Wilson, R. Salas, A. Guiseppi-Elie, Bioactive hydrogels demonstrate mediated release of a chromophore by chymotrypsin, J. Controlled Release, 160 (2012) 41-47.

351. Y.Y. Xie, R.L. Huang, W. Qi, Y.F. Wang, R.X. Su, Z.M. He, Enzyme-substrate interactions promote the self-assembly of amino acid derivatives into supramolecular hydrogels, J. Mater. Chem. B, 4 (2016) 844-851.

352. P.D. Thornton, R.J. Mart, S.J. Webb, R.V. Ulijn, Enzymeresponsive hydrogel particles for the controlled release of proteins: Designing peptide actuators to match payload, Soft Matter, 4 (2008) 821-827.

353. C.E. Brubaker, P.B. Messersmith, Enzymatically degradable mussel-inspired adhesive hydrogel, Biomacromolecules, 12 (2011) 4326-4334.

354. L. Zhu, T. Wang, F. Perche, A. Taigind, V.P. Torchilin, Enhanced anticancer activity of nanopreparation containing an MMP2sensitive PEG-drug conjugate and cell-penetrating moiety, Proc. Natl. Acad. Sci. U.S.A., 110 (2013) 17047-17052.

355. D. Bacinello, E. Garanger, D. Taton, K.C. Tam, S. Lecommandoux, Enzyme-degradable self-assembled nanostructures from polymer-peptide hybrids, Biomacromolecules, 15 (2014) 1882-1888

356. D. Maxwell, Q. Chang, X. Zhang, E.M. Barnett, D. PiwnicaWorms, An improved cell-penetrating, caspase-activatable, near-infrared fluorescent peptide for apoptosis imaging, Bioconjugate Chem., 20 (2009) 702-709.

357. C. de la Torre, L. Mondragon, C. Coll, F. Sancenon, M.D. Marcos, R. Martinez-Manez, P. Amoros, E. Perez-Paya, M. Orzaez, Cathepsin-B induced controlled release from peptide-capped mesoporous silica nanoparticles, Chem. Eur. J., 20 (2014) 15309-15314.

358. Y. Dai, X.L. Ma, Y.H. Zhang, K. Chen, J.Z. Tang, Q.Y. Gong, K. Luo, A biocompatible and cathepsin B sensitive nanoscale system of dendritic polyHPMA-gemcitabine prodrug enhances antitumor activity markedly, Biomater. Sci., 6 (2018) 2976-2986.

359. J. Wen, S.M. Anderson, J.J. Du, M. Yan, J. Wang, M.Q. Shen, Y.F. Lu, T. Segura, Controlled protein delivery based on enzyme-responsive nanocapsules, Adv. Mater., 23 (2011) 4549-4553.

360. F. Anjum, P.S. Lienemann, S. Metzger, J. Biernaskie, M.S. Kallos, M. Ehrbar, Enzyme responsive GAG-based naturalsynthetic hybrid hydrogel for tunable growth factor delivery and stem cell differentiation, Biomaterials, 87 (2016) 104117. 
361. S.L. Rowe, S. Lee, J.P. Stegemann, Influence of thrombin concentration on the mechanical and morphological properties of cell-seeded fibrin hydrogels, Acta Biomater., 3 (2007) 59-67.

362. S. Toledano, R.J. Williams, V. Jayawarna, R.V. Ulijn, Enzymetriggered self-assembly of peptide hydrogels via reversed hydrolysis, J. Am. Chem. Soc., 128 (2006) 1070-1071.

363. J.M. Knipe, F. Chen, N.A. Peppas, Enzymatic biodegradation of hydrogels for protein delivery targeted to the small intestine, Biomacromolecules, 16 (2015) 962-972.

364. Y.B. Xing, C. Wang, P. Han, Z.Q. Wang, X. Zhang, Acetylcholinesterase responsive polymeric supraamphiphiles for controlled self-assembly and disassembly, Langmuir, 28 (2012) 6032-6036.

365. R.J. Amir, Enzyme-responsive PEG-dendron hybrids as a platform for smart nanocarriers, Synlett, 26 (2015) 26172622.

366. S. Thamphiwatana, W.W. Gao, D. Pornpattananangkul, Q.Z. Zhang, V. Fu, J.Y. Li, J.M. Li, M. Obonyo, L.F. Zhang, Phospholipase A2-responsive antibiotic delivery via nanoparticle-stabilized liposomes for the treatment of bacterial infection, J. Mater. Chem. B, 2 (2014) 8201-8207.

367. Y.X. Wang, D.S. Guo, Y. Cao, Y. Liu, Phosphatase-responsive amphiphilic calixarene assembly, RSC Adv., 3 (2013) 80588063.

368. Z.J. Hai, J.D. Li, J.J. Wu, J.C. Xu, G.L. Liang, Alkaline phosphatase-triggered simultaneous hydrogelation and chemiluminescence, J. Am. Chem. Soc., 139 (2017) 1041 1044.

369. Z.M. Yang, G.L. Liang, L. Wang, B. Xu, Using a kinase/ phosphatase switch to regulate a supramolecular hydrogel and forming the supramoleclar hydrogel in vivo, J. Am. Chem. Soc., 128 (2006) 3038-3043.

370. E.L. Ferguson, R. Duncan, Dextrin-phospholipase $A(2)$ : Synthesis and evaluation as a bioresponsive anticancer conjugate, Biomacromolecules, 10 (2009) 1358-1364.

371. Q. Zhao, J.M. Zhang, L.J. Song, Q. Ji, Y. Yao, Y. Cui, J. Shen, P.G. Wang, D.L. Kong, Polysaccharide-based biomaterials with on-demand nitric oxide releasing property regulated by enzyme catalysis, Biomaterials, 34 (2013) 8450-8458

372. T. Legigan, J. Clarhaut, B. Renoux, I. Tranoy-Opalinski, A. Monvoisin, J.M. Berjeaud, F. Guilhot, S. Papot, Synthesis and antitumor efficacy of a beta-glucuronidase-responsive albumin-binding prodrug of doxorubicin, J. Med. Chem., 55 (2012) 4516-4520.

373. X. Gao, Z. Yu, B.X. Liu, J.X. Yang, X.Y. Yang, Y.Q. Yu, A smart drug delivery system responsive to $\mathrm{pH} /$ enzyme stimuli based on hydrophobic modified sodium alginate, Eur. Polym. J., 133 (2020) 1-9.

374. S.J. Sofia, A. Singh, D.L. Kaplan, Peroxidase-catalyzed crosslinking of functionalized polyaspartic acid polymers, J. Macromol. Sci., Pure Appl. Chem., A39 (2002) 1151-1181.

375. R. Wakabayashi, W. Ramadhan, K. Moriyama, M. Goto, N. Kamiya, Poly(ethylene glycol)-based biofunctional hydrogels mediated by peroxidase-catalyzed cross-linking reactions, Polym. J., 52 (2020) 899-911.

376. J.Y. Rao, A. Khan, Enzyme sensitive synthetic polymer micelles based on the azobenzene motif, J. Am. Chem. Soc., 135 (2013) 14056-14059.

377. J.H. Kang, D. Asai, J.H. Kim, T. Mori, R. Toita, T. Tomiyama, Y. Asami, J. Oishi, Y.T. Sato, T. Niidome, B. Jun, H. Nakashima, Y Katayama, Design of polymeric carriers for cancer-specific gene targeting: Utilization of abnormal protein kinase $C$ alpha activation in cancer cells, J. Am. Chem. Soc., 130 (2008) 14906-14907.
378. K.A. Mosiewicz, K. Johnsson, M.P. Lutolf, Phosphopantetheinyl transferase-catalyzed formation of bioactive hydrogels for tissue engineering, J. Am. Chem. Soc., 132 (2010) 5972-5974.

379. C.W. Yung, , W.E. Bentley, T.A. Barbari, Diffusion of interleukin-2 from cells overlaid with cytocompatible enzyme-crosslinked gelatin hydrogels, J. Biomed. Mater. Res., Part A, 95a (2010) 25-32.

380. S.M.E. Swainson, V. Taresco, A.K. Pearce, L.H. Clapp, B. Ager, M. McAllister, C. Bosquillon, M.C. Garnett, Exploring the enzymatic degradation of poly(glycerol adipate), Eur. J. Pharm. Biopharm., 142 (2019) 377-386.

381. W.J.R. Gilbert, S.J. Johnson, J.S. Tsau, J.T. Liang, A.M. Scurto, Enzymatic degradation of polyacrylamide in aqueous solution with peroxidase and $\mathrm{H}_{2} \mathrm{O}_{2}$, J. Appl. Polym. Sci., 134 (2017) 1-10.

382. S. Saxena, M. Jayakannan, Enzyme and pH dual responsive I-amino acid based biodegradable polymer nanocarrier for multidrug delivery to cancer cells, J. Polym. Sci., Part A: Polym. Chem., 54 (2016) 3279-3293.

383. A.J. Harnoy, I. Rosenbaum, E. Tirosh, Y. Ebenstein, R. Shaharabani, R. Beck, R.J. Amir, Enzyme-responsive amphiphilic PEG-dendron hybrids and their assembly into smart micellar nanocarriers, J. Am. Chem. Soc., 136 (2014) 7531-7534.

384. J.W. Woodcock, X. Jiang, R.A.E. Wright, B. Zhao, Enzymeinduced formation of thermoreversible micellar gels from aqueous solutions of multiresponsive hydrophilic $A B A$ triblock copolymers, Macromolecules, 44 (2011) 5764-5775.

385. K. Chen, H. Cai, H. Zhang, H.Y. Zhu, Z.W. Gu, Q.Y. Gong, K. Luo, Stimuli-responsive polymer-doxorubicin conjugate: Antitumor mechanism and potential as nano-prodrug, Acta Biomater., 84 (2019) 339-355.

386. P.S. Pramod, R. Shah, M. Jayakannan, Dual stimuli polysaccharide nanovesicles for conjugated and physically loaded doxorubicin delivery in breast cancer cells, Nanoscale, 7 (2015) 6636-6652

387. Y.K. Wu, Q.Y. Lai, S.Q. Lai, J. Wu, W. Wang, Z. Yuan, Facile fabrication of core cross-linked micelles by RAFT polymerization and enzyme-mediated reaction, Colloids Surf., B, 118 (2014) 298-305.

388. M.L. Picchio, J.C. Cuggino, G. Nagel, S. Wedepohl, R.J. Minari, C.I.A. Igarzabal, L.M. Gugliotta, M. Calderon, Crosslinked casein-based micelles as a dually responsive drug delivery system, Polym. Chem., 9 (2018) 3499-3510.

389. M. Kurisawa, J.E. Chung, Y.Y. Yang, S.J. Gao, H. Uyama, Injectable biodegradable hydrogels composed of hyaluronic acid-tyramine conjugates for drug delivery and tissue engineering, Chem. Commun., (2005) 4312-4314.

390. H.L. Fuchsbauer, U. Gerber, J. Engelmann, T. Seeger, C. Sinks, T. Hecht, Influence of gelatin matrices cross-linked with transglutaminase on the properties of an enclosed bioactive material using beta-galactosidase as model system, Biomaterials, 17 (1996) 1481-1488.

391. M. Ehrbar, S.C. Rizzi, R.G. Schoenmakers, B. San Miguel, J.A. Hubbell, F.E. Weber, M.P. Lutolf, Biomolecular hydrogels formed and degraded via site-specific enzymatic reactions, Biomacromolecules, 8 (2007) 3000-3007.

392. T.H. Chen, H.D. Embree, L.Q. Wu, G.F. Payne, In vitro protein-polysaccharide conjugation: Tyrosinase-catalyzed conjugation of gelatin and chitosan, Biopolymers, 64 (2002) 292-302. 
393. T.H. Chen, H.D. Embree, E.M. Brown, M.M. Taylor, G.F. Payne, Enzyme-catalyzed gel formation of gelatin and chitosan: Potential for in situ applications, Biomaterials, 24 (2003) 2831-2841.

394. R. Wang, D.L. Xu, L. Liang, T.T. Xu, W. Liu, P.K. Ouyang, B. Chi, H. Xu, Enzymatically crosslinked epsilon-poly-L-lysine hydrogels with inherent antibacterial properties for wound infection prevention, RSC Adv., 6 (2016) 8620-8627.

395. K.N. Plunkett, K.L. Berkowski, J.S. Moore, Chymotrypsin responsive hydrogel: Application of a disulfide exchange protocol for the preparation of methacrylamide containing peptides, Biomacromolecules, 6 (2005) 632-637.

396. B.K. Mann, A.S. Gobin, A.T. Tsai, R.H. Schmedlen, J.L. West, Smooth muscle cell growth in photopolymerized hydrogels with cell adhesive and proteolytically degradable domains: synthetic ECM analogs for tissue engineering, Biomaterials, 22 (2001) 3045-3051.

397. M. van Dijk, C.F. van Nostrum, W.E. Hennink, D.T.S Rijkers, R.M.J. Liskamp, Synthesis and characterization of enzymatically biodegradable PEG and peptide-based hydrogels prepared by click chemistry, Biomacromolecules, 11 (2010) 1608-1614

398. S. Kim, K.E. Healy, Synthesis and characterization of injectable poly( $\mathrm{N}$-isopropylacrylamide-co-acrylic acid) hydrogels with proteolytically degradable cross-links, Biomacromolecules, 4 (2003) 1214-1223.

399. Y. Kumashiro, T.K. Lee, T. Ooya, N. Yui, Enzymatic degradation of semi-IPN hydrogels based on $\mathrm{N}$-isopropylacrylamide and dextran at a specific temperature range, Macromol. Rapid Commun., 23 (2002) 407-410.

400. T.O. McDonald, H.L. Qu, B.R. Saunders, R.V. Ulijn, Branched peptide actuators for enzyme responsive hydrogel particles, Soft Matter, 5 (2009) 1728-1734.

401. A.G. Patrick, R.V. Ulijn, Hydrogels for the detection and management of protease levels, Macromol. Biosci., 10 (2010) 1184-1193.

402. L. Perlin, S. MacNeil, S. Rimmer, Cell adhesive hydrogels synthesised by copolymerisation of arg-protected Gly Arg-Gly-Asp-Ser methacrylate monomers and enzymatic deprotection, Chem. Commun., (2008) 5951-5953.

403. D. Klinger, E.M. Aschenbrenner, C.K. Weiss, K. Landfester Enzymatically degradable nanogels by inverse miniemulsion copolymerization of acrylamide with dextran methacrylates as crosslinkers, Polym. Chem., 3 (2012) 204-216.

404. P.D. Thornton, G. McConnell, R.V. Ulijn, Enzyme responsive polymer hydrogel beads, Chem. Commun., volume? (2005) 5913-5915.

405. P.D. Thornton, R.J. Mart, R.V. Ulijn, Enzyme-responsive polymer hydrogel particles for controlled release, Adv. Mater., 19 (2007) 1252-1256.

406. P.D. Thornton, A. Heise, Bio-functionalisation to enzymatically control the solution properties of a selfsupporting polymeric material, Chem. Commun., 47 (2011) 3108-3110.

407. R.J. Amir, S. Zhong, D.J. Pochan, C.J. Hawker, Enzymatically triggered self-assembly of block copolymers, J. Am. Chem. Soc., 131 (2009) 13949-13951.

408. H. Kuhnle, H.G. Borner, Biotransformation on polymerpeptide conjugates: A versatile tool to trigger microstructure formation, Angew. Chem., Int. Ed., 48 (2009) 6431-6434.

409. N. Morimoto, N. Ogino, T. Narita, S. Kitamura, K. Akiyoshi, Enzyme-responsive molecular assembly system with amylose-primer surfactants, J. Am. Chem. Soc., 129 (2007) 458-459.
410. D.B. Wright, A. Ramirez-Hernandez, M.A. Touve, A.S. Carlini, M.P. Thompson, J.P. Patterson, J.J. de Pablo, N.C. Gianneschi, Enzyme-induced kinetic control of peptide-polymer micelle morphology, ACS Macro Lett., 8 (2019) 676-681.

411. T.H. Ku, M.P. Chien, M.P. Thompson, R.S. Sinkovits, N.H. Olson, T.S. Baker, N.C. Gianneschi, Controlling and switching the morphology of micellar nanoparticles with enzymes, J. Am. Chem. Soc., 133 (2011) 8392-8395.

412. M.P. Chien, A.M. Rush, M.P. Thompson, N.C. Gianneschi, Programmable shape-shifting micelles, Angew. Chem., Int. Ed., 49 (2010) 5076-5080.

413. D. Koda, T. Maruyama, N. Minakuchi, K. Nakashima, M. Goto, Proteinase-mediated drastic morphological change of peptide-amphiphile to induce supramolecular hydrogelation, Chem. Commun., 46 (2010) 979-981.

414. P.F. Caponi, X.P. Qiu, F. Vilela, F.M. Winnik, R.V. Ulijn, Phosphatase/temperature responsive poly(2-isopropyl-2oxazoline), Polym. Chem., 2 (2011) 306-308.

415. M.M. Nguyen, A.S. Carlini, M.P. Chien, S. Sonnenberg, C.L. Luo, R.L. Braden, K.G. Osborn, Y.W. Li, N.C. Gianneschi, K.L. Christman, Enzyme-responsive nanoparticles for targeted accumulation and prolonged retention in heart tissue after myocardial infarction, Adv. Mater., 27 (2015) 5547-5552.

416. M.P. Chien, A.S. Carlini, D.H. Hu, C.V. Barback, A.M. Rush, D.J. Hall, G. Orr, N.C. Gianneschi, Enzyme-directed assembly of nanoparticles in tumors monitored by in vivo whole animal imaging and ex vivo super-resolution fluorescence imaging, J. Am. Chem. Soc., 135 (2013) 18710-18713.

417. M.P. Chien, M.P. Thompson, E.C. Lin, N.C. Gianneschi, Fluorogenic enzyme-responsive micellar nanoparticles, Chem. Sci., 3 (2012) 2690-2694.

418. P.F. Caponi, R.V. Ulijn, A systematic study on the selfassembly behaviour of multi component fmoc-amino acidpoly(oxazoline) systems, Polymers, 4 (2012) 1399-1415.

419. M. Zelzer, L.E. McNamara, D.J. Scurr, M.R. Alexander, M.J. Dalby, R.V. Ulijn, Phosphatase responsive peptide surfaces, J. Mater. Chem., 22 (2012) 12229-12237.

420. S.J. Todd, D.J. Scurr, J.E. Gough, M.R. Alexander, R.V. Ulijn, Enzyme-activated RGD ligands on functionalized poly(ethylene glycol) monolayers: Surface analysis and cellular response, Langmuir, 25 (2009) 7533-7539.

421. R.E. Rawsterne, J.E. Gough, F.J.M. Rutten, N.T. Pham, W.C.K. Poon, S.L. Flitsch, B. Maltman, M.R. Alexander, R.V. Ulijn, Controlling protein retention on enzyme-responsive surfaces, Surf. Interface Anal., 38 (2006) 1505-1511.

422. S.J. Todd, D. Farrar, J.E. Gough, R.V. Ulijn, Enzyme-triggered cell attachment to hydrogel surfaces, Soft Matter, 3 (2007) 547-550.

423. Q.Y. Hu, P.S. Katti, Z. Gu, Enzyme-responsive nanomaterials for controlled drug delivery, Nanoscale, 6 (2014) 12273 12286.

424. T. Miyata, N. Asami, T. Uragami, A reversibly antigenresponsive hydrogel, Nature, 399 (1999) 766-769.

425. 425. T. Miyata, N. Asami, T. Uragami, Structural design of stimuli-responsive bioconjugated hydrogels that respond to a target antigen, J. Polym. Sci., Part B: Polym. Phys. 47 (2009) 2144-2157.

426. G.Ye, C.Q. Yang, X.G. Wang, Sensing diffraction gratings of antigen-responsive hydrogel for human immunoglobulin-G detection, Macromol. Rapid Commun., 31 (2010) 1332-1336.

427. Z.R. Lu, P. Kopeckova, J. Kopecek, Antigen responsive hydrogels based on polymerizable antibody Fab ' fragment, Macromol. Biosci., 3 (2003) 296-300. 
428. R. Zhang, A. Bowyer, R. Eisenthal, J. Hubble, A smart membrane based on an antigen-responsive hydrogel, Biotechnol. Bioeng., 97 (2007) 976-984.

429. T. Miyata, N. Asami, Y. Okita, T. Uragami, Controlled permeation of model drugs through a bioconjugated membrane with antigen-antibody complexes as reversible crosslinks, Polym. J., 42 (2010) 834-837.

430. G. Li, Q.B. Meng, Z.Y. Li, Y.L. An, X.X. Zhu, Interaction of Antigen and antibody on core-shell polymeric microspheres, Chin. J. Polym. Sci., 29 (2011) 267-273.

431. Y.T. Wei, F.Z. Cui, W.M. Tian, Fabrication and characterization of hyaluronic-acid-based antigen sensitive degradable hydrogel, Front. Mater. Sci. China, 3 (2009) 353-358.

432. S.L. Lim, C.W. Ooi, W.S. Tan, E.S. Chan, K.L. Ho, B.T. Tey, Biosensing of hepatitis B antigen with poly(acrylic acid) hydrogel immobilized with antigens and antibodies, Sens. Actuators, B, 252 (2017) 409-417.

433. Q. Wu, L. Wang, H.J. Yu, J.J. Wang, Z.F. Chen, Organization of glucose-responsive systems and their properties, Chem. Rev., 111 (2011) 7855-7875.

434. R.M. Luo, H. Li, K.Y. Lam, Modeling the effect of environmental solution $\mathrm{pH}$ on the mechanical characteristics of glucosesensitive hydrogels, Biomaterials, 30 (2009) 690-700.

435. C.R. Gordijo, A.J. Shuhendler, X.Y. Wu, Glucose-responsive bioinorganic nanohybrid membrane for self-regulated insulin release, Adv. Funct. Mater., 20 (2010) 1404-1412.

436. T. Kishigawa, Y. Tagami, T. Narita, Y. Oishi, Volume change behavior of poly(L-lysine-alt-terephthalic acid) microcapsules encapsulating glucose oxidase, Chem. Lett. 41 (2012) 1148-1150

437. S.R. Marek, N.A. Peppas, Insulin release dynamics from poly(diethylaminoethyl methacrylate) hydrogel systems, AlChE J., 59 (2013) 3578-3585.

438. Y. Ito, M. Casolaro, K. Kono, Y. Imanishi, An insulin-releasing system that is responsive to glucose, J. Controlled Release, 10 (1989) 195-203.

439. K. Ishihara, M. Kobayashi, N. Ishimaru, I. Shinohara, Glucoseinduced permeation control of insulin through a complex membrane consisting of immobilized glucose-oxidase and a poly(amine), Polym. J., 16 (1984) 625-631.

440. A. Guiseppi-Elie, S.I. Brahim, D. Narinesingh, A chemically synthesized artificial pancreas: Release of insulin from glucose-responsive hydrogels, Adv. Mater., 14 (2002) 743746.

441. T. Traitel, Y. Cohen, J. Kost, Characterization of glucosesensitive insulin release systems in simulated in vivo conditions, Biomaterials, 21 (2000) 1679-1687.

442. L.Y. Chu, Y.J. Liang, W.M. Chen, X.J. Ju, H.D. Wang, Preparation of glucose-sensitive microcapsules with a porous membrane and functional gates, Colloids Surf., B, 37 (2004) 9-14.

443. N. Kashyap, B. Viswanad, G. Sharma, V. Bhardwaj, P. Ramarao, M.N.V.R. Kumar, Design and evaluation of biodegradable, biosensitive in situ gelling system for pulsatile delivery of insulin, Biomaterials, 28 (2007) 2051-2060.

444. L.Y. Chu, Y. Li, J.H. Zhu, H.D. Wang, Y.J. Liang, Control of pore size and permeability of a glucose-responsive gating membrane for insulin delivery, J. Controlled Release, 97 (2004) 43-53

445. Y. Miura, Y. Hoshino, H. Seto, Glycopolymer nanobiotechnology, Chem. Rev., 116 (2016) 1673-1692.

446. T. Miyata, A. Jikihara, K. Nakamae, A.S. Hoffman, Preparation of reversibly glucose-responsive hydrogels by covalent immobilization of lectin in polymer networks having pendant glucose, J. Biomater. Sci., Polym. Ed., 15 (2004) 1085-1098.
447. T. Miyata, A. Jikihara, K. Nakamae, A.S. Hoffman, Preparation of poly(2-glucosyloxyethyl methacrylate)concanavalin A complex hydrogel and its glucose-sensitivity, Macromol. Chem. Phys., 197 (1996) 1135-1146.

448. K. Yasugi, T. Nakamura, Y. Nagasaki, M. Kato, K. Kataoka, Sugar-installed polymer micelles: Synthesis and micellization of poly(ethylene glycol)-poly(D,L-lactide) block copolymers having sugar groups at the PEG chain end, Macromolecules, 32 (1999) 8024-8032.

449. S.Y. Cheng, J. Gross, A. Sambanis, Hybrid pancreatic tissue substitute consisting of recombinant insulin-secreting cells and glucose-responsive material, Biotechnol. Bioeng., 87 (2004) 863-873.

450. R.X. Yin, K.M. Wang, S. Du, L. Chen, J. Nie, W.J. Zhang, Design of genipin-crosslinked microgels from concanavalin A and glucosyloxyethyl acrylated chitosan for glucose-responsive insulin delivery, Carbohydr. Polym., 103 (2014) 369-376.

451. A. Kawamura, Y. Hata, T. Miyata, T. Uragami, Synthesis of glucose-responsive bioconjugated gel particles using surfactant-free emulsion polymerization, Colloids Surf., B, 99 (2012) 74-81.

452. R.X. Yin, Z. Tong, D.Z. Yang, J. Nie, Glucose-responsive insulin delivery microhydrogels from methacrylated dextran/ concanavalin A: Preparation and in vitro release study, Carbohydr. Polym., 89 (2012) 117-123.

453. H.P. Tan, X.H. Hu, Injectable in situ forming glucoseresponsive dextran-based hydrogels to deliver adipogenic factor for adipose tissue engineering, J. Appl. Polym. Sci., 126 (2012) E180-E186.

454. C.H. Lu, X.S. Chen, Z.G. Xie, T.C. Lu, X. Wang, J. Ma, X.B. Jing, Biodegradable amphiphilic triblock copolymer bearing pendant glucose residues: Preparation and specific interaction with Concanavalin A molecules, Biomacromolecules, 7 (2006) 1806-1810

455. L.C. You, F.Z. Lu, Z.C. Li, W. Zhang, F.M. Li, Glucose-sensitive aggregates formed by poly(ethylene oxide)-block-poly(2glucosyl-oxyethyl acrylate) with coneanavalin $\mathrm{A}$ in dilute aqueous medium, Macromolecules, 36 (2003) 1-4.

456. J. Kumar, A. Bousquet, M.H. Stenzel, Thiol-alkyne chemistry for the preparation of micelles with glycopolymer corona: dendritic surfaces versus linear glycopolymer in their ability to bind to lectins, Macromol. Rapid Commun., 32 (2011) 1620-1626

457. J.P. Lorand, J.O. Edwards, Polyol complexes and structure of the benzeneboronate ion, The Journal of Organic Chemistry, 24 (1959) 769-774

458. S. Hajizadeh, A.E. Ivanov, M. Jahanshahi, M.H. Sanati, N.V. Zhuravleva, L.I. Mikhalovska, I.Y. Galaev, Glucose sensors with increased sensitivity based on composite gels containing immobilized boronic acid, React. Funct. Polym., 68 (2008) 1625-1635.

459. C. Sugnaux, H.A. Klok, Glucose-sensitive QCM-sensors via direct surface RAFT polymerization, Macromol. Rapid Commun., 35 (2014) 1402-1407.

460. G. Springsteen, B.H. Wang, A detailed examination of boronic acid-diol complexation, Tetrahedron, 58 (2002) 5291-5300.

461. S.B. Zhang, L.Y. Chu, D. Xu, J. Zhang, X.J. Ju, R. Xie, Poly(Nisopropylacrylamide)-based comb-type grafted hydrogel with rapid response to blood glucose concentration change at physiological temperature, Polymers for Advanced Technologies, 19 (2008) 937-943. 
462. J. Li, W.Q. Hu, Y.J. Zhang, H. Tan, X.J. Yan, L.L. Zhao, H.Z Liang, $\mathrm{pH}$ and glucose dually responsive injectable hydrogel prepared by in situ crosslinking of phenylboronic modified chitosan and oxidized dextran, J. Polym. Sci., Part A: Polym. Chem., 53 (2015) 1235-1244.

463. T. Yang, R. Ji, X.X. Deng, F.S. Du, Z.C. Li, Glucose-responsive hydrogels based on dynamic covalent chemistry and inclusion complexation, Soft Matter, 10 (2014) 2671-2678.

464. E. Holz, K. Rajagopal, In situ-forming glucose-responsive hydrogel from hyaluronic acid modified with a boronic acid derivative, Macromol. Chem. Phys., (2020) 2000055.

465. D. Roy, B.S. Sumerlin, Glucose-sensitivity of boronic acid block copolymers at physiological pH, ACS Macro Lett., 1 (2012) 529-532.

466. L. Li, G.H. Jiang, X.X. Du, H. Chen, Y.K. Liu, Q. Huang, X.D. Kong, J.M. Yao, Preparation of glucose-responsive and fluorescent micelles via a combination of RAFT polymerization and chemoenzymatic transesterification for controlled release of insulin, RSC Adv., 5 (2015) 75766-75772.

467. G. Jiang, T. Jiang, H. Chen, L. Li, Y. Liu, H. Zhou, Y. Feng, J. Zhou, Preparation of multi-responsive micelles for controlled release of insulin, Colloid Polym. Sci., 293 (2015) 209-215.

468. Y. Yao, L.Y. Zhao, J.J. Yang, J. Yang, Glucose-responsive vehicles containing phenylborate ester for controlled insulin release at neutral pH, Biomacromolecules, 13 (2012) 1837 1844.

469. W. Yuan, T. Shen, J. Wang, H. Zou, Formation-dissociation of glucose, $\mathrm{pH}$ and redox triply responsive micelles and controlled release of insulin, Polym. Chem., 5 (2014) 3968 3971.

470. D. Roy, J.N. Cambre, B.S. Sumerlin, Triply-responsive boronic acidblock copolymers: solution self-assembly induced by changes in temperature, $\mathrm{pH}$, or sugar concentration, Chem. Commun., (2009) 2106-2108.

471. H. Kim, Y.J. Kong, E.S. Jeong, S. Kong, K.T. Kim, Glucoseresponsive disassembly of polymersomes of sequencespecific boroxole-containing block copolymers under physiologically relevant conditions, ACS Macro Lett., 1 (2012) 1194-1198.
472. Q.A. Jin, L.P. Lv, G.Y. Liu, J.P. Xu, J.A. Ji, Phenylboronic acid as a sugar- and $\mathrm{pH}$-responsive trigger to tune the multiple micellization of thermo-responsive block copolymer, Polymer, 51 (2010) 3068-3074.

473. R.H. Deng, Y. Ning, E.R. Jones, V.J. Cunningham, N.J.W. Penfold, S.P. Armes, Stimulus-responsive block copolymer nano-objects and hydrogels via dynamic covalent chemistry, Polym. Chem., 8 (2017) 5374-5380.

474. H.L. Liu, Y.Y. Li, K. Sun, J.B. Fan, P.C. Zhang, J.X. Meng, S.T. Wang, L. Jiang, Dual-responsive surfaces modified with phenylboronic acid-containing polymer brush to reversibly capture and release cancer cells, J. Am. Chem. Soc., 135 (2013) 7603-7609.

475. T. Chen, D.P. Chang, T. Liu, R. Desikan, R. Datar, T. Thundat, R. Berger, S. Zauscher, Glucose-responsive polymer brushes for microcantilever sensing, J. Mater. Chem., 20 (2010) 3391-3395.

476. K. Akamatsu, T. Yamaguchi, Molecular recognition gating membranes made by plasma-graft polymerization, J. Photopolym. Sci. Technol., 18 (2005) 229-232.

477. A. Kikuchi, K. Suzuki, O. Okabayashi, H. Hoshino, K. Kataoka, Y. Sakurai, T. Okano, Glucose-sensing electrode coated with polymer complex gel containing phenylboronic acid, Anal. Chem., 68 (1996) 823-828.

478. S. Kitano, Y. Koyama, K. Kataoka, T. Okano, Y. Sakurai, A novel drug delivery system utilizing a glucose responsive polymer complex between poly (vinyl alcohol) and poly (N-vinyl-2pyrrolidone) with a phenylboronic acid moiety, J. Controlled Release, 19 (1992) 161-170.

479. A. Matsumoto, S. Ikeda, A. Harada, K. Kataoka, Glucoseresponsive polymer bearing a novel phenylborate derivative as a glucose-sensing moiety operating at physiological $\mathrm{pH}$ conditions, Biomacromolecules, 4 (2003) 1410-1416.

480. A. Matsumoto, R. Yoshida, K. Kataoka, Glucose-responsive polymer gel bearing phenylborate derivative as a glucose-sensing moiety operating at the physiological $\mathrm{pH}$, Biomacromolecules, 5 (2004) 1038-1045. 